\title{
Comparison of HYDRA Predictions to Temperature Data from \\ Two Single-Assembly Spent Fuel Heat Transfer Tests
}

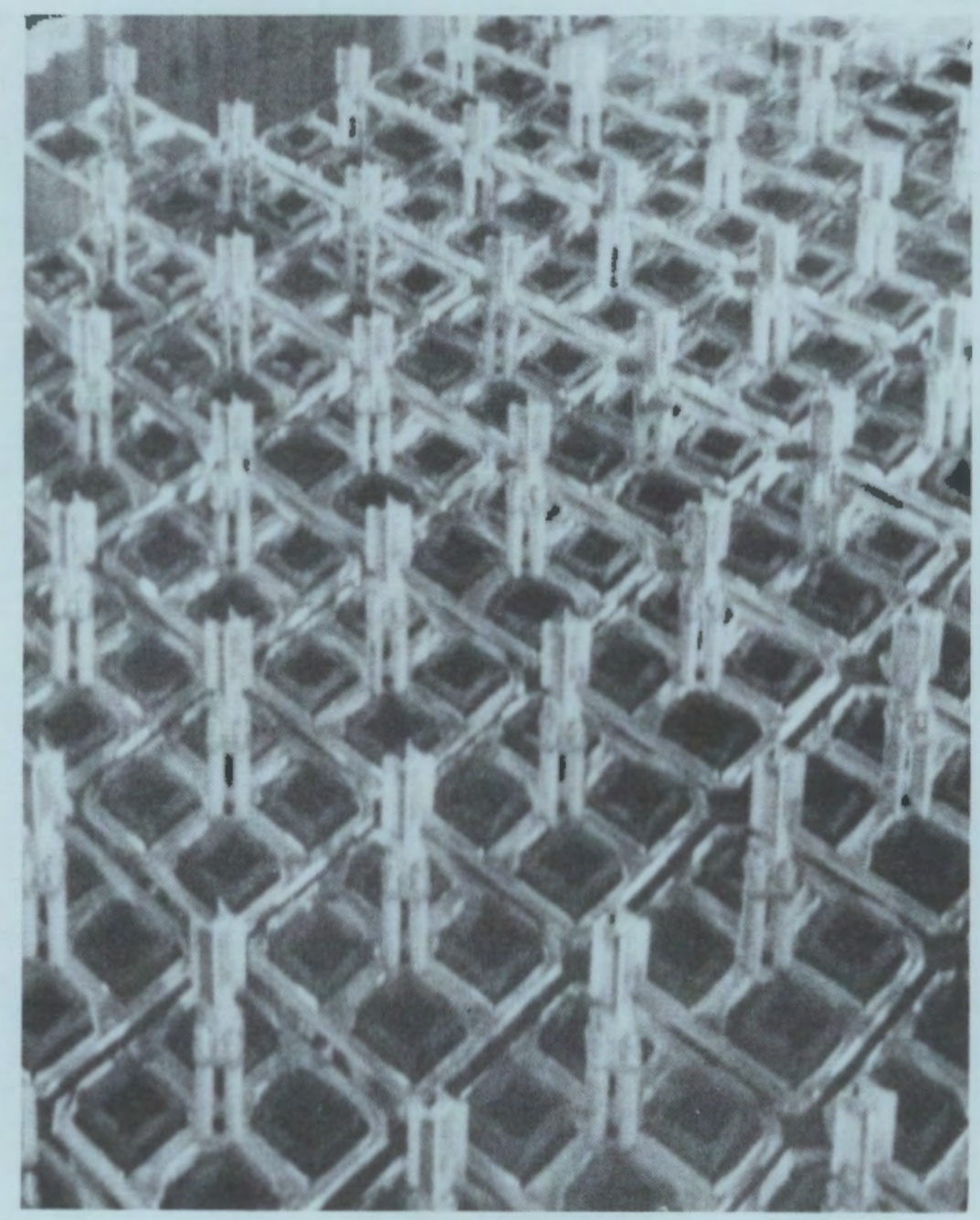

\section{December 1986}

Prepared for the U.S. Department of Energy under Contract DE-AC06-76RLO 1830

Pacific Northwest Laboratory Operated for the U.S. Department of Energy by Battelle Memorial Institute 


\title{
DISCLAIMER
}

This report was prepared as an account of work sponsored by an agency of the United States Government. Neither the United States Government nor any agency thereof, nor Battelle Memorial Institute, nor any of their employees, makes any warranty, expressed or implied, or assumes any legal liability or responsibility for the accuracy, completeness, or usefulness of any information, apparatus, product, or process disclosed, or represents that its use would not infringe privately owned rights. Reference herein to any specific commercial product, process, or service by trade name, trademark, manufacturer, or otherwise, does not necessarily constitute or imply its endorsement, recommendation, or favoring by the United States Government of any agency thereof, or Battelle Memorial Institute. The views and opinions of authors expressed herein do not necessarly state or reflect those of the United States Government or any agency thereof, or Battelle Memorial Institute.

\author{
PACIFIC NORTHWEST LABORATORY \\ operated by \\ BATTELLE \\ for the \\ UNITED STATES DEPARTMENT OF ENERGY \\ under Contract DE-AC06-76RLO 1830
}

\begin{tabular}{|c|c|}
\hline inted in the & s of America \\
\hline & \\
\hline National Tech & tion Service \\
\hline United States & f Commerce \\
\hline 5285 & oad \\
\hline Springt & 22161 \\
\hline NT & \\
\hline & \\
\hline & \\
\hline & Price \\
\hline Pages & Codes \\
\hline $001-025$ & A02 \\
\hline $026-050$ & $\mathrm{~A} 03$ \\
\hline 051-075 & AO4 \\
\hline $076-100$ & A05 \\
\hline $101-125$ & A06 \\
\hline $126-150$ & A07 \\
\hline $151-175$ & $A 0 B$ \\
\hline $176-200$ & $A 09$ \\
\hline 201-225 & A010 \\
\hline $226-250$ & A011 \\
\hline $251-275$ & A012 \\
\hline $276-300$ & $A 013$ \\
\hline
\end{tabular}


COMPARISON OF HYDRA PREDICTIONS TO

TEMPERATURE DATA FROM TWO SINGLE-ASSEMBLY

SPENT FUEL HEAT TRANSFER TESTS

\author{
R. A. McCann
}

December 1986

Prepared for the U.S. Department of Energy under Contract DE-AC06-76RLO 1830

Pacific Northwest Laboratory

Richland, Washington 99352 
.

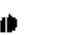

. 


\section{EXECUTIVE SUMMARY}

The HYORA computer code was used to simulate the thermal performance of an actual and a model spent fuel assembly. The HYDRA-predicted temperatures were then compared with measured data from two single-assembly test sections. The objective of this effort was to further verify the predictive capabilities of the HYDRA code for use in assessments of the hydrothermal performance of spent fuel dry storage systems. After HYDRA has been adequately evaluated and validated, the code will be documented to permit design and licensing safety analyses.

\section{THE HYDRA CODE}

HYDRA is a fully three-dimensional hydrothermal computer code that solves the equations of motion, continuity, and heat transfer by finite-difference techniques. The time-dependent conservation equations of momentum and mass for compressible fluids are used as the basis for calculating single-phase flow fields. The time-dependent conservation equation of energy with convection and heat sources is the basis for calculating the temperature field. The heat source term in the energy equation includes both internally generated heat and thermal radiation transport. The coupled field variables are solved on a Cartesian computational mesh. A cylindrical coordinate system is also available for computing the temperature field in an exterior cask body.

HYDRA has been designed to provide a user-oriented input interface that eliminates the need for internal code changes. Any application for which the code is an appropriate choice can be completely described through the construction of an input file.

\section{PWR SINGLE-ASSEMBLY SPENT FUEL SIMULATIONS}

The single-assembly spent fuel temperature tests were performed as part of the U.S. Department of Energy (DOE) Spent Fuel Handling and Packaging Program 1978 Demonstration and the Commercial Waste and Spent Fuel Packaging Programs. The objectives of these programs were to develop and test the capability to satisfactorily encapsulate typical spent fuel assemblies from commercial light 
water reactors and to establish the suitability of one or more techniques for interim dry storage.

Some of these tests were performed in a test stand to provide spent fuel assembly temperature data under simulated dry storage conditions. The PWR fuel assembly used for these tests was contained within a canister and held in a vertical orientation. Figure $\$ .1$ shows a vertical cross section of the test stand.

Pre-look and post-test HYDRA predict tons of temperatures were compared to experimentally measured data from three tests. The tests selected for simulation used canister backfill enviranments of air, vacuum (low-pressure air), and helium, respectively. To ensure an unblased evaluation of the code, all pre-look predictions were conducted without access to the experimentally measured fuel assembly temperature data. Post-test simulations were undertaken later with a slightly refined version of the code.

The input files for the pre-look and post-test simulations are also not identical. Improved information about the actual test conditions became available subsequent to the pre-look simulations, and this new information was incorporated into the post-test input files. The new information resulted in corrections to the fuel assembly decay heat generation rate and gas backftll pressures.

The post-test simulations reflect the best available information, and selected results are shown in Figure 5.2. The results of pre-look simulations are not included in Figure 5.2 because those simulations were based on incorrect test data; however, for completeness they are presented and discussed in the body of the report. The curves and data shown in figure $\$ .2$ represent temperatures along the center instrumentation tube of the fuel assembly. The lowest peak cladding temperature is observed for the hellum backfill. An intemnediate peak cladding temperature is observed for the air backfill primarily because the thermal conductivity of air is lower than that of helium. The peak cladding temperature increases as the pressure of the air backfill is reduced. The increase in temperature is a consequence of reduced convection 


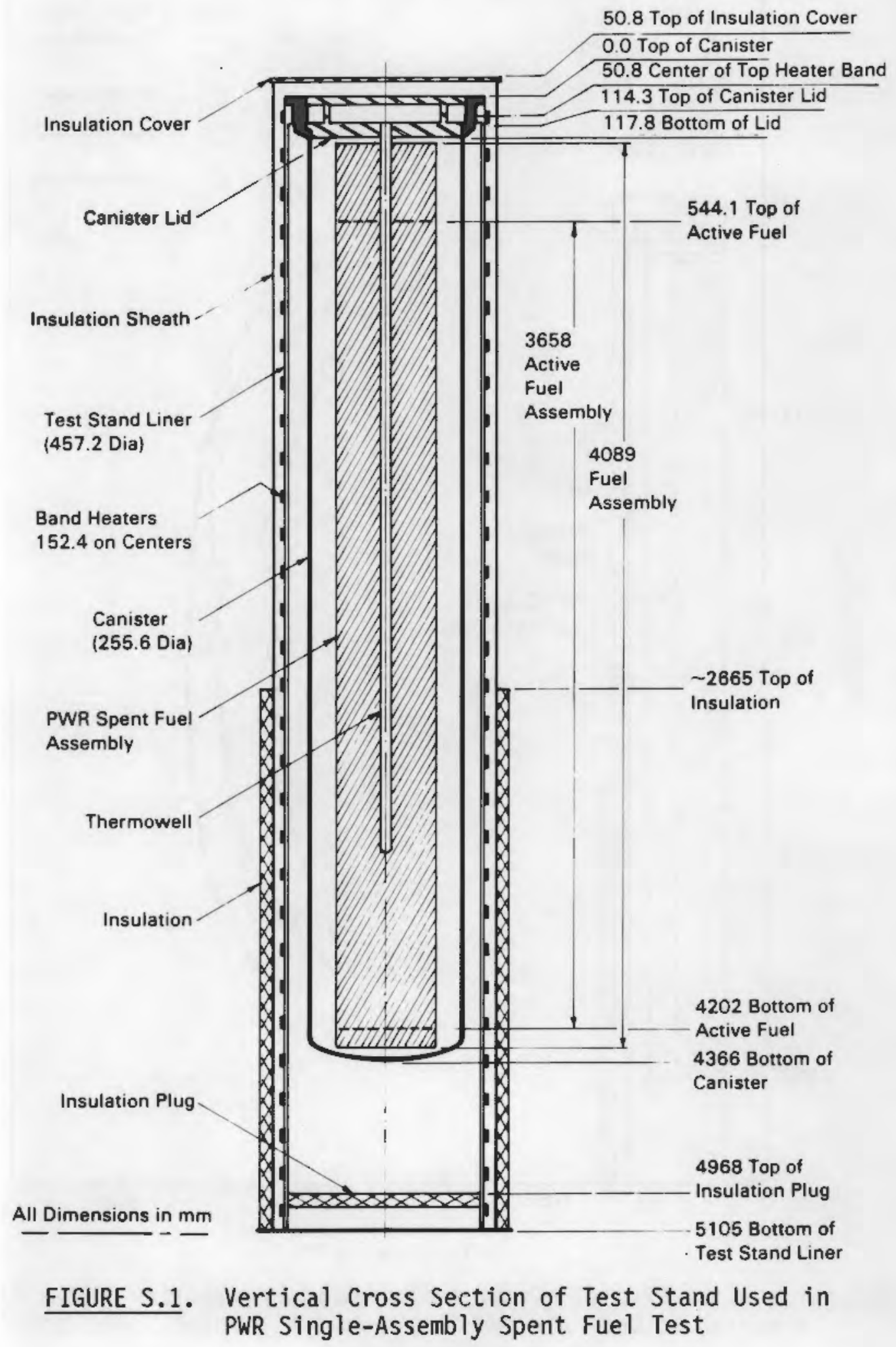




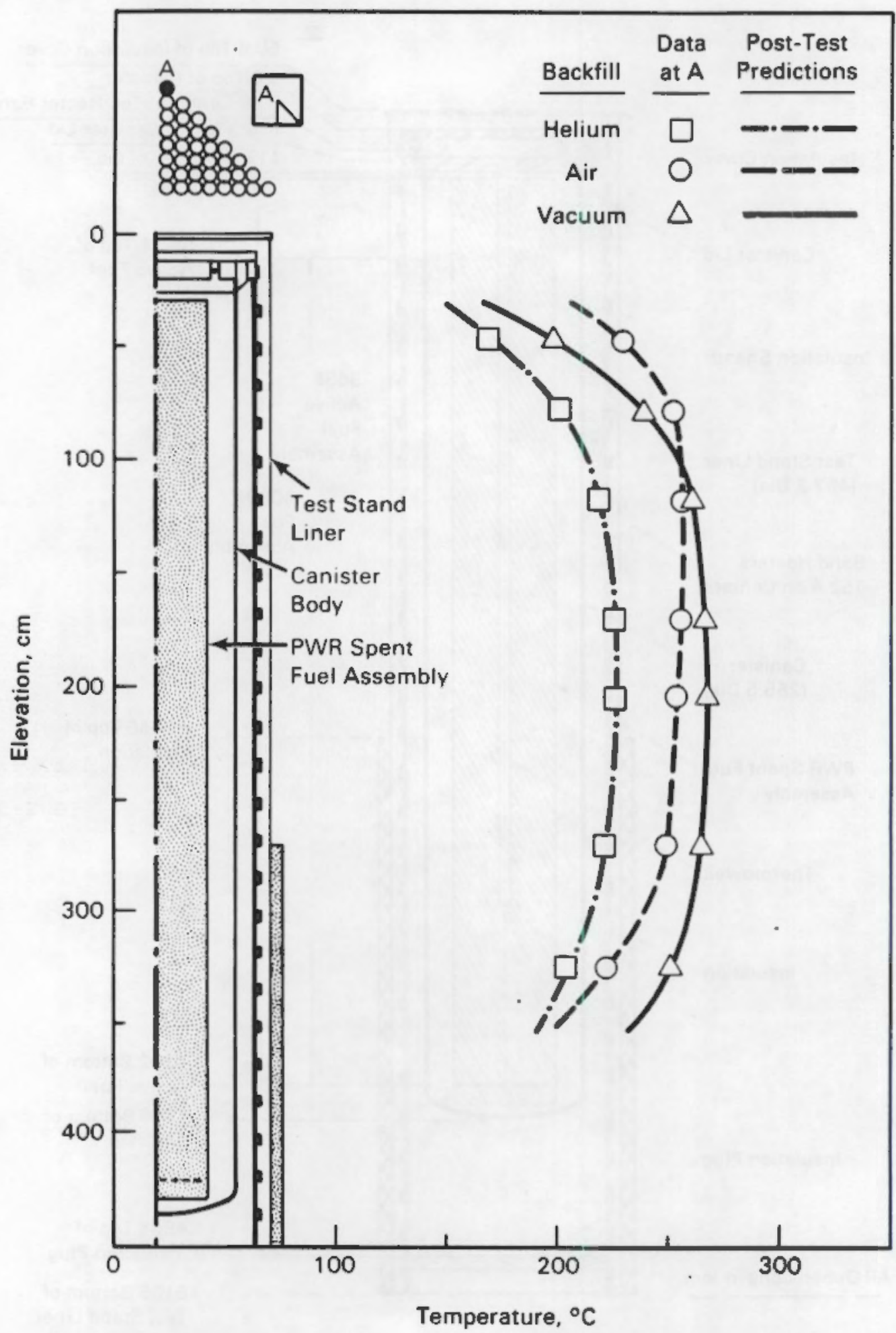

FIGURE S.2. Post-Test Predictions of Fuel Assembly Centerline Temperatures Compared to Data for PWR Single-Assembly Spent Fuel Simulations 
although the increase is mitigated somewhat by an increase in thermal radiation transport. The agreement between predictions and data is $3^{\circ} \mathrm{C}$ or better for the results shown in Fgiure S.2.

No modification to the algorithms or models in HYDRA is required as a result of these simulations. However, one code enhancement is considered worthwhile. The air backfill simulation showed evidence of relatively high gas velocities, and an appropriate turbulence transport model will provide improved results.

\section{ELECTRICALLY-HEATED SINGLE-ASSEMBLY SIMULATIONS}

The single-assembly heat transfer tests were performed as part of the DOE's Commercial Spent Fuel Management Program. The tests were conducted at the Pacific Northwest Laboratory using hardware designed and assembled by Allied General Nuclear Services at the Barnwell Nuclear Fuel Plant in Barnwell, South Carolina.

The primary objective of these tests was to provide experimental data for controlled conditions characteristic of dry storage of spent light water reactor fuel. This data could then form a partial basis on which to evaluate the predictive capability of thermohydraulic computer codes used to simulate spent fuel dry storage systems.

The test hardware included an electrically heated model of a PWR spent fuel assembly contained within a heavy-walled cask illustrated in Figure S.3. The test matrix consisted of:

- three cask orientations

- horizontal

- $25^{\circ}$ inclination from horizontal

- vertical

- three cask backfill media

- air at atmospheric pressure

- vacuum (air at approximately 0.1 atmosphere

- helium at slightly above atmospheric pressure 


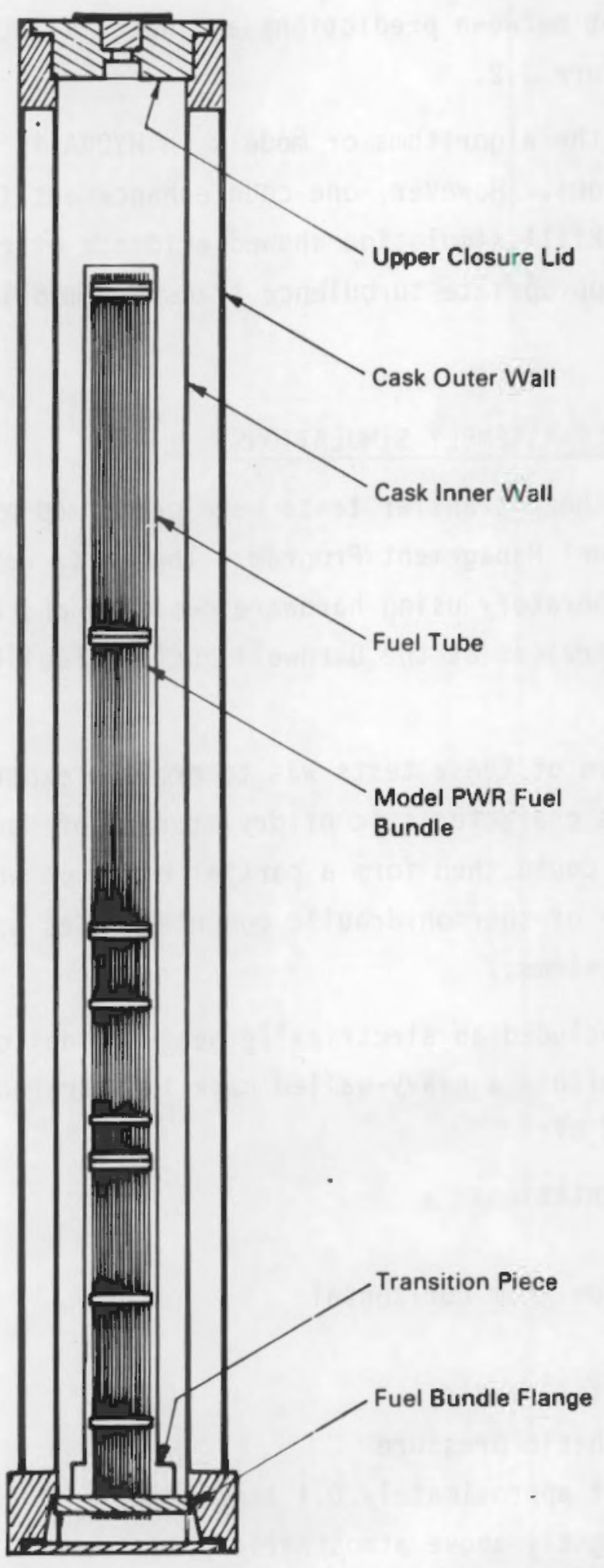

FIGURE S.3. Longitudinal Cross Section of the Electrically-Heated Single-Assembly Test Section 
- two nominal assembly power levels

$-0.5 \mathrm{~kW}$

$-1.0 \mathrm{~kW}$.

The test matrix was devised to exercise a range of code modeling capabilities appropriate to dry storage systems. Thus, the three cask orientations require a corresponding specification of the gravitational vector within the code that directly affects the gas flow field. The three different backfill media promote a different relative contribution from conduction, convection, and thermal radiation heat transfer mechanisms. And, the two power levels reflect typical 5- and 10-year-old PWR fuel.

All pre-look predictions were conducted without the modelers having access to the experimental results (except cask internal gas pressure, power generation rate, and temperature boundary conditions), and this cask had not been previously modeled. A single post-test simulation was performed to demonstrate the important benefits that turbulence modeling may provide. All simulations were conducted with the same version of HYDRA, and all input files were identical except for the unique parameters of each test.

Figure S. 4 shows the comparison between predictions and data for all simulations by means of 1) the temperature difference between the center rod and fuel tube and 2) the temperature difference between the fuel tube and cask. For example, the first simulation shown in Figure $S .4$ is for vertical orientation, 1-kW heat generation rate, and air backfill. The temperature difference of approximately $+8^{\circ} \mathrm{C}$ for center rod to fuel tube means that the predicted temperature difference is $8^{\circ} \mathrm{C}$ higher than what was measured. Similarly, the temperature difference of $+10^{\circ} \mathrm{C}$ for fuel tube to cask means that the code prediction is $10^{\circ} \mathrm{C}$ greater than the measured temperature difference.

The fuel tube represents a barrier to both convective and radiative energy transport. Furthermore, the energy transport within the fuel tube (i.e., within the rod assembly) is characterized and modeled differently from that external to the fuel tube (i.e., a free field). The temperature differences 
for these two regions might therefore be used as an indicator of the correctness of the separate models and heat transfer modes.

Each temperature difference shown in Figure S.4 is derived from average temperatures at the elevation nearest to the peak rod temperature where experimental data exists. The temperature differences shown for center rodto-fuel tube average to approximately $0^{\circ} \mathrm{C}$ when all simulations are considered, and are at most $\$ 8^{\circ} \mathrm{C}$ when considered individually. Probably the most significant trend indicated is that all air and vacuum simulations show temperature differences in the range of $0^{\circ} \mathrm{C}$ to $+8^{\circ} \mathrm{C}$ and all helium simulations show a temperature difference of approximately $-8^{\circ} \mathrm{C}$.

All temperature differences shown for fuel tube-to-cask are in the range of $0^{\circ} \mathrm{C}$ to $+10^{\circ} \mathrm{C}$. A positive average of all temperature differences is believed to be significant. A possible explanation for the overprediction of this temperature difference is that the assumed emittance of the cask is too low.

The results for the vertical orientation, 1-kW heat generation rate, and air backfill, mentioned above, display the largest discrepancy between predictions and data of all the simulations. One of the most striking results of this simulation is that peak temperatures occur near the top of the heated length of the rod assembly. The axial location of peak temperatures as well as the complete axial temperature profiles do not reflect the axial heat generation rate profile, which is believed to be nearly uniform over the length of the rod assembly. The general shape of the profiles indicates that strong convection currents are present. Moreover, the predicted velocities are high enough so that appreciable turbulence is expected.

One post-test simulation was conducted to demonstrate the benefit of an appropriate turbulence model. Figure $S .5$ shows the comparison between pre-look and post-test predictions and data. Improved agreement was achieved by incorporating a turbulent transport mechanism in the upper half of the cask where velocities are greatest.

The results for the rest of the simulations are considered, for the most part, very good. Discrepancies that do exist between predictions and data are comparable to experimental uncertainties. 


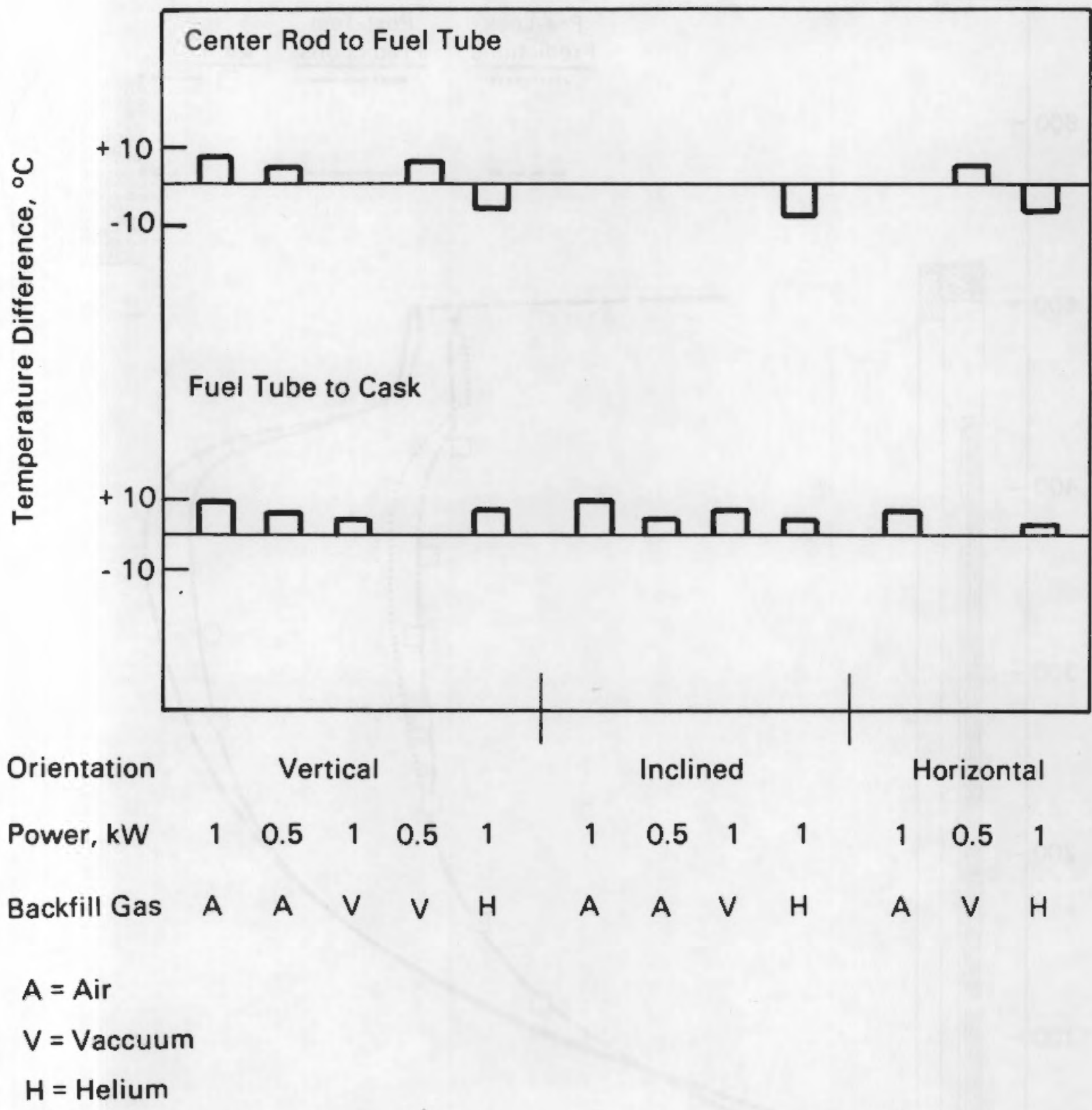

FIGURE S.4. Summary of Predictions Compared to Data Showing Temperature Differences for Electrically-Heated Single-Assembly Simulations 


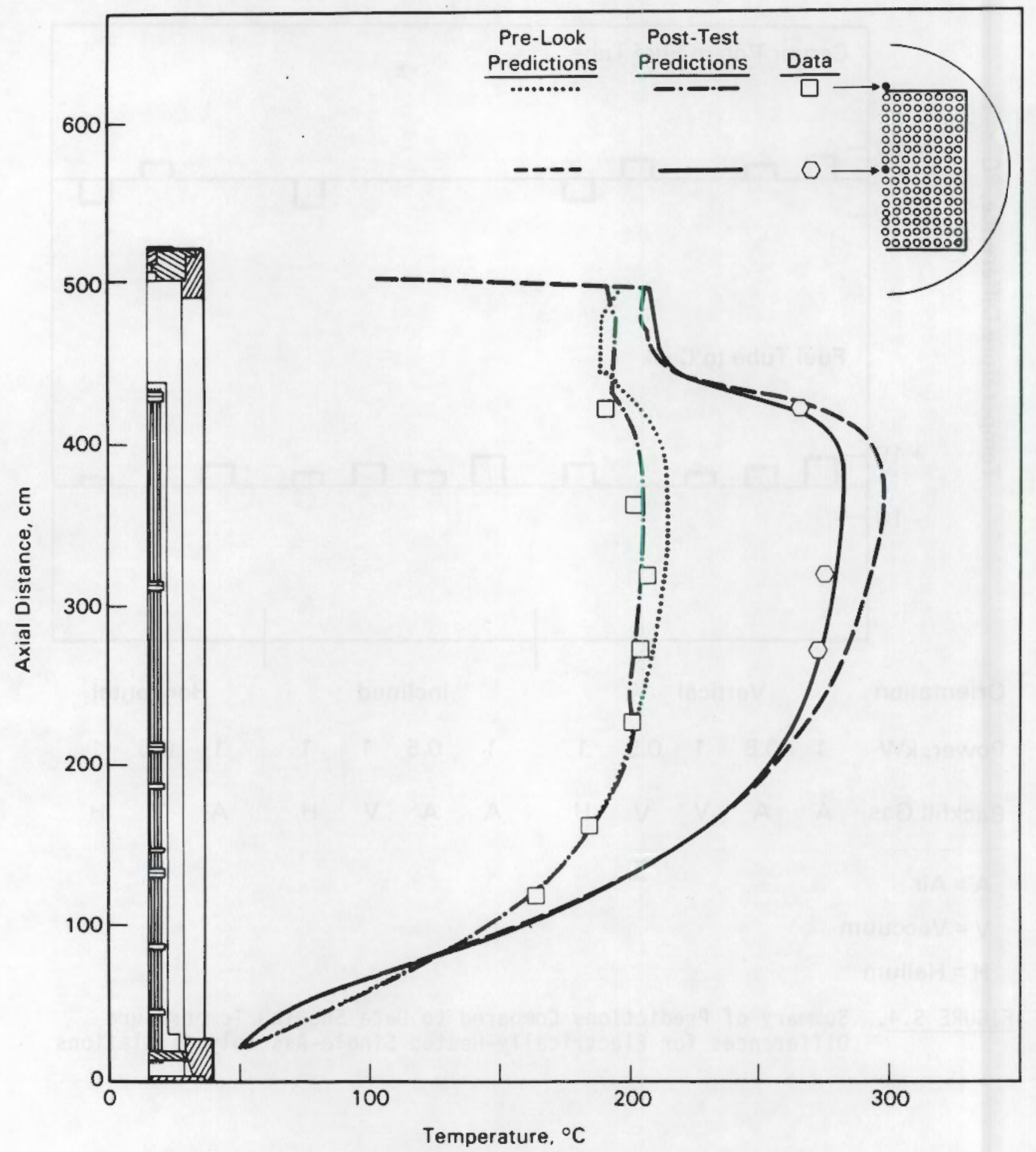

FIGURE S.5. Pre-Look and Post-Test Predictions Compared to Electrically-Heated Single-Assembly Test Data for Vertical Orientation, $1 \mathrm{~kW}$ Power, Air Backfill 


\section{CONCLUSIONS AND RECOMMENDATIONS}

The principal conclusions to be drawn from the work described in this report are:

- The agreement between predictions and data is $\pm 10^{\circ} \mathrm{C}$ or better for the two single-assembly tests.

- No justification can be found to modify any of the algorithms or models currently in HYORA.

- A turbulence transport model improved the agreement between predictions and data from $18^{\circ} \mathrm{C}$ to $6^{\circ} \mathrm{C}$.

Recommendations based on the results of and conclusions drawn from this work are:

- HYDRA should continue to be used to predict the thermohydrautic performance of spent fuel dry storage systems.

- A turbulence model should be added to the code for enhanced accuracy in those situations where turbulent flow is present.

- HYDRA should be documented and made available for design and licensing safety analyses. 
. 


\section{ACKNOWLEDGMENTS}

Appreciation is extended to the U.S. Department of Energy and to D. R. Oden, Jr. and G. H. Beeman of the Commercial Spent Fuel Management Program Office at Pacific Northwest Laboratory for their support of this activity. Project management for important elements of the experimental and analytical tasks was provided by J.M. Creer. J. M. Bates contributed significantly in the generation and clarification of experimental data and procedures. A. $J$. Currie was in charge of technical editing, and E. C. Darby supervised word processing. 



\section{CONTENTS}

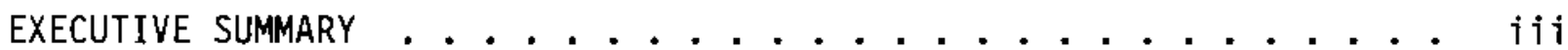

ACKNOWLEDGMENTS ........................ xiv

1.0 INTRODUCTION . . . . . . . . . . . . . . . . . . 1.1

2.0 CONCLUSIONS AND RECOMMENDATIONS . . . . . . . . . . 2.1

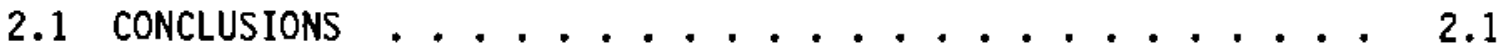

2.2 RECOMMENDATIONS . . . . . . . . . . . . . 2.1

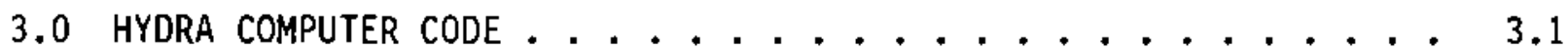

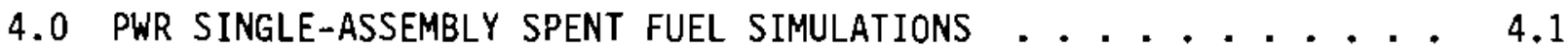

4.1 TEST DESCRIPTION . . . . . . . . . . . . . . 4.2

4.1.1 Hardware Description . . . . . . . . . . 4.2

4.1.2 Test Conditions .............. 4.5

4.2 COMPUTATIONAL MODEL DESCRIPTION . . . . . . . . . 4.6

4.2.1 Computational Mesh . . . . . . . . . . 4.7

4.2.2 Material Properties .............. . 4.11

4.2.3 Modeling Uncertainties ............. 4.11

4.3 PREDICTIONS COMPARED TO DATA . . . . . . . . . . 4.17

4.3.1 Pre-Look Predictions ............ 4.18

4.3.2 Post-Test Predictions . . . . . . . . . . 4.22

5.0 ELECTRICALLY-HEATED SINGLE-ASSEMBLY SIMULATIONS $\ldots \ldots .1$

5.1 TEST DESCRIPTION . . . . . . . . . . . . . . 5.1

5.1.1 Hardware Description ........... 5.1

5.1 .2 Test Conditions . . . . . . . . . . 5.7

5.2 COMPUTATIONAL MODEL DESCRIPTION . . . . . . . . 5.8

5.2.1 Computational Mesh . . . . . . . . . . 5.9 
5.2 .2 Material Properties . . . . . . . . 5.9

5.2 .3 Modeling Uncertainties $\ldots \ldots \ldots . \ldots . . \ldots$

5.3 PREDICTIONS COMPARED TO DATA $\ldots \ldots \ldots \ldots \ldots$

5.3.1 Pre-Look Predictions ,........... 5.15

5.3 .2 Post-Test Predictions ............ 5.29

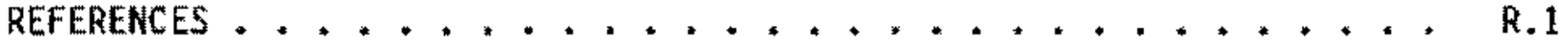

APPENDIX - ELECTRICALLY-HEATED SINGLE-ASSEMBLY TESTS

ADDITIONAL PREDICTIONS OF TEMPERATURES COMPARED TO DATA * A A.1 


\section{FIGURES}

S.1 Vertical Cross Section of the Test Stand Used in

PWR Single-Assembly Spent Fuel Test ............ v

S.2 Post-Test Predictions of Fuel Assembly Centerline Temperatures

Compared to Data from PWR Single-Assembly Spent Fuel Tests ... vi

S. 3 Longitudinal Cross Section of the Cask Used in the Electrically-

Heated Single-Assembly Tests ..................... vii

S.4 Summary of Predictions Compared to Data Showing Temperature

Differences for Electrically-Heated Single-Assembly Simulations . xi

S.5 Pre-Look and Post-Test Predictions Compared to

Electrically-Heated Single-Assembly Test Data for

Vertical Orientation, $1 \mathrm{~kW}$ Power, Air Backfill ....... xii

4.1 Fuel Temperature Test Assembly ............. 4.3

4.2 Test Stand Vertical Cross Section . . . . . . . . . 4.4

4.3 Test Stand Horizontal Cross Section ........... 4.5

4.4 Relative Axial Activity Profile ........... 4.8

4.5 Horizontal Computational Mesh for Pre-Look Simulations . . . 4.9

4.6 Horizontal Computational Mesh for Post-Test Simulations . . . 4.9

4.7 Physical Features Modeled in the Horizontal Cross Section . . 4.10

4.8 Vertical Computational Mesh for Pre-Look Simulations . . . . 4.12

4.9 Vertical Computational Mesh for Post-Test Simulations . . . 4.13

4.10 Fuel Assembiy Position Relative to Canister Inside Surface

vertical Cross Section ............. 4.14

4.11 Pre-Look Predictions of Temperatures Compared to Data

Air Backfill (1.41 atm)

Decay Heat $1.21 \mathrm{~kW}$.............. 4.19

4.12 Pre-Look Predictions of Temperature Compared to Data

Vacuum Backfill (0.0 atm)

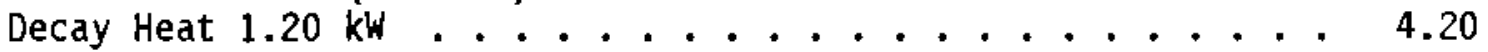


4.13 Pre-Look Predictions of Temperatures Compared to Data Helium Backfill (1.35 atm)

Decay Heat $1.20 \mathrm{kw} \ldots \ldots . . \ldots . . . \ldots 4.21$

4.14 Post-Test Predictions of Temperatures Compared to Data Air Backfill $(1.0 \mathrm{~atm})$

Decay Heat $1.17 \mathrm{kw} \ldots \ldots \ldots \ldots . \ldots \ldots . \ldots \ldots$

4.15 Post-Test Predictions of Temperatures Compared to Data

Turbulence Model

Alr Backfill (1.0 atm)

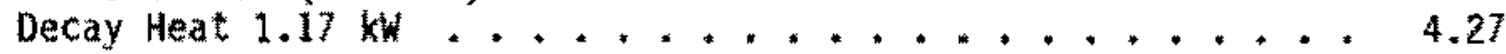

4.16 Post-Test Predictions of Temperatures Compared to Data

Low Pressure Air $(0.2 \mathrm{~atm})$

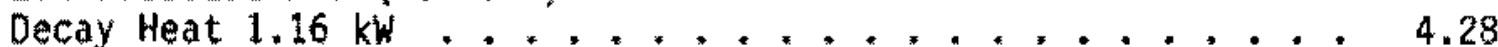

4.17 Post-Test Predictions of Temperatures Compared to Data

Helium Backfill (1.07 atm)

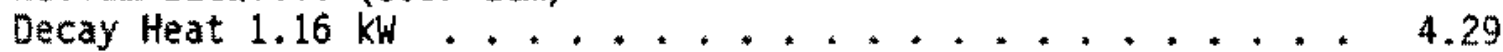

5.1 Test Assembly Mounted on Skid Assembly ......... 5.2

5.2 Transverse Cross Section of the Test Section ...... 5.3

5.3 Longitudinal cross section of the Test Section ...... 5.4

5.4 Cross Section of $15 \times 15$ Electrically-Heated Model Fuel Assembly 5.6

5.5 Transverse Computational Mesh ............ 5.10

5.6 Alignment of Transverse Cross Section Computational Mesh with

Physical Features .................., 5.11

5.7 Longitudinal Computational Mesh ............. 5.12

5.8 Physical Features Modeled in the Longitudinal Cross Section . . 5.13

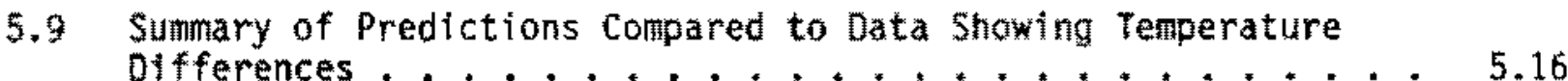

\$.10 Pre-Look Predictions of Temperatures Compared to Data Vertical Orientation, $1 \mathrm{~kW}$ Power, Alr Backfill ...... 5.19

5,11 Pre-Look Predictions of Temperatures Compared to Data Vertical orientation, $1 \mathrm{~kW}$ Power, Vaculum Backfill ...... 5.20

5.12 Pre-Look Predictions of Temperatures Compared to Data Vertical Orientation, $1 \mathrm{~kW}$ Power, Helium Backfill ..... 5.21 
5.13 Pre-Look Predictions of Temperatures Compared to Data Inclined Orientation, $1 \mathrm{~kW}$ Power, Air Backfill .......

5.14 Pre-Look Predictions of Temperatures Compared to Data Inclined Orientation, $1 \mathrm{~kW}$ Power, Vacuum Backfill ....... 5.24

5.15 Pre-Look Predictions of Temperatures Compared to Data Inclined Orientation, $1 \mathrm{~kW}$ Power, Helium Backfill ...... 5.25

5.16 Pre-Look Predictions of Temperatures Compared to Data Horizontal Orientation, $1 \mathrm{~kW}$ Power, Air Backfill ..... 5.26

5.17 Pre-Look Predictions of Temperatures Compared to Data Horizontal Orientation, $0.5 \mathrm{~kW}$ Power, Vacuum Backfill . . . 5.27

5.18 Pre-Look Predictions of Temperatures Compared to Data Horizontal Orientation, $1 \mathrm{~kW}$ Power, Helium Backfill . . . . 5.28

5.19 Post-Test Predictions of Temperatures Compared to Data Turbulence Model Vertical Orientation, $1 \mathrm{~kW}$ Power, Air Backfill . . . . . . 5.32

A.1 Pre-Look Predictions of Temperatures Compared to Data Vertical Orientation, $0.5 \mathrm{~kW}$ Power, Air Backfill ...... A.2

A.2 Pre-Look Predictions of Temperatures Compared to Data Vertical Orientation, $0.5 \mathrm{~kW}$ Power, Vacuum Backfill ..... A.3

A.3 Pre-Look Predictions of Temperatures Compared to Data Inclined Orientation, $0.5 \mathrm{~kW}$ Power, Air Backfill ...... 


\section{TABLES}

4.1 Geonetrical Parameters for Fuel Assemblylcanister * * **..4.5

4.2 Test operating Conditions . . . . . . . . . . . 4.7

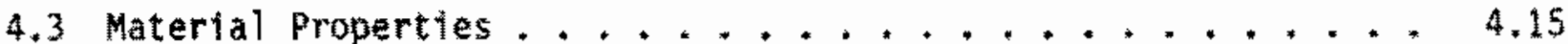

5.1 Electrically-Heated Single Assembly Test Matrix . * * , . . . 5.8

5.2 Material Properties ..................... 5.14 
COMPARISON OF HYDRA PREDICTIONS TO TEMPERATURE DATA FROM

TWO SINGLE-ASSEMBLY SPENT FUEL HEAT TRANSFER TESTS

\subsection{INTRODUCTION}

Implementation of spent fuel dry storage systems may be required in the late 1980s because several at-reactor storage basins will attain maximum capacity (DOE 1985). The Nuclear Waste Policy Act of 1982 (NWPA) assigns the U.S. Department of Energy (DOE) the responsibility for assisting utilities with their spent fuel storage problems. One of the provisions of the NWPA is that DOE shall provide generic research and development of alternative spent fuel storage systems to assist utilities in their licensing activities.

One of the important requirements for storage systems is that they dissipate heat while maintaining the temperature of the stored materials below established limits. The thermal performance of a storage system can be assessed by a comprehensive testing program. Such testing programs are typically timeconsuming and expensive. Analysis tools (e.g., computer codes), while not intended to entirely supplant testing methods, can perform a valuable service. Appropriately qualified computer codes can provide predictions of thermal performance as a function of system design and operating conditions. Moreover, when tests are to be performed, computer codes can help select test conditions, spent fuel decay heat generation rates, and instrumentation placements, as well as aid in interpreting test data.

The qualification of a code for a given application generally involves comparing the code predictions with results of relevant tests. The credibility of a code is proportionately increased by the number of favorable comparisons that can be provided. This report presents comparisons of HYDRA code predictions to temperature data previously measured for two single-assembly spent fuel heat transfer tests.

The first test, the PWR Single-Assembly Spent Fuel Test, comprised one PWR spent fuel assembly, a vertical canister enclosure, and three gas backfill environments. The second, the Electrically-Heated Single-Assembly Test, used 
an electrically-heated model PWR rod assembly, a cask oriented in the vertical, $25^{\circ}$ from horizontal, and horizontal direction, and three gas backfill

environments. The three backftll environments for both tests were air, vacutam (low-pressure air), and helitum.

conclusions and recommendations based on the work described in this report are presented in Section 2.0. Section 3.0 provides an overview of the current capabilities of HYORA that are of special interest to the analysis of spent fuel storage casks and canlsters. Section 4.0 documents the HroRA simulations of the PWR Single-Assembly spent Fuel Test. In Section 5.0. HYORA simulations of the Electrically-Heated Single-Assembly Test are presented. Both sections 4.0 and 5.0 provide descriptions of the original heat transfer tests, the HYORA computational model, and comparisons of HYDRA predictions with the actual test data. 


\subsection{CONCLUSIONS AND RECOMMENDATIONS}

The HYDRA computer code was used to predict the thermohydraulic performance of two single-assembly heat transfer tests. The code predictions, initially generated without access to experimental results, were then compared to experimentally measured data. Such comparisons are essential in establishing an acceptable and verifiable level of confidence in the code's predictive capabilities. Important conclusions and recomnendations established from the work described in this report are presented in this section.

\subsection{CONCLUSIONS}

The principal conclusions to be drawn from the work described in this report are:

- HYDRA successfully performed predictions of temperatures for the two single-assembly tests. The agreement between predictions and data was $\pm 10^{\circ} \mathrm{C}$ or better. This type of predictive capability is one consequence of the reliance on fundamental conservation laws that do not depend on the application.

- No justification was found for modifying any of the algorithms or models currently in HYDRA. This is not meant to imply that the code cannot be improved. Historically, new applications have often led to new challenges, and these, in turn, have resulted in code improvements.

- A turbulence transport model is a desirable addition to the code. Two of the 15 pre-look simulations show evidence of turbulent flow. The benefit that an appropriate turbulence transport model could provide is demonstrated by the results of two post-test simulations.

\subsection{RECOMMENDATIONS}

Recommendations based on the results of and conclusions drawn from this work are:

- HYDRA should continue to be used to predict the thermohydraulic performance of spent fuel dry storage systems. 
- A turbulence model should be added to the code for enhanced accuracy in those situations where turbulent flow is present.

- HYDRA should be documented and made avallable for design and licensing safety analyses. 


\subsection{HYDRA COMPUTER CODE}

This section provides an overview of the current capabilities of HYDRA that are of special interest to the analysis of spent fuel storage systems. HYDRA is a fully three-dimensional hydrothermal computer code that solves the equations of motion, continuity, and heat transfer by finite-difference techniques. HYDRA is constructed with reasonable generality and therefore has considerable applicability beyond storage cask applications.

Extensive assessment of HYDRA have been conducted using applications ranging from model problems with known analytic solutions to full-scale spent fuel storage casks with experimental data. The current analyses of two singleassembly heat transfer tests continue the series of applications intended to establish an acceptable and verifiable level of confidence in the code's predictive capabilities. After HYDRA has been adequately evaluated and validated, the code will be documented to permit its use in design and licensing safety analyses.

The time-dependent conservation equations of momentum and mass for compressibie fluids are used as the basis for calculating single-phase flow fields. The time-dependent conservation equation of energy with convection and heat sources is the basis for calculating the temperature field. These conservation equations are as follows:

\section{Momentum}

$$
\frac{\partial}{\partial t}(\vec{m})=\rho \vec{g}-\nabla p-D \vec{m}+\nabla \cdot(\mu \nabla \vec{v})-\nabla \cdot(\vec{v} \vec{m})
$$

$$
\text { where } \begin{aligned}
& t=\text { time } \\
& \overrightarrow{\mathrm{m}}=\text { mass flux } \\
\rho & =\text { density } \\
\overrightarrow{\mathrm{g}} & =\text { gravitational vector }
\end{aligned}
$$




$$
\begin{aligned}
& \mathrm{p}=\text { pressure } \\
& 0=\text { Darcy and orifice drag } \\
& \vec{H}=\text { viscosity } \\
& \vec{\forall}=\text { velocity }
\end{aligned}
$$

\section{Mass}

$$
\frac{\partial}{\partial t}(p)=-\nabla \cdot\left(\frac{m}{m}\right)
$$

Energy

$$
\frac{\partial}{\partial t}\left(p C_{p} T\right)=\nabla \cdot(A V T)-\nabla \cdot\left(C_{p} \cdot T T\right)+\dot{q}
$$

where $c_{p}=$ specific heat

$$
\begin{aligned}
& T=\text { temperature } \\
& \lambda=\text { thermal conductivity. }
\end{aligned}
$$

The source term, $\dot{q}$, in Equation (3.3) represents heat generation and therma radiation transport. The latter is given by an expression of the form

$$
\stackrel{q}{\text { rad } i \neq j}=H_{i j}\left(T_{i}^{4}-T_{j}^{4}\right)
$$

where $\mathrm{H}_{1 \mathrm{j}}$ is an exchange factor based on geometry and emittances. A thermodynamic state relationship of the form 


$$
\rho=f(p, 1)
$$

is required, as are other relationships needed to define temperature-dependent material properties.

The conservation equations are converted to finte-difference equations using the locally one-dimensional philosophy embodied in Spaulding's Hybrid scheme [see, for example, Patankar (1980)]. Both the energy equation and the three linear momentum equations are solved using an alternating-direction algorithm described by Douglas and Gunn (1964). The momentum equations are linked with the conservation of mass equation in a manner consistent with the spirit of the CTS SIMPLE algorithm described by Raithby and Schneider $(1979,1980)$.

HYDRA uses a Cartesian coordinate system for the computational mesh in the interior of casks. A cylindrical coordinate system is avallable for convenience in calculating the temperature field in an exterior cask body. When both coordinate systems are invoked to model a single application, the code will automatically align the two systems and enforce conservation of energy at their interface.

HYORA is designed to provide a usermoriented input interface that eliminates the need for internal code changes. Any application for which the code is an appropriate choice can be completely described through the construction of an input file. The user may optionally request a formatted echo of the input file to confirm that the intended parameters are actually those used by the code. A selectable commentary monitoring the progress of the code toward a steady-state solution is available, as is a sumary of energy balances. Finally, a tape may be written at the conclusion of a rum, in the event that the user might wish to restart the solution from its most recent point. 


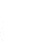




\subsection{PWR SINGLE-ASSEMBLY SPENT FUEL SIMULATIONS}

The selected single-assembly fuel temperature tests outlined in this section were performed as part of the DOE Spent Fuel Handling and Packaging Program (SFMP) 1978 Demonstration and the Commercial waste and spent Fuel Packaging Programs. The objectives of these programs were to develop and test the capability to satisfactorliy encapsulate typical spent fuel assemblies from coumerclal light water reactors and to establish the sultability of one or more techniques for interim dry storage. Near-surface and above-surface storage concepts were chosen for testing during the SFHPP Demonstration.

These tests were performed at the Engine Maintenance, Assembly and Disassembly (E-MAD) facility at the Nevada Test site. The E-MAD facility is operated for the DOE Nevada Operations Office by the Advanced Energy Systems Division (AESD) of the Westinghouse Electric Corporation. All testing at E-MAD was. performed by Westinghouse AESD personnel.

The primary objective of these tests was to demonstrate that commercial spent fuel could be passively stored in near-surface drywells at the Nevada Test 5ite. The test hardware for the drywell tests consisted of an instrumented carbon steel liner, an instrumented stainless steel canister (containing a PWR spent fuel assembly), and a concrete-filled shleld plug that supported the canister from the liner top. The drywell liner was grouted into a hole in the soll. Radially spaced themocouple wells measured ground temperature response to the spent fuel decay heat. Throughout the tests, temperature readings from the thermocouples on the canister, liner, and in the soll were recorded.

Subsequent fuel temperature tests were performed in a test stand in one of the E-MAD process cel1s to provide spent fuel assembly temperatures under simulated dry storage conditions. The PwR fuel assembly used for these tests was contained within a canister and held in a vertical orientation. The three tests selected for HYDRA simulation used atmospheres of air, vacuum (lowpressure air), and helium. 
The test hardware and test conditions needed for numerical simulation are described in Section 4.1. Section 4.2 contains computational models for this application and a discussion of modeling uncertainties. Section 4.3 presents HYDRA predictions and comparisons to data.

\subsection{TEST DESCRIPTION}

This section contains a brief description of the test hardware and test conditions needed for numerical simulation. A full account of all test details is available in Unterzuber et al. (1982). A condensed but complete sumnary of details needed for simulation is contained in Bates (1986).

\subsubsection{Hardware Description}

The hardware consisted of a main test assenbly with a number of auxiliary systems and components. The main test assembly. lllustrated in Figure 4.1, consisted of 1) a test stand supporting a representative storage cell liner, 2) a seismic restraint fixture providing test stand lateral support, 3) a test canister (representative of a storage canister), 4) a canister lid assembly containing instrumented tubes that were inserted into the spent fuel assembly, and 5) a PWR spent fuel assembly. Auxiliary equipment included 1) an evacuation and backfill system, 2) test stand electric heater controls, 3) themocouples, and 4) a data acquistition system to record thermocouple data.

Figure 4.2 shows a vertical cross section of the test stand. The general configuration of liner and canister is indicated, along with the position of the fuel assembly. The fuel assembly consists of a $15 \times 15$ array of 204 fuel rods, 20 control rod guide thimbles, and one instrumentation tube.

A horizontal cross section of the test stand is shown in Figure 4.3. The positions of thermocouple tubes are indicated. These tubes hang from the canister lid and slide into control rod guide thimbles and the center instrumentation tube. Each thermocouple tube contains seven axially spaced themocouples. Geometrical information for the fuel assembly and canister is given in Table 4.1 . 


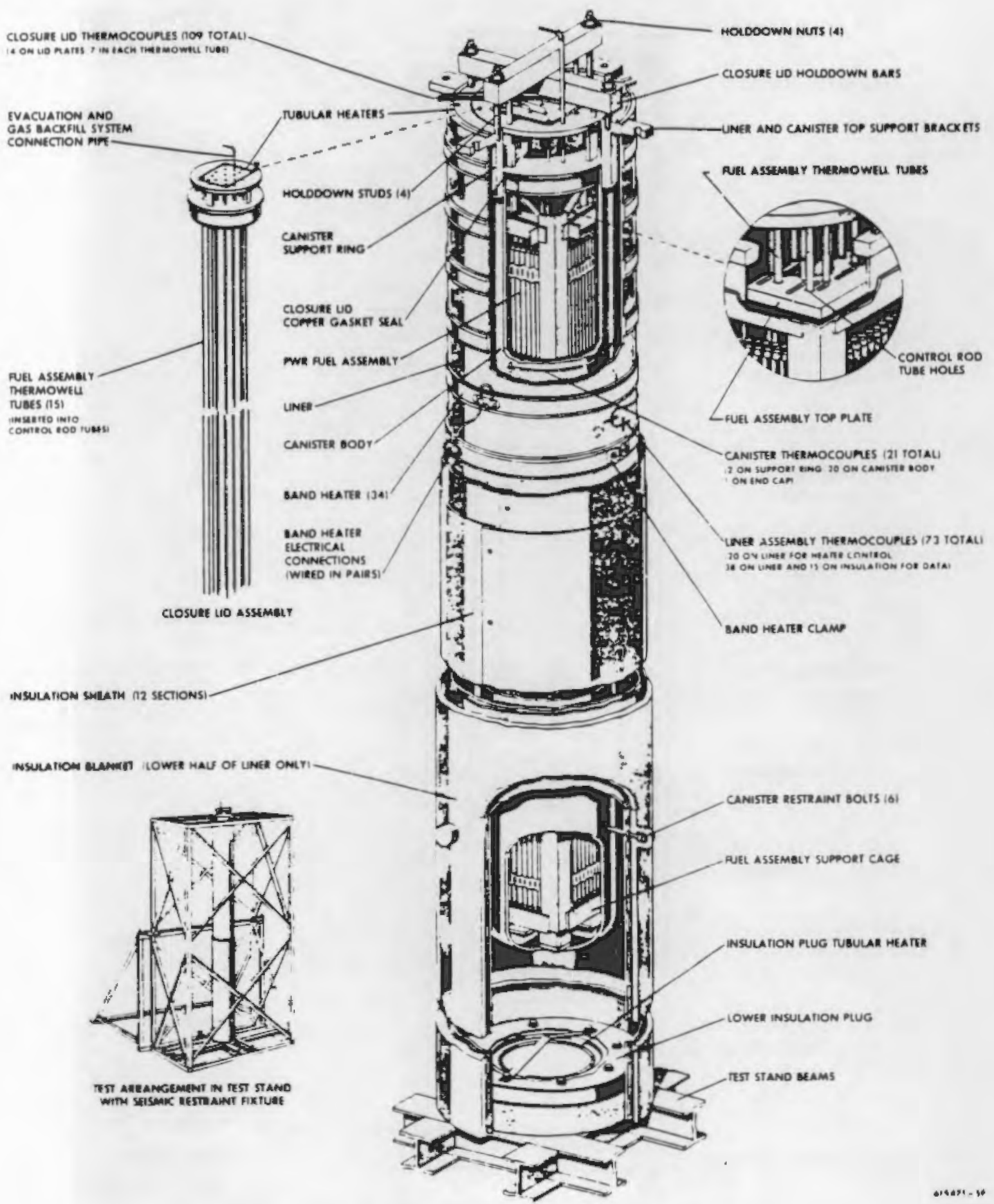

FIGURE 4.1. Fuel Temperature Test Assembly

Source: Unterzuber et al. (1982) 


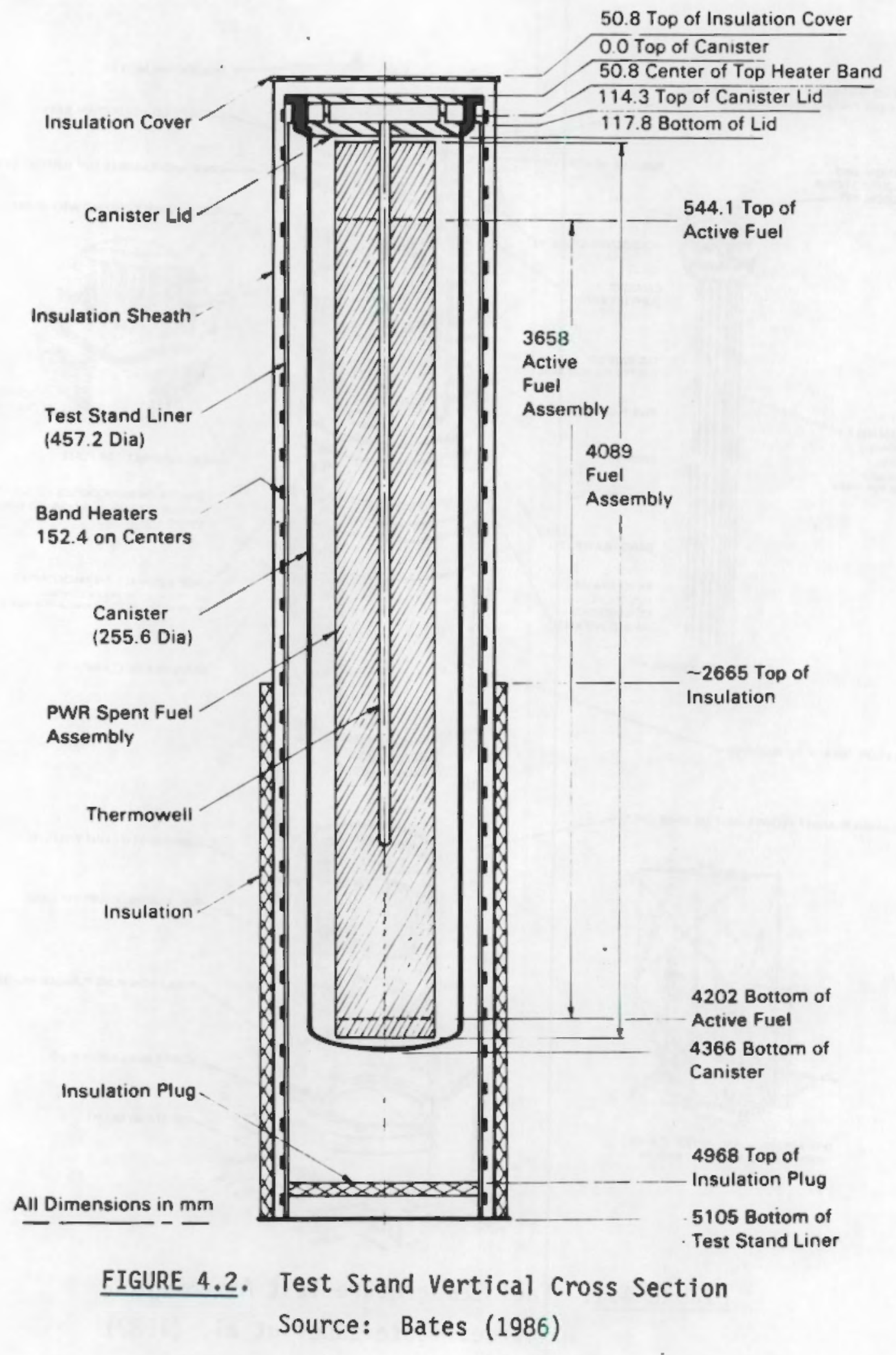




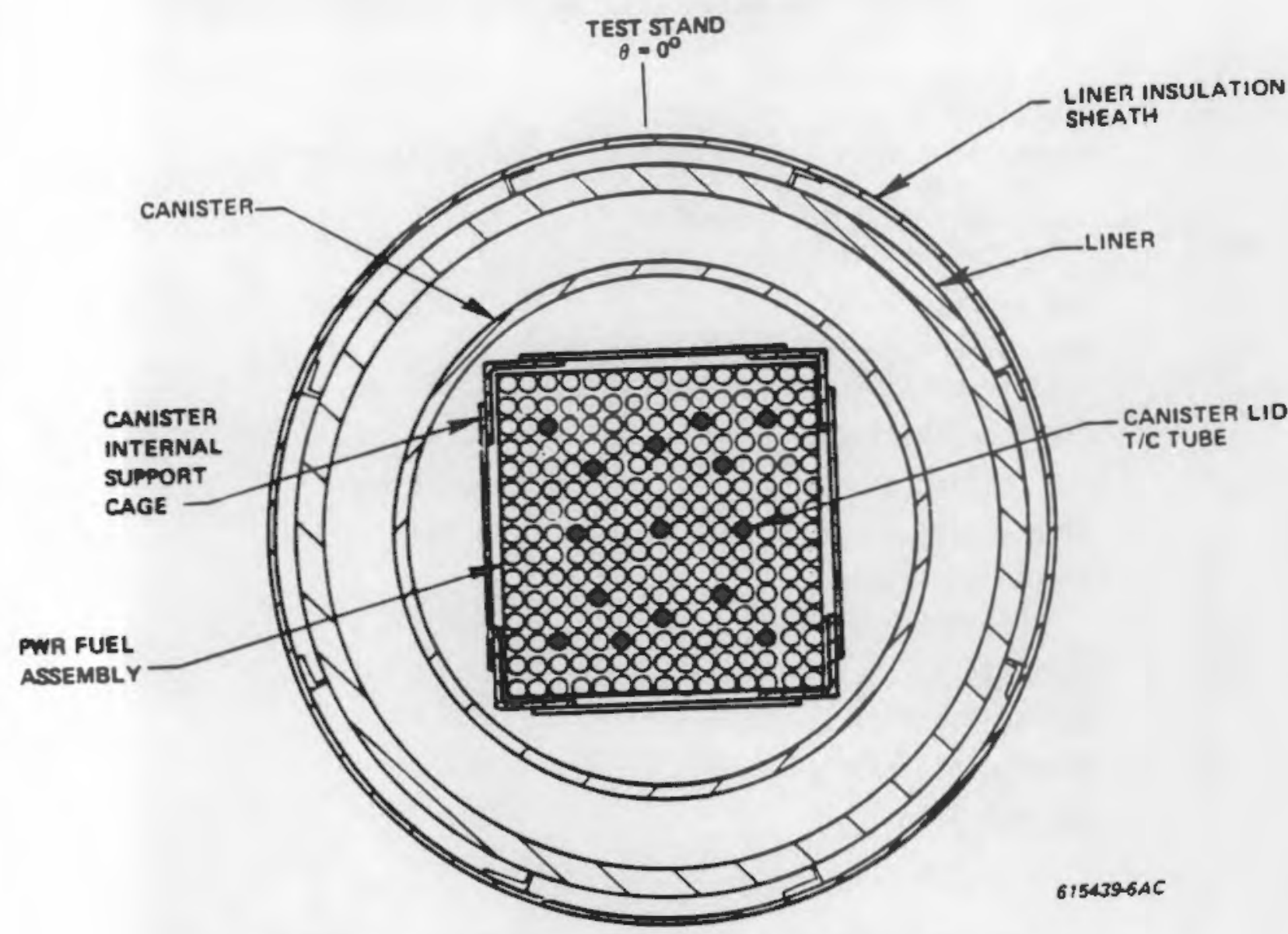

FIGURE 4.3. Test Stand Horizontal Cross Section

Source: Unterzuber et al. (1982)

\subsubsection{Test Conditions}

The test operating conditions that were used to construct the input file for the HYDRA code are given in Table 4.2. The test conditions include decay heat generation, type of gas and pressure, and canister temperature.

The decay heat generation rates and gas pressures used for the pre-look simulations differ from those used for the post-test simulations. The reason for this difference is that after the pre-look simulations had been completed it was discovered that these furnished data were incorrect. The data used for the post-test simulations are believed to be correct. 
TABLE 4.1. Geometrical Parameters for Fuel Assembly/Canister

\begin{tabular}{lc} 
Fuel Assembly & \\
\hline Number of rods & $225(15 \times 15$ array) \\
$\quad$ Fuel rods & 204 \\
Control rod guide thimbles & 20 \\
Instrumentation tube & 1 \\
Rod diameter & $1.072 \mathrm{~cm}$ \\
$\begin{array}{l}\text { Control rod guide thimble and } \\
\text { instrumentation tube diameters }\end{array}$ & $1.387 \mathrm{~cm}$ \\
Cladding thickness & $0.062 \mathrm{~cm}$ \\
Fuel pellet diameter & $0.948 \mathrm{~cm}$ \\
Pitch-to-diameter ratio & 1.334 \\
Active fuel length & \\
$\quad$ (includes swelling) & $367.0 \mathrm{~cm}$ \\
Canister & \\
Inside diameter & $33.7 \mathrm{~cm}$ \\
Outside diameter & $35.6 \mathrm{~cm}$ \\
Outside length & $436.6 \mathrm{~cm}$
\end{tabular}

The canister surface temperature at a given elevation shown in Table 4.2 represents, in general, the average reading of several thermocouples located around the circumference of the canister at that elevation. The axial distribution of decay heat was obtained by interpreting data given in Davis (1980). The relative axial activity is plotted in Figure 4.4.

\subsection{COMPUTATIONAL MODEL DESCRIPTION}

The complete description of a given application is contained on an input file. The input file is read by HYDRA, and the information contained is stored and used to guide subsequent execution of the code. The computational mesh and material properties contained on the input file are described in this section. Modeling uncertainties are also discussed. 
TABLE 4.2. Test Operating Conditions

Pre-Look Simulations

\begin{tabular}{lcll}
\multicolumn{1}{c}{ Test } & $\begin{array}{c}\text { Decay Heat } \\
\text { Generation Rate }\end{array}$ & $\frac{\text { Pressure }}{1.41 \mathrm{~atm}}$ \\
\cline { 1 - 1 } Air & $1.21 \mathrm{~kW}$ & \\
Vacuum & $1.20 \mathrm{~kW}$ & $0.0 \mathrm{~atm}$ \\
Helium & $1.20 \mathrm{~kW}$ & $1.35 \mathrm{~atm}$
\end{tabular}

Post-Test Simulations

\begin{tabular}{|c|c|c|}
\hline Test & $\begin{array}{c}\text { Decay Heat } \\
\text { Generation Rate }\end{array}$ & Pressure \\
\hline Air & $1.17 \mathrm{~kW}$ & $1.0 \mathrm{~atm}$ \\
\hline $\begin{array}{l}\text { Vacuum (low- } \\
\text { pressure air) }\end{array}$ & $1.16 \mathrm{~kW}$ & $0.2 \mathrm{~atm}$ \\
\hline Helium & $1.16 \mathrm{~kW}$ & $1.07 \mathrm{~atm}$ \\
\hline
\end{tabular}

Canister Temperature Profiles

Distance Below
Top of Canister, cm

41.9

129.5

217.2

304.8

392.4

435.9

\begin{tabular}{lrrr}
\multicolumn{3}{l}{ Average } & Measured Temperature, ${ }^{\circ}{ }^{\circ} \mathrm{C}$ \\
\hline Air & Vacuum & Helium \\
138.8 & & 114.7 & 116.5 \\
159.5 & 149.8 & 150.0 \\
160.8 & 158.9 & 159.7 \\
156.1 & 157.8 & 157.5 \\
127.8 & 127.8 & 128.8 \\
88.8 & 90.5 & 91.3
\end{tabular}

\subsubsection{Computational Mesh}

The horizontal cross section presented in Figure 4.3 shows the fuel assembly inside a circular canister. The symmetrical location of unheated guide thimbles within the fuel assembly and the centered position of the fuel assembly within the canister allow the use of a one-quarter symmetry model.

Figure 4.5 shows the computational mesh employed for the pre-look simulations, and Figure 4.6 shows the computational mesh employed for the post-test simulations. The difference between the two meshes can be seen 


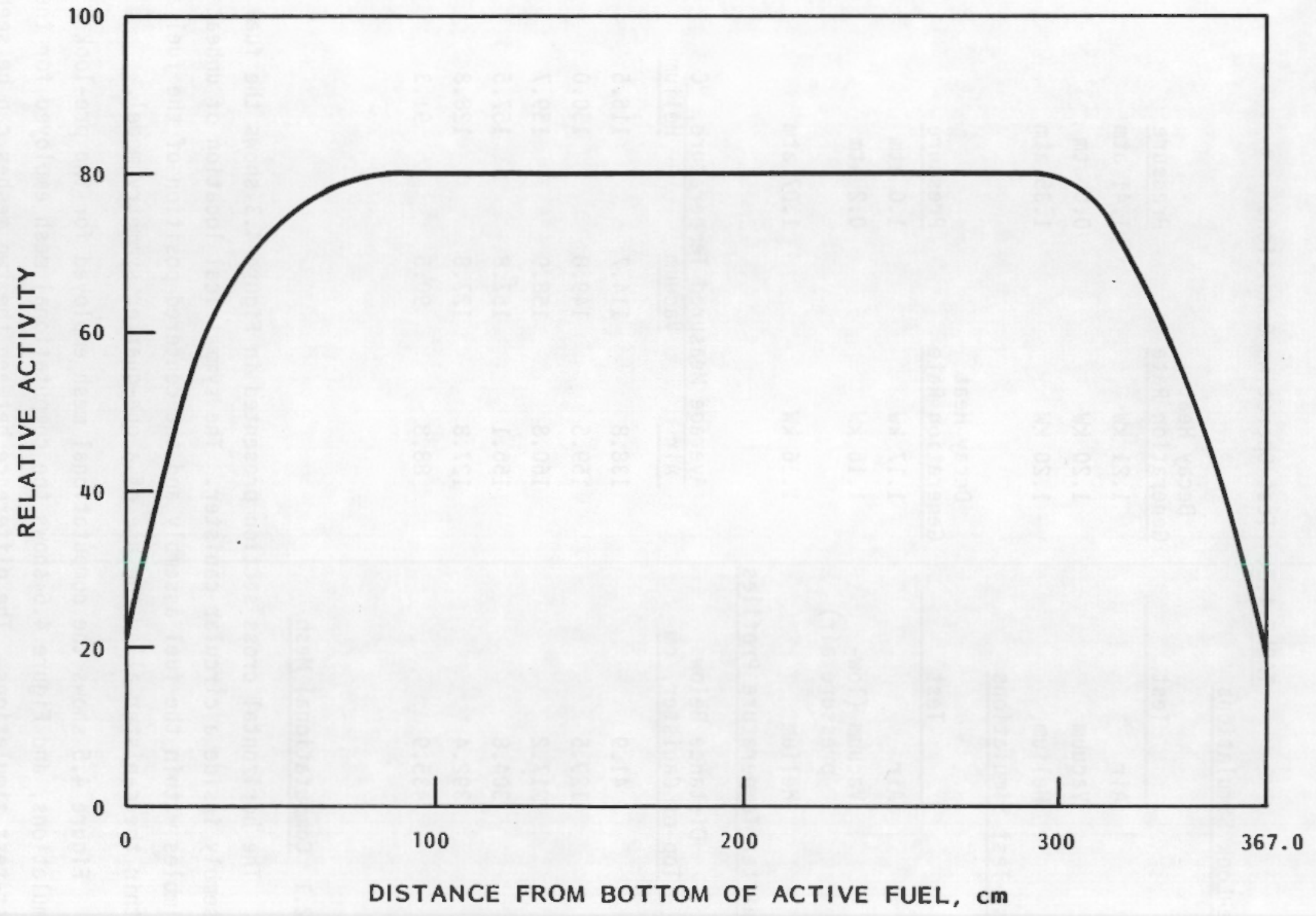

FIGURE 4.4. Relative Axial Activity Profile 


\section{Fuel Assembly}

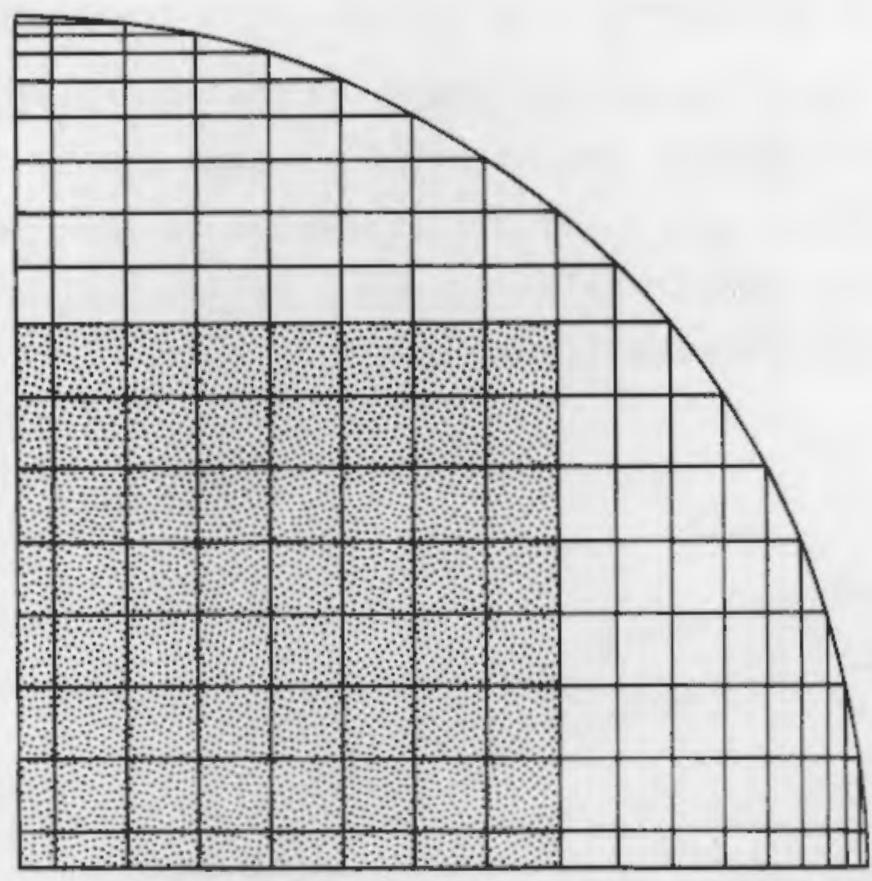

FIGURE 4.5. Horizontal Computational Mesh for Pre-Look Simulations

\section{Fuel Assembly}

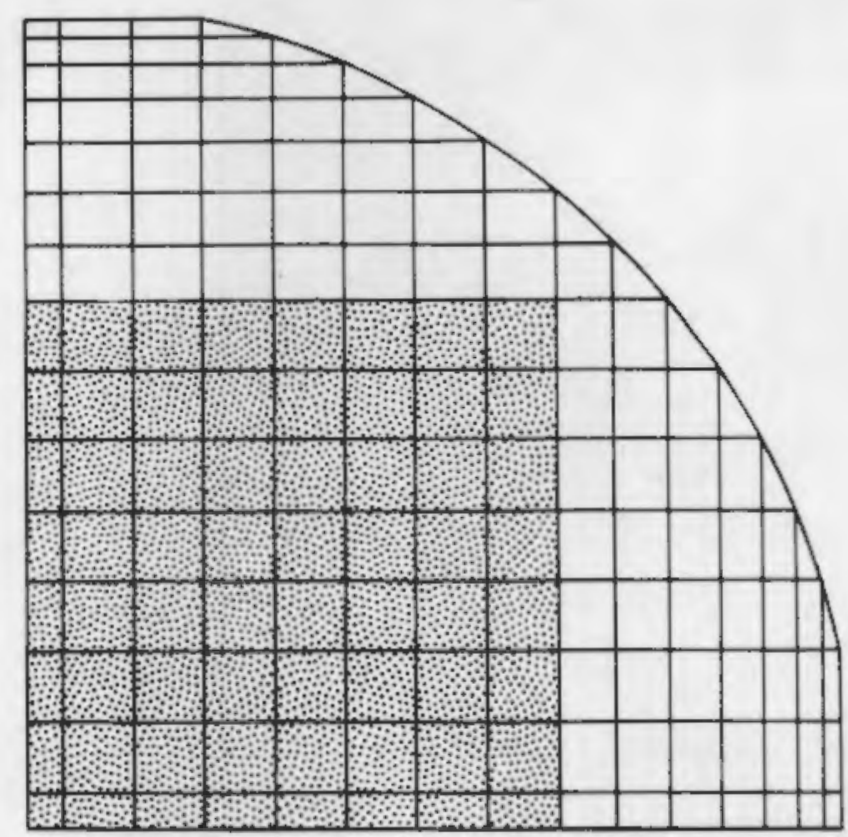

FIGURE 4.6. Horizontal Computational Mesh for Post-Test Simulations 
along the canister boundary. The two straight-line segments shown on the post-test computational mesh were introduced to reduce computer storage without significantly affecting predicted fuel assembly temperatures.

Figure 4.7 indicates the alignment of the computational mesh with the fuel assembly and canister inside surface. Each rod is contained within a single square cell except along the boundaries representing planes of symmetry. The boundary cells contain half of a rod. The central boundary cell contains one quarter of the instrumentation tube.

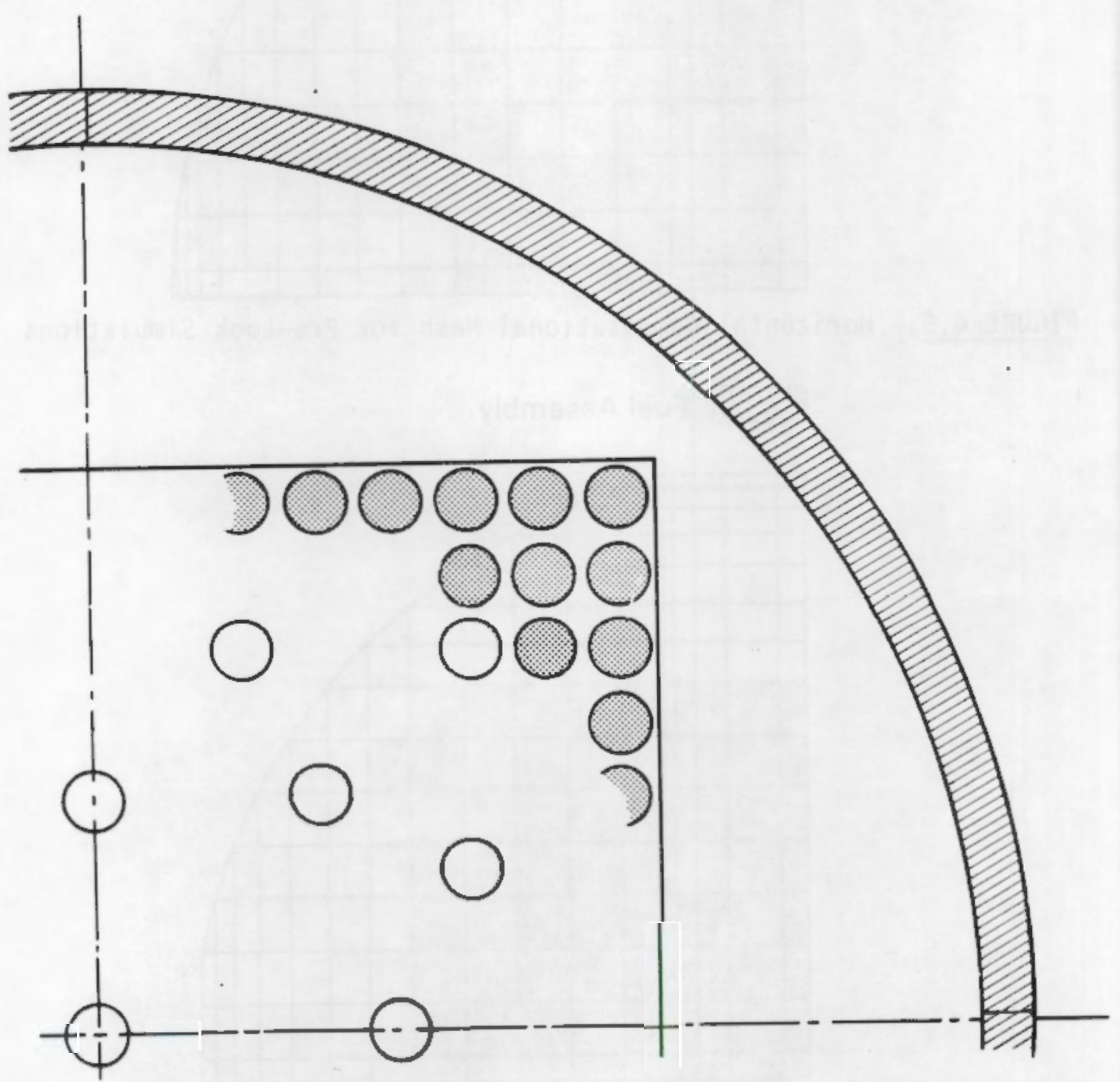

FIGURE 4.7. Physical Features Modeled in the Horizontal Cross Section 
A vertical cross section of the canister has been shown in Figure 4.2. A corresponding cross section of the computational mesh is shown in Figure 4.8 for the pre-look simulations. Figure 4.9 shows the computational mesh employed for the post-test simulations. An increased number of cells in the vertical direction was used in the post-test simulations for improved accuracy.

Figure 4.10 indicates the location of the fuel assembly relative to the canister inside surface.

\subsubsection{Material Properties}

Material properties were obtained from Touloukian and Ho (1970). Table 4.3 lists the material properties used for all simulations. Effective thermal conductivities were estimated for those computational cells containing more than one material. For the pre-look simulation denoted as vacuum, the thermal conductivity of the backfill gas was set to zero. For the post-look simulation denoted as low-pressure (0.2-atm) air, the mean free path is less than any significant length. The properties used for the low-pressure simulation are, therefore, those of air.

The emittance of the canister surface and support structure was specified as 0.45 for the pre-look simulations and as 0.3 for the post-look simulations. Data given in Peterson (1975) and in EG\&G (1980) suggest that rod emittances may vary over a considerable range of values. For very clean, nonoxidized rods, the emittance may be below 0.3 . For oxidized rods described as having considerable surface crud, the emittance may be above 0.9. Visual examinations of spent fuel assemblies reported in Davis (1980) identified the presence of crud that varied somewhat with axial position. The fuel assembly used in the E-MAD test was from the same reactor as the assemblies examined by Davis. As a result of this review, a rod emittance of 0.8 was used.

\subsubsection{Modeling Uncertainties}

Typical spent fuel storage casks and canisters are large and complex thermohydraulic systems, and some uncertainty about how best to construct an accurate overall model will always be present. These uncertainties lead 

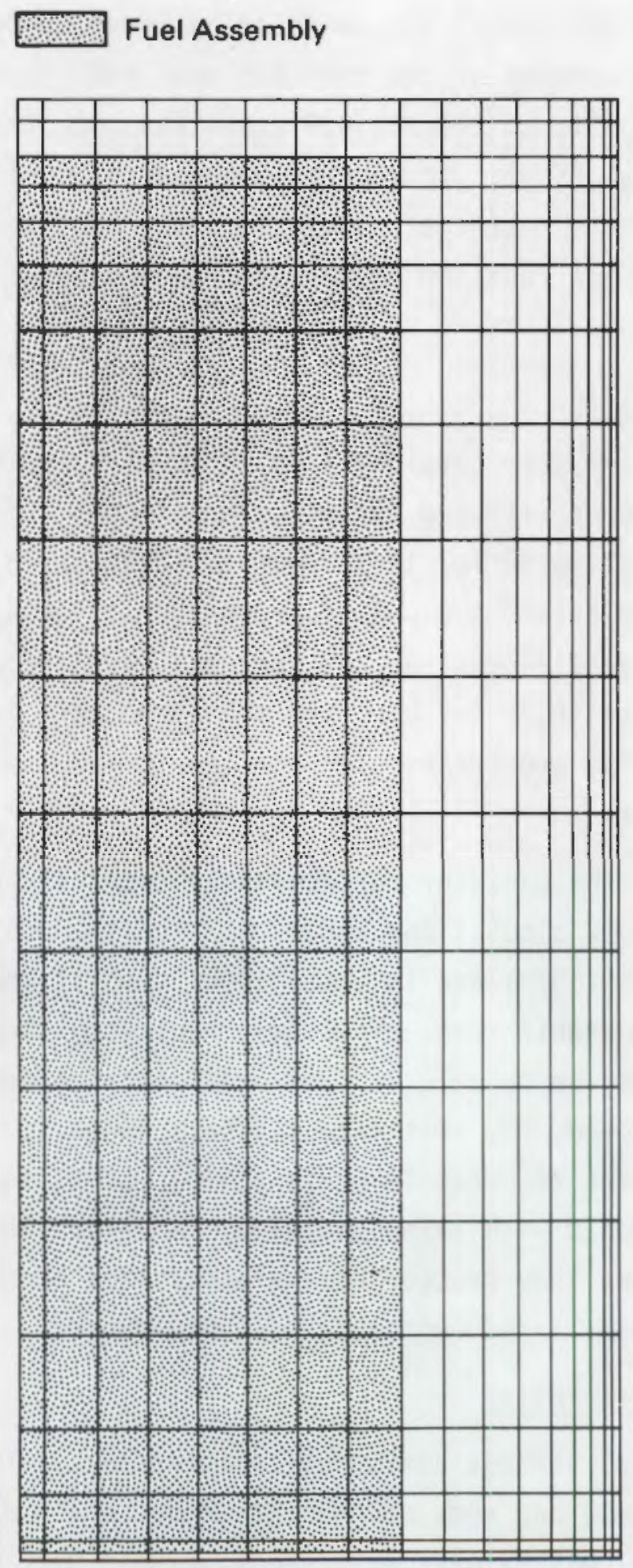

FIGURE 4.8. Vertical Computational Mesh for Pre-Look Simulations 


\section{Fuel Assembly}

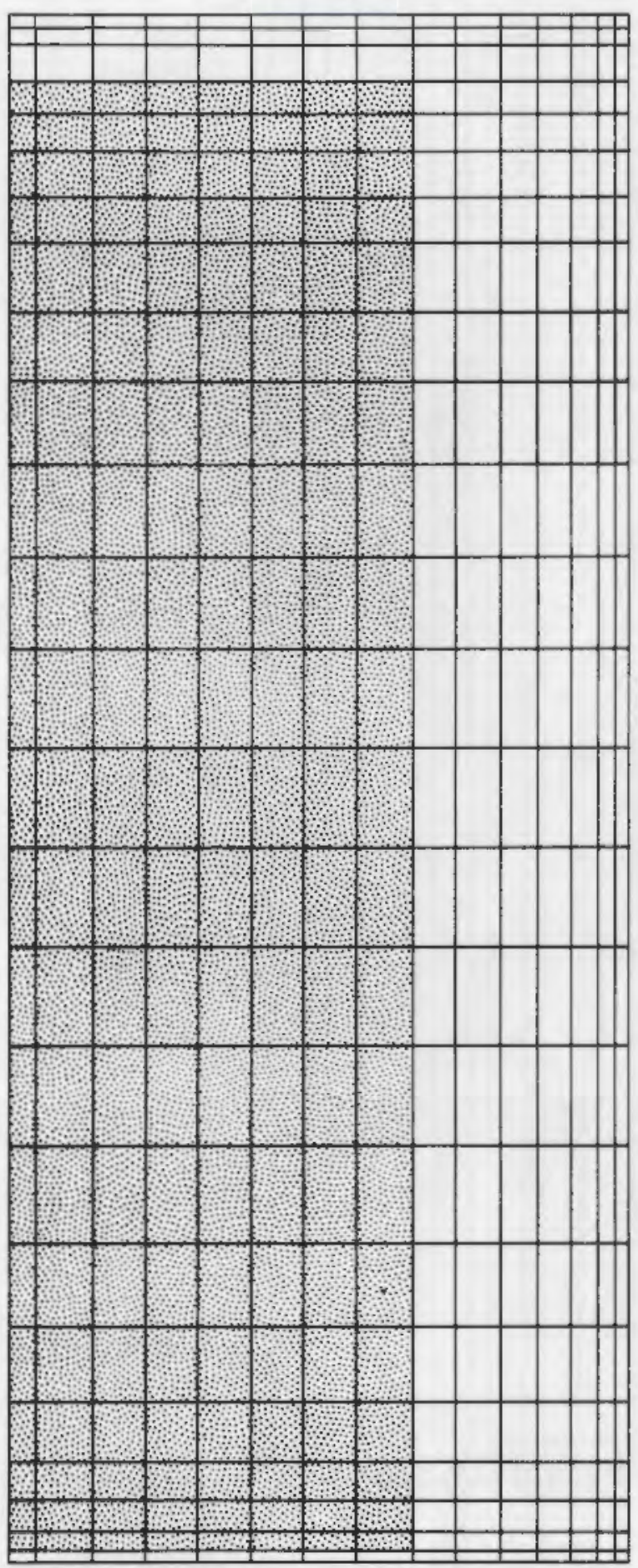

FIGURE 4.9. Vertical Computational Mesh for Post-Test Simulations 


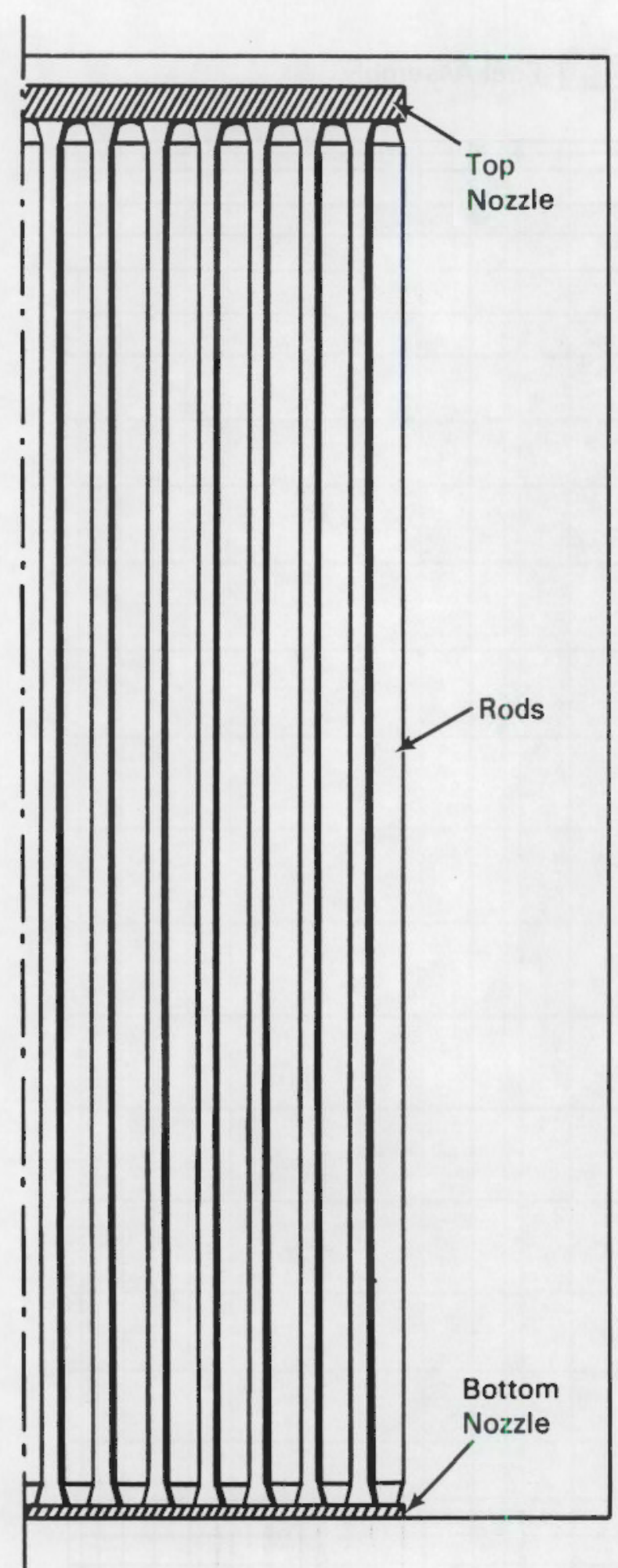

FIGURE 4.10. Fuel Assembly Position Relative to Canister Inside Surface Vertical Cross Section 
TABLE 4.3. Material Properties

Thermal conductivity, $\mathrm{w} / \mathrm{cm}^{2}{ }^{\circ} \mathrm{K}$

Stainless steel

Air

Helium

Specific heat, w sec $/ \mathrm{g}^{\circ} \mathrm{K}$

Air

Helium

Viscosity, $\mathrm{g} / \mathrm{cm} \mathrm{sec}$

Air

Helium

Emittance

Fuel cladding

Stainless steel (pre-look)

Stainless steel (post-test)
$0.09215+(0.1465 E-3) T$

$0.688 \mathrm{E}-4+(0.634 \mathrm{E}-6) \mathrm{T}$

$0.52 E-3+(0.32 E-5) T$

1.0

5.234

$0.608 \mathrm{E}-4+(0.400 \mathrm{E}-6) \mathrm{T}$

$0.700 E-4+(0.400 E-6) T$

inevitably to approximations, some of which may be difficult to quantify. Most uncertainties may be placed within one of three broad categories:

1. basic information that is application-specific and measurable (e.g., container dimensions, heat generation rates, ambient conditions)

2. information generic to most applications (e.g., property values, correlations)

3. decisions about how to achieve the best match between a particular code and the application (e.g., computational mesh, internal algorithms).

Some of the more important factors falling within these categories are:

- The information shown on the furnished cask or canister drawings may not accurately reflect the as-built structure.

- Dimensional tolerances may be particularly significant when they influence small gaps with important thermal resistances. The input to HYDRA specified nominal dimensions. 
- Potential eccentricities, such as the actual placement of the basket or fuel assembly support structure within the container cavity, are a source of uncertainty. Other eccentricities, such as the placement of a fuel assembly within the basket, are certain to occur and can substantially alter some thermal and flow resistances. The input to HYDRA specified no eccentricity.

- The total heat generation rate and the generation rate axial profile have a direct impact on predicted cladding temperatures. Both the total generation rate and the axial profile are amenable to experimental determination, and that is the preferred approach.

- All material property values possess a range of uncertainty, although the range for most well-characterized materials is usually not significant. Exceptions include the emittance of some materials, especially if the surface has been altered by some process (e.g., cladding corrosion, or sandblasting basket structures). The input file specified values believed to be typical. The potential consequences of a range of values on the temperature field have not been investigated.

- Some boundary conditions may be difficult to determine. Examples include sparse temperature data for the external cask or canister body and means for determining the total mass or pressure of the gas within the cask or canister.

- Some uncertainties are inherent in the use of discrete solution methods. An example is the trade-off between mesh coarseness and accuracy. The conservation equations have been formulated within HYDRA in an entirely consistent fashion. Basically, this means that any desired numerical accuracy may be achieved by using a sufficiently large number of computational cells. The practical trade-off is between accuracy and computer time and costs. The optimum is difficult to determine a priori.

- Another source of uncertainty results from limitations of models constructed internal to the code. Thermal radiation models are a good example. All radiation enclosures within the cask are three-dimensional. Two-dimensional radiation models are used extensively within HYDRA for 
practical reasons. The errors associated with this approximation can be reduced, but not eliminated, by careful selection of a computational mesh. Finally, there is a fourth category of uncertainty not mentioned previously-human error. The internal coding or input specifications intended may not be what is actually present. This situation is at its worst when the offending mistake results in an error that is both significant and unobtrusive.

\subsection{PREDICTIONS COMPARED TO DATA}

Pre-look and post-test predictions of temperatures are compared to experimentally measured test data in this section. All pre-look predictions were conducted without the modelers having access to the experimentally measured fuel assembly temperatures, to permit an unbiased evaluation of the HYDRA code. Post-test predictions are much improved over pre-look predictions and are in excellent agreement with the test data. The post-test simulations were performed with a better refined version of HYDRA than that used for the prelook simulations.

The input files for the pre-look and post-test simulations were also not identical. Significant changes were made as a result of improved knowledge about the experimental test conditions. These changes were stated in Section 4.2 and are briefly mentioned again as an aid in interpreting the pre-look predictions:

- The emittance of the assembly support structure and canister was reduced from 0.45 (pre-look) to 0.3 (post-test).

- The decay heat was reduced approximately $3 \%$ for the post-test simulations to reflect experimental calorimetric measurements.

- The gas pressures were corrected as follows:

\begin{tabular}{lll} 
Backfill & Pre-Look & Post-Test \\
\cline { 2 - 3 } & $1.41 \mathrm{~atm}$ & $1.0 \mathrm{~atm}$ \\
$\begin{array}{l}\text { Vacuum } \\
\text { (low-pressure air) }\end{array}$ & $0.0 \mathrm{~atm}$ & $0.2 \mathrm{~atm}$ \\
Helium & $1.35 \mathrm{~atm}$ & $1.07 \mathrm{~atm}$
\end{tabular}

- The distribution and size of some computational cells were changed. 


\subsubsection{Pre-Look Predictions}

This subsection includes temperature profiles showing the comparison between pre-look predictions and measured data. Comparisons are made for each of the three tests. All tests were conducted with the canister in a vertical orientation. The legend at the top of each subsequent figure in this section identifies the thermocouple locations. The figure in the legend is a one-eighth symmetrical section of the fuel assembly with the center instrumentation tube identified as location A. Most of the discussion of code predictions and comparisons to data is deferred until post-test results are presented.

Figure 4.11 shows axial temperature profiles for the test with an air backfill. The comparison between predictions and data is favorable in the central range of axial elevations; however, there is a growing discrepancy toward the ends of the assembly. The underprediction of temperatures near the bottom of the assembly and overprediction near the top suggests too much convection. The average gas pressure indicated for this simulation was 1.41 atm when, in fact, the actual test condition was $1.0 \mathrm{~atm}$. Higher gas densities do favor increased convection.

Figure 4.12 shows axial temperature profiles for the test originally denoted as vacuum. As was subsequently learned, the backfill was actually lowpressure air at $0.2 \mathrm{~atm}$. The fuel assembly centerline temperatures are uniformly overpredicted. This overprediction is to be expected when thermal radiation is the only mode of radial heat transfer. The temperature predictions near the exterior of the fuel assembly are in good agreement with the experimental data, despite the fact that no radial conduction is present in the simulation. Apparently, the assumed emittance of the canister surface for the pre-look simulations is too high and misleadingly compensates for the lack of conduction.

Figure 4.13 shows axial temperature profiles for the helium backfill test. The predicted temperatures at all positions are slightly low, although 


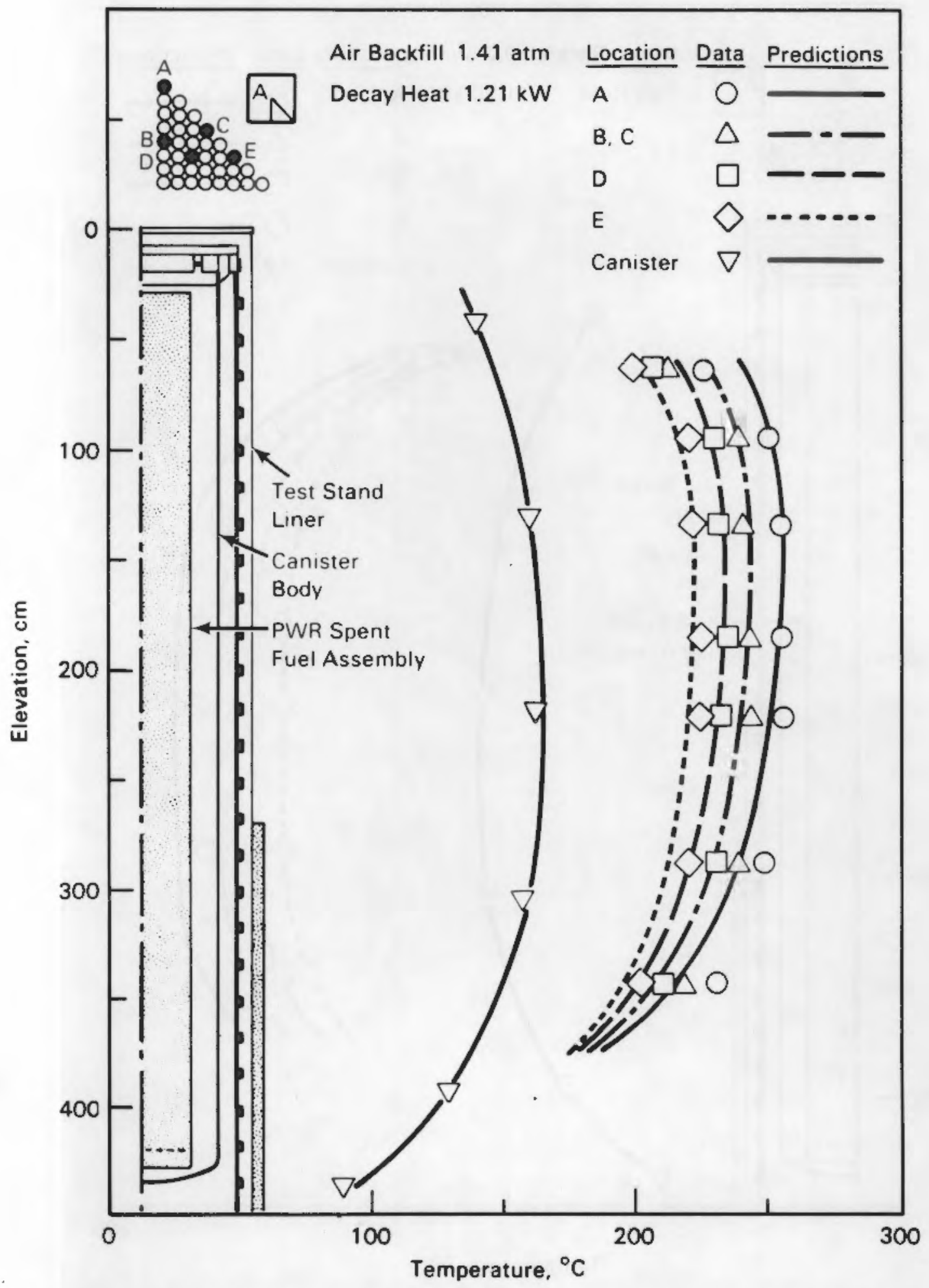

FIGURE 4.11. Pre-Look Predictions of Temperatures Compared to Data Air Backfill (1.41 atm)

Decay Heat $1.21 \mathrm{~kW}$ 


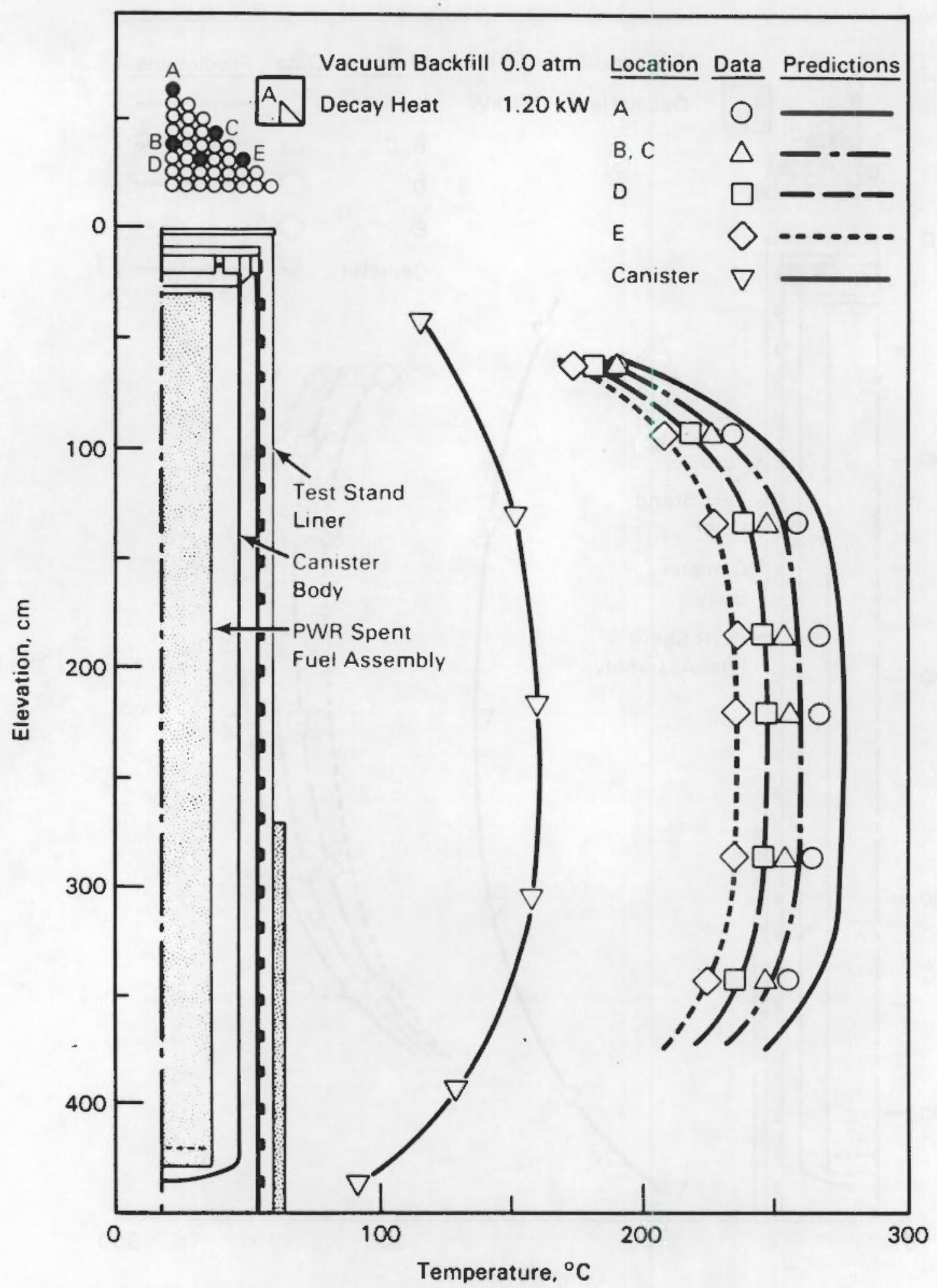

FIGURE 4.12. Pre-Look Predictions of Temperature Compared to Data Vacuum Backfill (0.0 atm)

Decay Heat $1.20 \mathrm{~kW}$ 


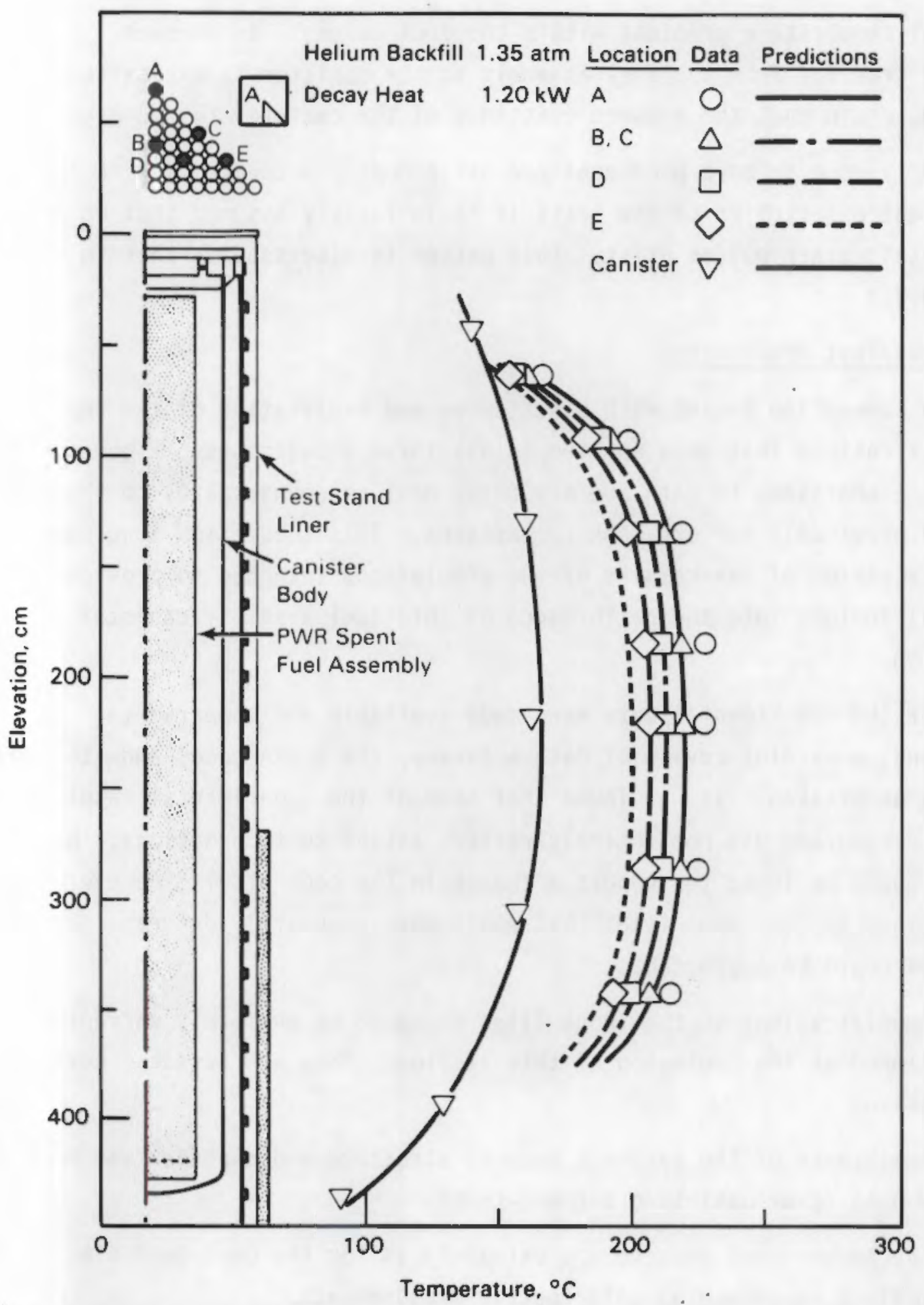

FIGURE 4.13. Pre-Look Predictions of Temperatures Compared to Data Helium Backfill (1.35 atm) Decay Heat $1.20 \mathrm{~kW}$ 
the radial temperature gradient within the fuel assembly is correct. It appears that heat transfer from the fuel assembly to the canister is excessive, suggesting again that the assumed emittance of the canister is too high.

Clearly, one or more phenomena are not properly accounted for in the mathematical description of the tests if it is tacitly assumed that no serious experimental data problems exist. This matter is discussed further in Section 4.3.2.

\subsubsection{Post-Test Predictions}

This subsection begins with a statement and explanation of the input file modifications that were applied to all three simulations. Figures showing post-test comparisons to data are presented next as counterparts to those displayed previously for pre-look comparisons. This subsection concludes with a discussion of the results of the simulations intended to provide additional insight into the performance of this fuel assembly/canister combination.

After the experimental data were made available and compared to predictions, a careful review of data accuracy, the HYDRA code, and its input files was undertaken. It was found that some of the experimental results originally reported did not entirely reflect actual test conditions. No evidence could be found to support a change in the code itself; however, modifications to the input files that would more accurately describe the test conditions could be supported.

The modifications to the input files found to be uniformly warranted were mentioned at the beginning of this section. They are restated here with amplification.

- The emittance of the assembly support structure and canister was reduced from 0.45 (pre-look) to 0.3 (post-test).

- The decay heat was reduced approximately $3 \%$ for the post-test simulations to reflect experimental calorimetric measurements.

- The gas pressures were corrected as follows: 


$\begin{array}{lll}\frac{\text { Backfill }}{\text { Air }} & \text { Pre-Look } & \text { Post-Test } \\ \begin{array}{l}\text { Vacuum } \\ \text { (low-pressure air) }\end{array} & 1.41 \mathrm{~atm} & 1.0 \mathrm{~atm} \\ \text { Helium } & 0.0 \mathrm{~atm} & 0.2 \mathrm{~atm} \\ & 1.35 \mathrm{~atm} & 1.07 \mathrm{~atm}\end{array}$

- The distribution and size of some computational cells were changed. Each of the modifications is discussed in turn.

The emittances of the stainless steel canister and fuel assembly support structure were not measured. An emittance of 0.45 , falling within the range of plausible emittances, was selected for the pre-look simulations. Comparisons of pre-look predictions with measured data suggested that a value of emittance somewhat lower in the range of plausible emittances would be more appropriate. An emittance of 0.3 was selected for the post-test simulations.

The spent fuel decay heat was both measured experimentally and predicted by computer code. The values of decay heat originally reported and used in the pre-look simulations represented an average of measured and predicted values. It is believed that the experimentally determined values are to be preferred. Therefore, the decay heat values used for the post-test simulations represent measured values and are approximately 3\% lower than the pre-look values.

The backfill gas pressures were determined in the pre-look simulations based on assumed canister and fuel assembly initial conditions. For the air and helium tests, it was assumed that the canister was sealed with the gas at $1.0 \mathrm{~atm}$ and in equilibrium with the canister temperature. The code then calculated the changes in pressure as canister internal temperatures approached steady state. For the test originally denoted as vacuum, it was assumed that the amount of air present was inconsequential.

Actual backfill pressures became available at the time the post-test simulations were to be performed. The code was instructed to simply hold the pressure fixed at the predetermined experimental value. 
The size and distribution of some computational cells were changed while the total number of cells was kept approximately constant. The results of numerical analysis during the interim between pre-look and post-test simulations indicated that an increased number of cells in the axial direction would be beneficial. Some cells in the radial direction were eliminated to keep overall computer storage nearly the same. The possible effects of this redistribution of computational cells are unknown due to the above concurrent changes to the input files.

Predicted and measured temperatures for the canister with an air backfill are shown in Figure 4.14. The comparison is favorable in the central range of axial elevations; however, there is a growing discrepancy toward the ends of the assembly. The underprediction of temperature near the bottom of the assembly and overprediction near the top suggest too much convection.

The natural convection flow field within the canister is driven by buoyancy forces resulting from temperature-dependent density variations in the fluid. As the fluid is heated within the fuel assembly, the fluid density decreases and the fluid rises toward the top of the fuel assembly. The heated fluid exits the fuel assembly at or near the top of the fuel assembly. The fluid flows outward and transfers heat to the cooler canister wall. This causes the fluid density to increase. The denser fluid flows downward in the open region between the fuel assembly and the canister wall. Near the bottom of the canister, the fluid flows back into the fuel assembly to complete the recirculation pattern. The horizontal flow component into the fuel assembly is at maximum near the bottom of the fuel assembly. On a relative basis, the horizontal flows into or out of the fuel assembly are significant only over the bottom or top $20 \%$ of the fuel assembly. Superimposed on this overall recirculating flow is some predicted small-scale recirculation, particularly near the top of the canister. This secondary recirculation is much less apparent for the low-pressure air and helium simulations.

The predicted velocities in the free field are high enough to indicate that turbulence is present in the air test. An effective thermal conductivity may be computed based on an estimated Rayleigh number for the free field. 


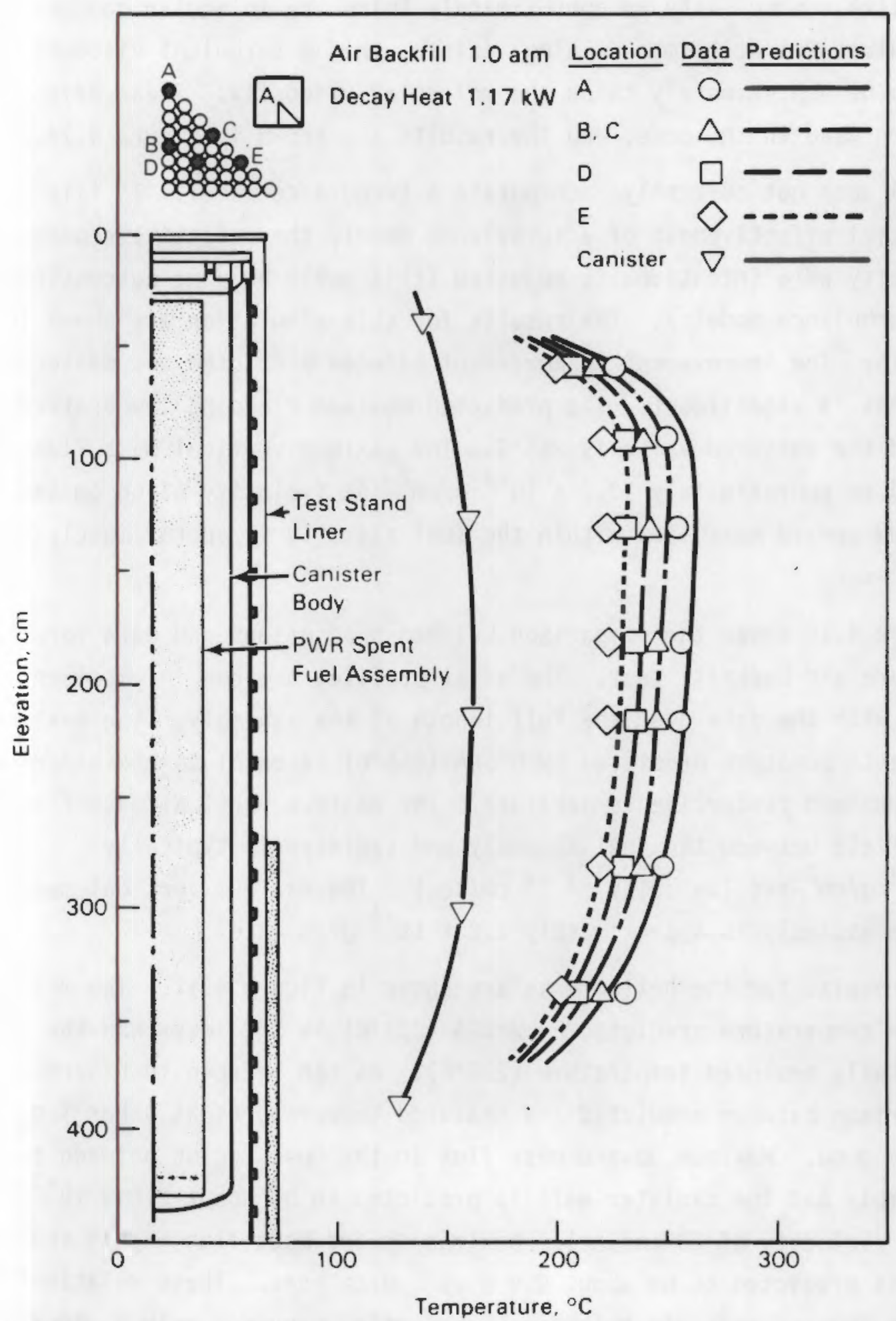

FIGURE 4.14. Post-Test Predictions of Temperatures Compared to Data Air Backfill (1.0 atm)

Decay Heat $1.17 \mathrm{~kW}$ 
The effective conductivity is approximately twice the molecular conductivity. If a turbulent Prandtl number analogy exists, then a turbulent viscosity value would also be approximately twice the molecular viscosity. These effective values were used in the code, and the results are shown in Figure 4.14.

HYDRA does not currently incorporate a turbulence model. To illustrate the potential effectiveness of a turbulence model, the effective conductivity and viscosity were intentionally adjusted (this would be done automatically by some turbulence models). The results for this simulation are shown in Figure 4.15. The improvement in agreement between predicted and measured temperatures is significant. The predicted maximum cladding temperature is $254^{\circ} \mathrm{C}$, and the measured value is $255^{\circ} \mathrm{C}$. The maximum vertical mass flux in the free field is approximately $10.0 \times 10^{-3} \mathrm{~g} / \mathrm{cm}^{2}-\mathrm{sec}$ (velocity of $66 \mathrm{~cm} / \mathrm{sec}$ ). The maximum upward mass flux within the fuel assembly is approximately $25.0 \times$ $10^{-4} \mathrm{~g} / \mathrm{cm}^{2}-\mathrm{sec}$.

Figure 4.16 shows the comparison between predictions and data for the low-pressure air backfill test. The axial profiles are now in excellent agreement with the data over the full length of the assembly. The maximum centerline temperature predicted by HYDRA $\left(266^{\circ} \mathrm{C}\right)$ is equal to the experimentally measured maximum centerline temperature. The maximum vertical mass flux in the free field between the fuel assembly and canister is typically $5.0 \times 10^{-3} \mathrm{~g} / \mathrm{cm}^{2}-\mathrm{sec}$ (velocity of $33 \mathrm{~cm} / \mathrm{sec}$ ). The maximum vertical mass flux within the assembly is approximately $1.0 \times 10^{-4} \mathrm{~g} / \mathrm{cm}^{2}-\mathrm{sec}$.

The results for the helium case are shown in Figure 4.17. The maximum centerline temperature predicted by HYDRA $\left(223^{\circ} \mathrm{C}\right)$ is $3^{\circ} \mathrm{C}$ less than the experimentally measured temperature $\left(226^{\circ} \mathrm{C}\right)$. As can be seen in Figure 4.17, the comparison between predicted and measured temperatures at other locations is equally good. Maximum upward mass flux in the open region between the fuel assembly and the canister wall is predicted to be about $2.0 \times 10^{-3}$ $\mathrm{g} / \mathrm{cm}^{2}-\mathrm{sec}$ (velocity of $20 \mathrm{~cm} / \mathrm{sec}$ ). Maximum upward mass flux within the fuel assembly is predicted to be about $0.4 \times 10^{-4} \mathrm{~g} / \mathrm{cm}^{2}-\mathrm{sec}$. These relatively small velocities suggest that, in this case, convection provides only a minor heat transfer component when helium is the backfill medium. 


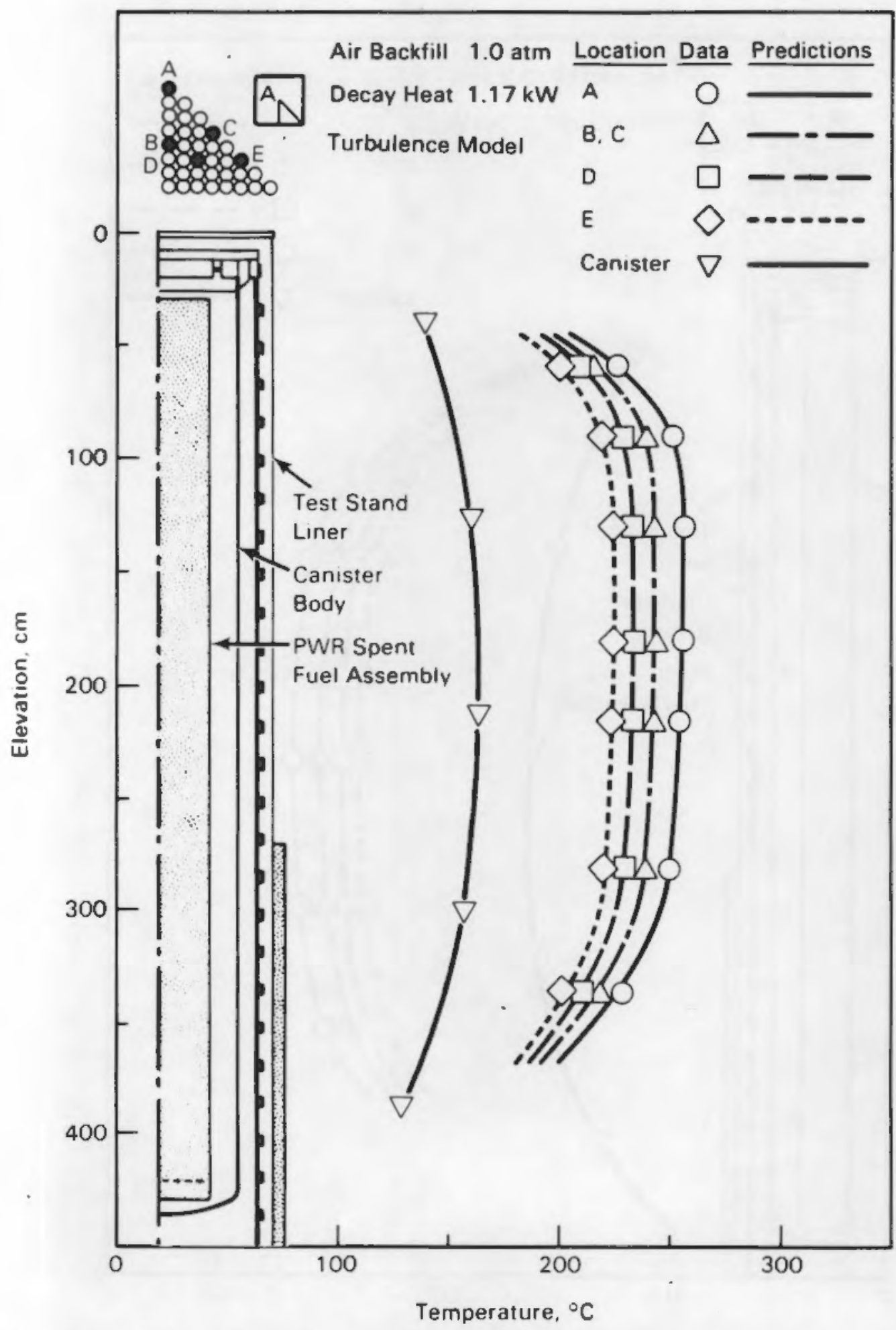

FIGURE 4.15. Post-Test Predictions of Temperatures Compared to Data Turbulence Model

Air Backfill (1.0 atm)

Decay Heat $1.17 \mathrm{~kW}$ 


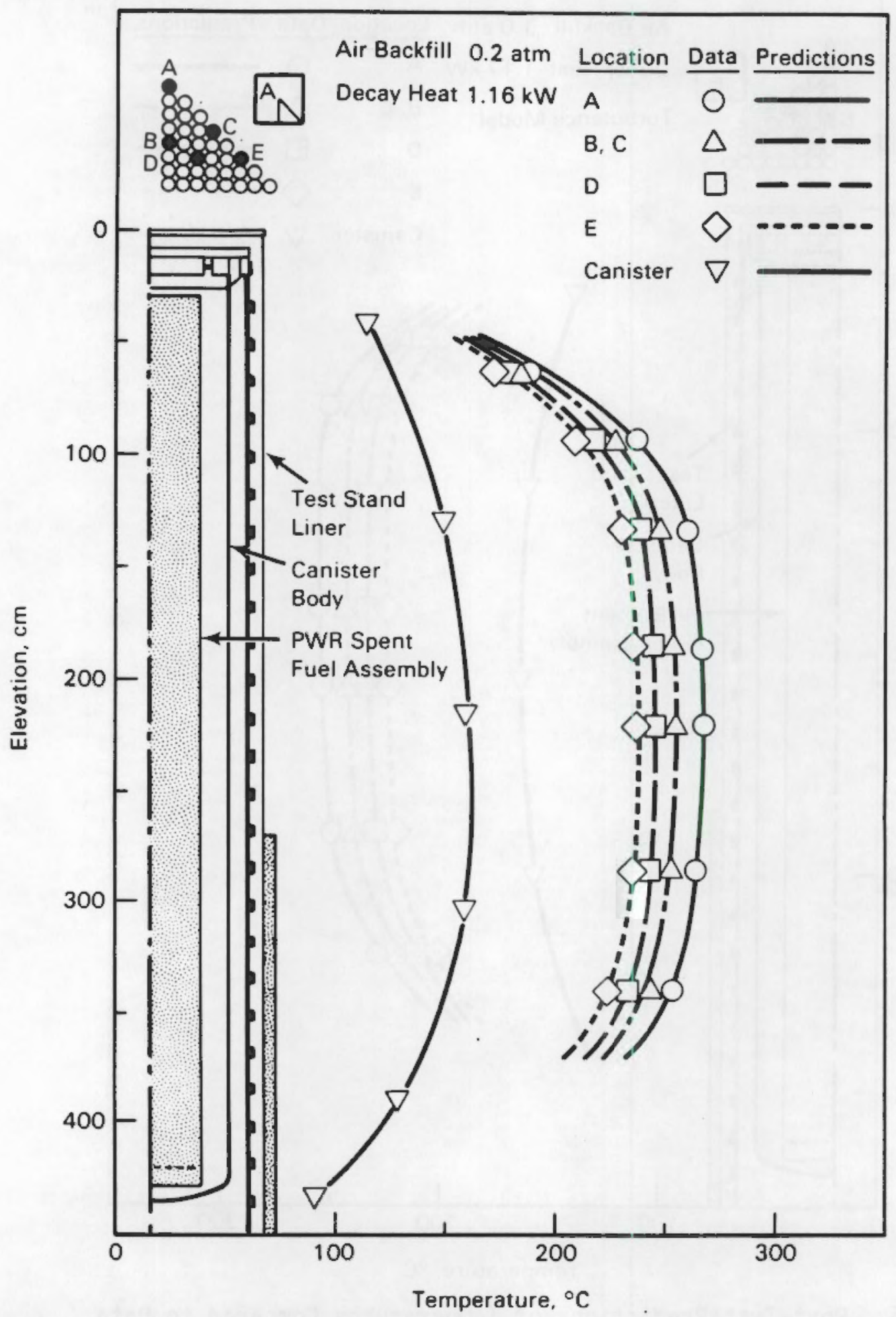

FIGURE 4.16. Post-Test Predictions of Temperatures Compared to Data Vacuum (low pressure air, $0.2 \mathrm{~atm}$ ) Decay Heat $1.16 \mathrm{~kW}$ 


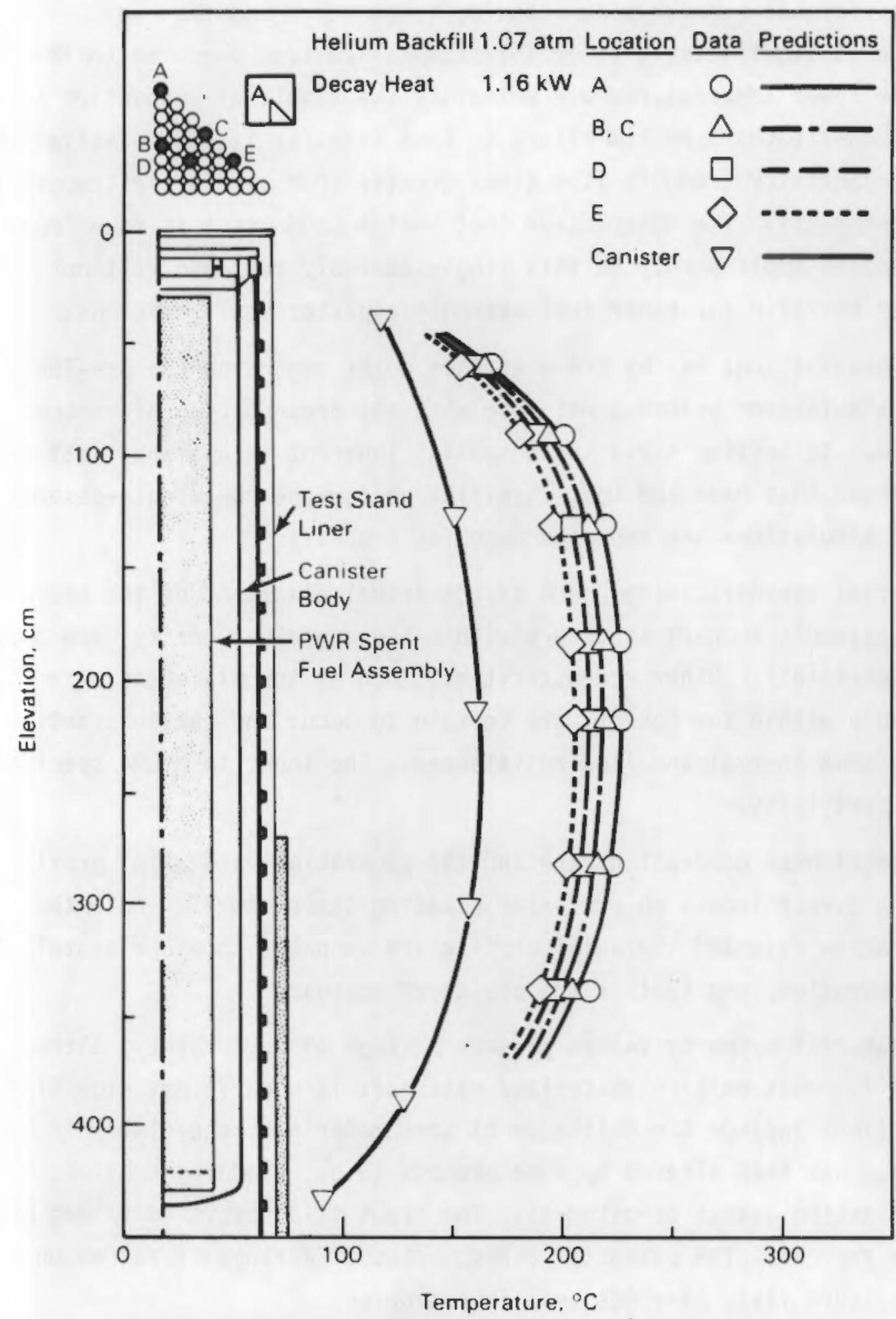

FIGURE 4.17. Post-Test Predictions of Temperatures Compared to Data Helium Backfill (1.07 atm)

Decay Heat $1.16 \mathrm{~kW}$ 
The difference between peak cladding temperature and the canister temperature is significantly lower for this helium test compared to the air tests. The lower temperatures are primarily the result of conduction by helium. The major benefit that helium offers to heat transfer is its relatively high thermal conductivity (roughly five times greater than air in the temperature range of interest). The observation that helium conduction is more important than convection applies only to this single-assembly test and will not necessarily be valid for other fuel assembly/canister configurations.

Some observations may be drawn at this point regarding the pre-look and post-test simulations before continuing with the presentation of another application. In Section 4.2.3 the potential inherent in any application were listed. Those that have the most significance for the PWR single-assembly spent fuel simulations are repeated here for emphasis:

- Potential eccentricities, such as the actual placement of the basket or fuel assembly support structure within the container cavity, are a source of uncertainty. Other eccentricities, such as the placement of a fuel assembly within the basket, are certain to occur and can substantially alter some thermal and flow resistances. The input to HYDRA specified no eccentricity.

- The total heat generation rate and the generation rate axial profile have a direct impact on predicted cladding temperatures. Both the total generation rate and the axial profile are amenable to experimental determination, and that is the preferred approach.

- All material property values possess a range of uncertainty, although the range for most well-characterized materials is usually not significant. Exceptions include the emittance of some materials, especially if the surface has been altered by some process (e.g., cladding erosion, or sandblasting basket structures). The input file specified values believed to be typical. The potential consequences of a range of values on the temperature field have not been investigated.

- Some boundary or initial conditions may be difficult to determine. Examples include sparse temperature data for the internal cask or canister 
body and means for determining the total mass or pressure of the gas within the cask or canister.

- Some uncertainties are inherent in the use of discrete solution methods. An example is the trade-off between mesh coarseness and accuracy. The conservation equations have been formulated within HYDRA in an entirely consistent fashion. Basically, this means that any desired numerical accuracy may be achieved by using a sufficiently large number of computational cells. The practical trade-off is between accuracy and computer time and costs. The optimum is difficult to determine a priori. Another source of uncertainty is the quality of the measured data. While this uncertainty is not, strictly speaking, a modeling uncertainty, the two types often become indistinguishable when predictions are compared to data. For example, in this application it was not unusual for variations in reported temperatures at nominally symmetric locations within the fuel assembly and on the canister to approach $10^{\circ} \mathrm{C}$. Considering all of the above uncertainties, the excellent agreement between predicted temperatures and measured data is perhaps better than what might be expected. 



\subsection{ELECTRICALLY-HEATED SINGLE-ASSEMBLY SIMULATIONS}

The single-assembly heat transfer tests discussed in this section were performed as part of the DOE Commercial Spent Fuel Management Program. The tests were executed at the Pacific Northwest Laboratory using hardware designed and assembled by Allied General Nuclear Services at the Barnwell Nuclear Fuel Plant in Barnwell, South Carolina.

The primary objective of these tests was to provide experimental data for a variety of controlled conditions that would be characteristic of dry storage of spent light water reactor fuel. This data could then form a partial basis on which to evaluate the predictive capability of thermohydraulic computer codes used to simulate spent fuel dry storage systems.

The test hardware and test conditions needed for numerical simulation are described in Section 5.1. Section 5.2 contains computational models for this application and a discussion of modeling uncertainties. Section 5.3 presents HYDRA predictions and comparisons to data.

\subsection{TEST DESCRIPTION}

This section contains a brief description of the test hardware and test conditions needed for numerical simulation. A full account of all test details is available in Bates (1986).

\subsubsection{Hardware Description}

The hardware consisted of the test assembly with a number of auxiliary systems and components. The test assembly consisted of 1) a pressure/vacuum vessel (cask), 2) a transition piece and fuel tube, and 3) an electricallyheated model spent fuel assembly. Auxiliary equipment included 1) an evacuation and backfill system, 2) test assembly electric heater power supplies, controls, and transducers, 3) thermocouples, and 4) a data acquisition system.

Figure 5.1 shows and external view of the test assembly mounted on its skid. Electrical resistance heaters are spirally wound along the length of the cask. The heaters were connected to a temperature feedback controller and used to maintain a specified cask interior wall temperature (approximately 


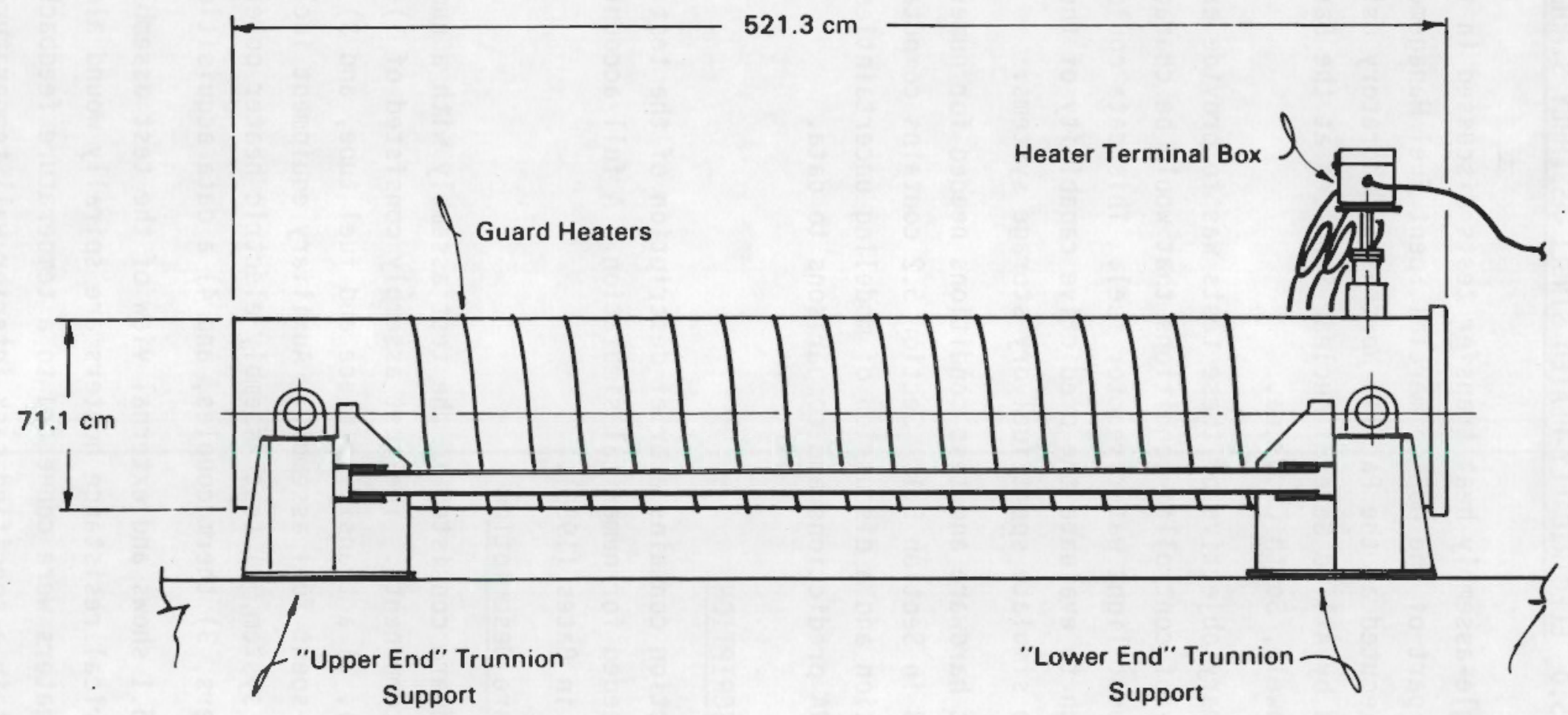

FIGURE 5.1. Test Assembly Mounted on Skid 
$178^{\circ} \mathrm{C}$ ) independent of the model fuel assembly power. An insulating blanket was placed over the cask body and guard heaters to minimize heat losses.

Figures 5.2 and 5.3 illustrate cross sections of the cask across its diameter and along its length, respectively. The transverse cross section of the cask illustrated in Figure 5.2 shows the double-wall construction, the location of thermocouples on the cask inside diameter, and the fuel tube location. The annulus bounded by the inner and outer cask walls was filled with air and sealed. The temperatures of the inside cask wall were used as boundary conditions for all simulations. These temperatures were estimated from thermocouples located near the inside cask wall. Four thermocouples were placed at each axial level. The five levels were approximately $1 \mathrm{~m}$ apart.

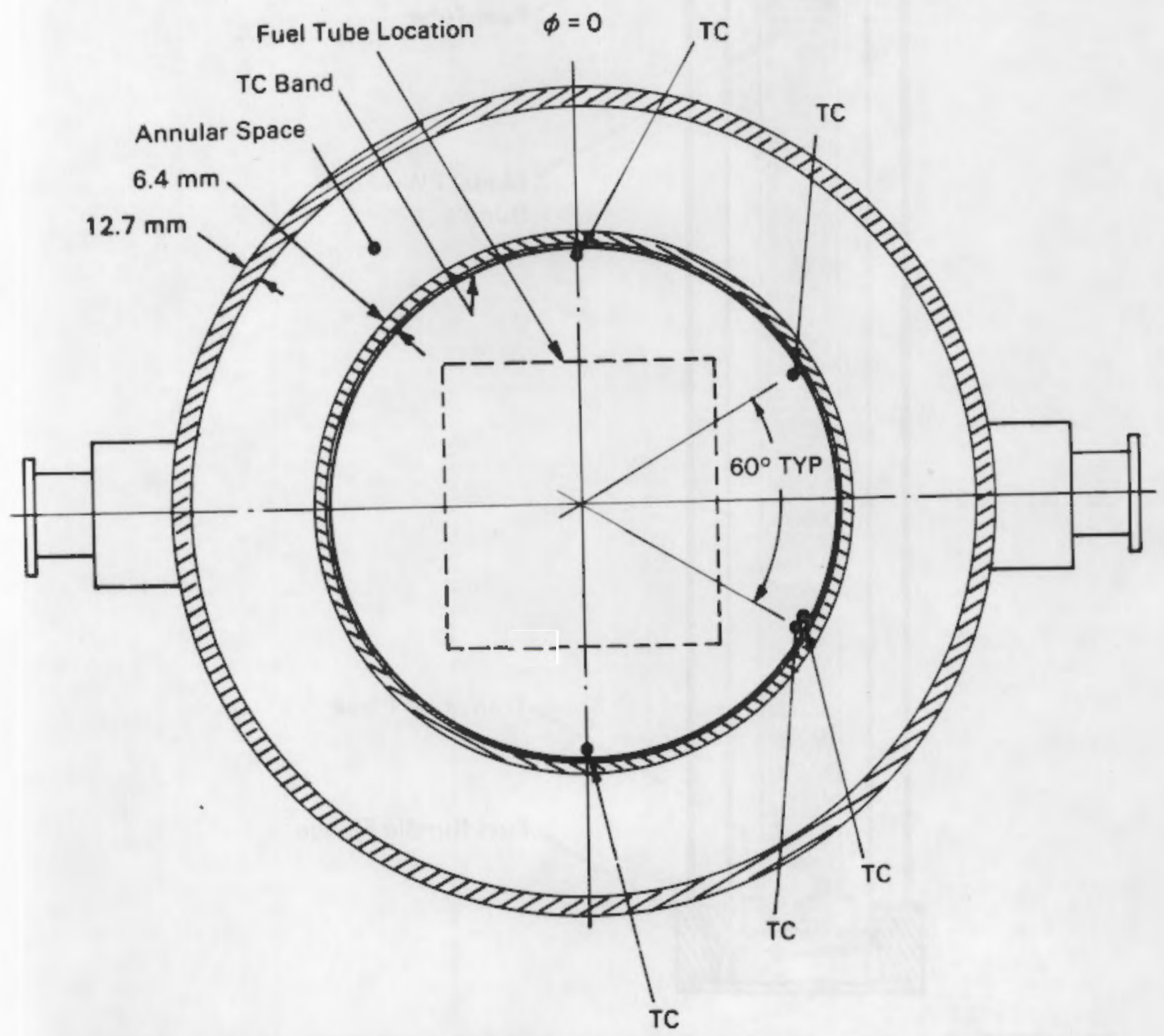

FIGURE 5.2. Transverse Cross Section of the Test Section 


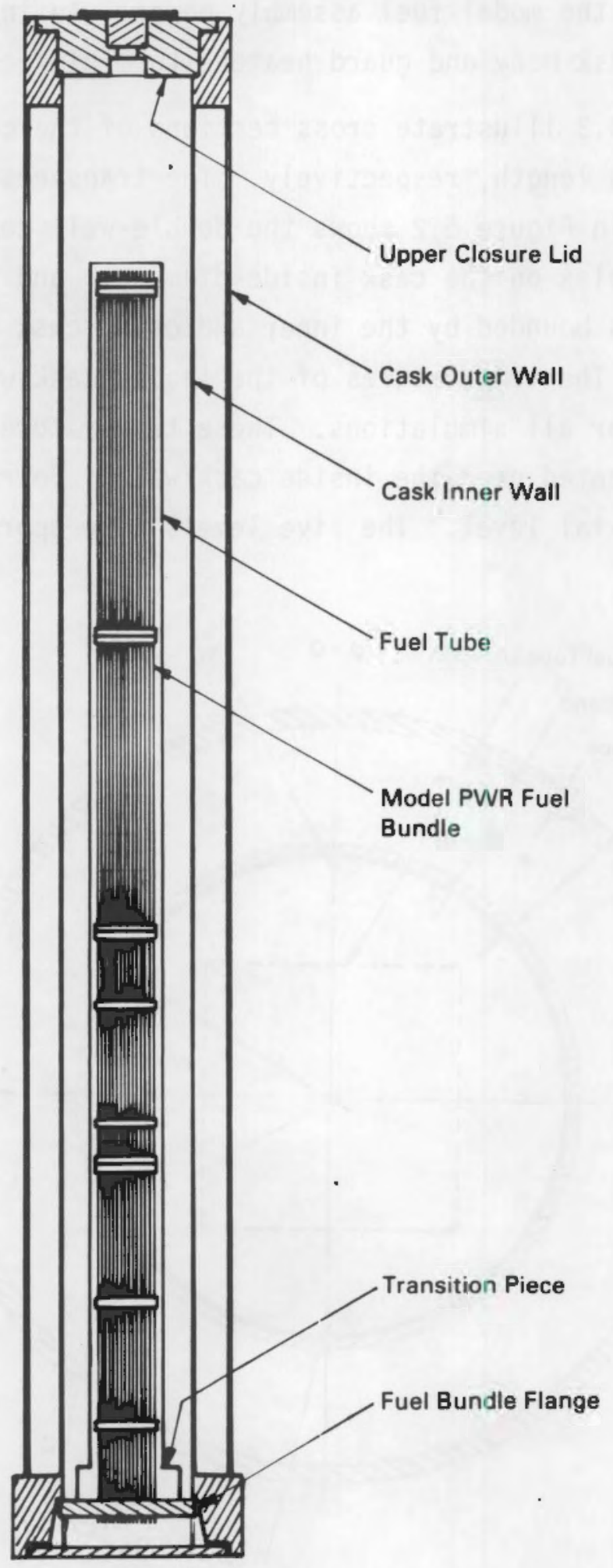

FIGURE 5.3. Longitudinal cross Section of the Test Section 
The fuel tube shown in Figures 5.2 and 5.3 is constructed in the form of a long box with a square cross section and open ends. The sides of the fuel tube are fabricated from Boral with stainless steel cladding. The fuel tube (and model fuel assembly) is intended to be concentrically located within the cask cavity. Post-test disassembly and inspection revealed that the upper end of the fuel tube/rod assembly centerline was offset from 1.25 to $2 \mathrm{~cm}$. In addition, it was found that the composite fuel tube had delaminated and the inner stainless steel cladding pressed against the rod assembly in places.

Figure 5.4 shows a cross section of the electrically heated model fuel assembly. It was designed and built to be physically and thermally characteristic of a typical $15 \times 15$ commercial light water reactor PWR fuel assembly. Of the total of 225 rods, 214 are electrically heated; the remaining 11 are unheated stainless steel rods.

The heater rods have a $366-\mathrm{cm}$ heated length containing a single spirally wound nichrome wire insulated from the cladding by magnesium oxide powder. The power generation was assumed to be uniform along the length. Several of the heater rods were disconnected as indicated in Figure 5.4 to mirror failed and unheated stainless steel rods and, by this means, to provide half symmetric power generation.

The square cross section of the assembly was maintained by a series of spacer grids positioned along the length of the assembly (see Figure 5.3). Four of the spacer grids were fabricated as an array of $222.2 \times 25.4 \times 3.2 \mathrm{~mm}$ $(8.75 \times 1.0 \times 0.125 \mathrm{in.})$ stainless steel flat bars. The remaining four spacer grids were of the more conventional "egg-crate" design used on PWR assemblies. The use of the spacer grids made from flat bars resulted in a variable rod pitch. The rod assembly was instrumented with 57 thermocouples although not all were functional. These thermocouples were apportioned over seven different axial planes. Some of the thermocouples were clipped to a rod surface. and others were attached to a stainless steel pad that was designed to be wedged between two neighboring rods. Post-test inspection revealed that some of the pads were loosely positioned near their original location. 


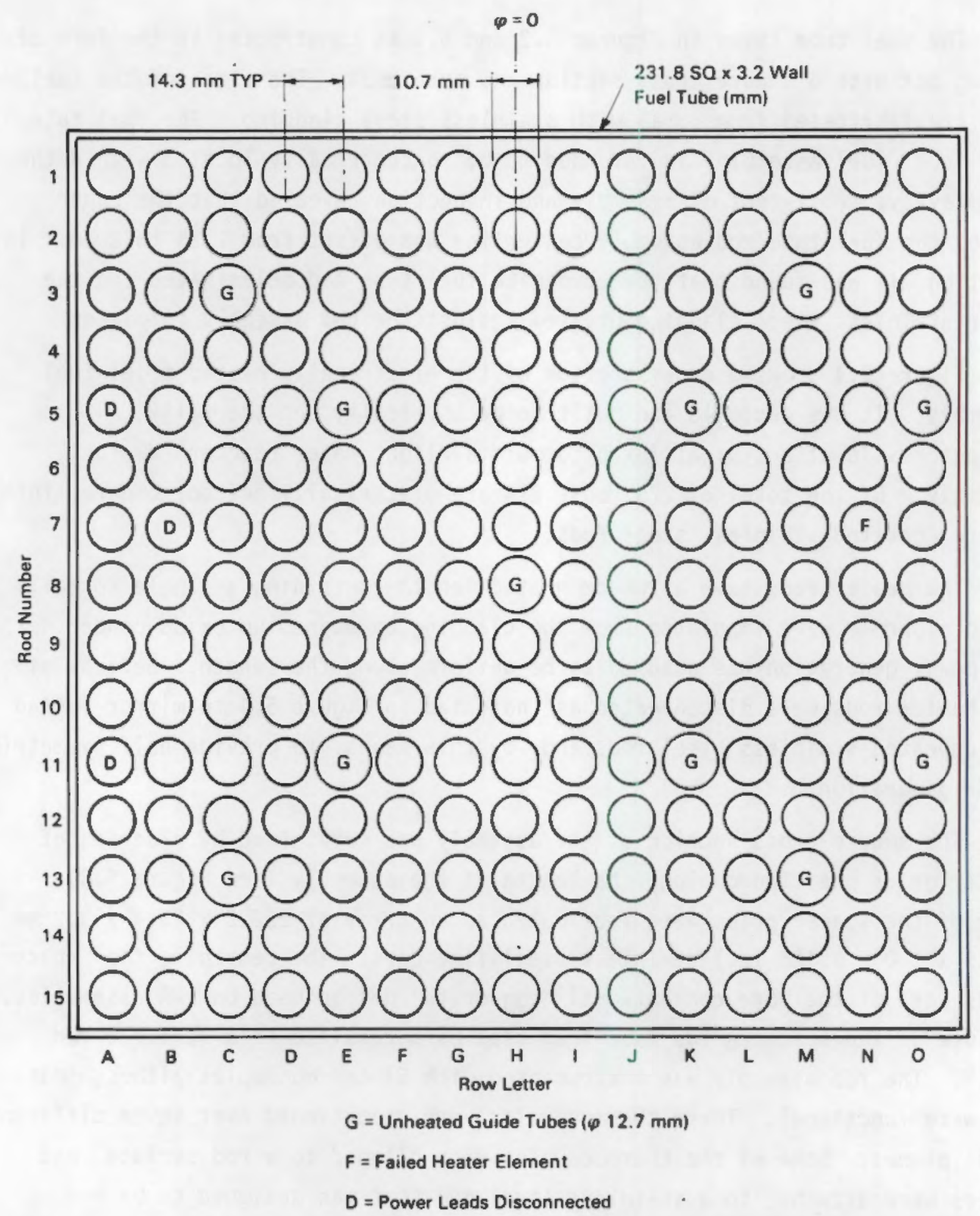

FIGURE 5.4. Cross Section of $15 \times 15$ Electrically-Heated Model Fuel Assembly 
The fuel tube was also instrumented with thermocouples at axial positions corresponding to those in the rod assembly. The thermocouples were welded to pads that were, in turn, welded to the outside surface of the fuel tube.

\subsubsection{Test Conditions}

Three independent primary parameters were selected to form a test matrix:

- cask orientation

- horizontal

- $25^{\circ}$ inclination from horizontal

- vertical

- cask backfill medium

- air at atmospheric pressure

- air at approximately 0.1 atmosphere

- helium at slightly above atmospheric pressure

- assembly power

$-0.5 \mathrm{~kW}$

$-1.0 \mathrm{~kW}$.

The resultant test matrix is shown in Table 5.1.

The test matrix was devised to exercise a range of code modeling capabilities appropriate to dry storage casks. Thus, the three cask orientations require a corresponding specification of the gravitational vector within the code, which directly affects the gas flow field. The three different backfill media promote a different relative contribution from conduction, convection, and thermal radiation heat transfer mechanisms. Further, the two heat generation levels employed reflect typical 5- and 10-year-old PWR fuel.

The inside surface temperature of the cask cavity served as a boundary condition for all simulations. The temperature at one point on the surface was held constant by adjusting power to the external guard heaters.

Temperatures at other positions did vary, depending on the particular parameters of a given test. A list of temperatures and their respective locations for each run may be obtained from Bates (1986). 
TABLE 5.1. Electrically-Heated Single-Assembly Test Matrix

\begin{tabular}{|c|c|c|c|c|c|c|c|}
\hline $\begin{array}{c}\text { Run } \\
\text { Nunber }\end{array}$ & $\begin{array}{c}\text { Cask } \\
\text { Orientation }\end{array}$ & $\begin{array}{c}\text { Guard Heater } \\
\text { Control Temp, }{ }^{\circ} \mathrm{C} \\
\end{array}$ & $\begin{array}{l}\text { Nom inal } \\
\text { Power, kll }\end{array}$ & $\begin{array}{c}\begin{array}{c}\text { Actual } \\
\text { Power, } \mathrm{kW}\end{array} \\
\end{array}$ & Backfill & $\begin{array}{l}\text { Pressure } \\
\mathrm{mm} \mathrm{Hg} \text { abs }\end{array}$ & $\begin{array}{l}\text { Test } \\
\text { Date }\end{array}$ \\
\hline 1 & Inclined & 170 & 1.0 & 0.951 & Air & 744.8 & $68 / 09 / 8$ \\
\hline 2 & Inclined & & 1.0 & 9.940 & Yacuun & 83.3 & $68 / 10 / 8$ \\
\hline 2 repeat 1 & Inclined & & 1.0 & 9.956 & Vacuun & 88.9 & $68 / 24 / 8$ \\
\hline 2 repest 12 & Inclined & & 1.0 & 0.960 & Vacuua & 85.3 & $99 / 14 / 8$ \\
\hline 2 repeat 13 & Incl ined & & 1.0 & 0.944 & Vacuun & 84.1 & $16 / 19 / 8$ \\
\hline 3 & Inclined & & 1.6 & 0.956 & Helius & 789.4 & $68 / 22 / 8$ \\
\hline 4 & Inclined & & 9.5 & 6.561 & Heliun & 789.9 & $68 / 20 / 8$ \\
\hline 5 & Incl ined & & 0.5 & 0.484 & Yacuun & 82.6 & $68 / 16 / 8$ \\
\hline 6 & Inclined & & 0.5 & 6.477 & Air & 746.8 & $98 / 15 / 8$ \\
\hline 7 & Horizontal & & 0.5 & 6.487 & Air & 749.8 & $99 / 64 / 8$ \\
\hline$B$ & Hor izontal & & 0.5 & 6.486 & Vacuua & 87.6 & $99 / 05 / 8$ \\
\hline 9 & Horizontal & & 0.5 & 0.500 & Heliun & 795.5 & $99 / 07 / 8$ \\
\hline 10 & Hor izontal & & 1.0 & 0.964 & Heliun & 787.4 & $88 / 30 / 8$ \\
\hline 11 & Hor izontal & & 1.0 & 0.949 & Vacuun & 87.1 & $68 / 28 / 8$ \\
\hline 12 & Hor izontal & & 1.0 & 6.943 & Air & 743.2 & $68 / 27 / 8$ \\
\hline 13 & Vertical & & 1.6 & 0.994 & Mir & 746.3 & $69 / 21 / 8$ \\
\hline 14 & Vertical & & 1.0 & 6.977 & Vacuum & 79.2 & $69 / 25 / 8$ \\
\hline 15 & Vertical & & 1.0 & 6.995 & Heliun & 787.4 & $99 / 28 / 8$ \\
\hline 16 & Vertical & & 0.5 & 0.501 & Holiun & 785.6 & $10 / 01 / 8$ \\
\hline 17 & Vertical & & 6.5 & 0.496 & Vacuun & 81.3 & $10 / 03 / 8$ \\
\hline 18 & Vertical & & 6.5 & 0.515 & Air & 749.8 & $16 / 65 / 8$ \\
\hline 19 & Vertical & & 1.0 & 9.981 & Vacuun & 29.2 & $69 / 26 / 8$ \\
\hline 26 & Hor i zontal & off & 6.5 & 0.497 & Air & 756.3 & $99 / 12 / 8$ \\
\hline 21 & Vertical & off & 0.5 & 6.515 & Mir & 747.3 & $10 / 09 / 8$ \\
\hline 22 & Horizontal & On & 6. 6 & 6.6 & Heliun & 787.9 & $10 / 23 / 8$ \\
\hline
\end{tabular}

\subsection{COMPUTATIONAL MODEL DESCRIPTION}

The complete description of a given application is contained on an input file. The input file is read by HYDRA, and the information contained is stored and used to guide subsequent execution of the code. The computational mesh and material properties contained on the input file are described in this section. Modeling uncertainties are also discussed. 


\subsubsection{Computational Mesh}

Transverse cross sections of the cask and rod assembly were illustrated previously in Figures 5.2 and 5.4 , respectively. These figures show the rod assembly within the square fuel tube, both of which are symmetrically positioned within the circular cask. The half-symmetrical heat generation allows the use of a half symmetry model regardless of cask orientation.

Figure 5.5 shows the transverse computational mesh employed for all simulations. The straight-line segments approximating the cask inside diameter were introduced to reduce computer storage without significantly affecting predicted rod assembly or fuel tube temperatures. Figure 5.6 indicates the alignment of the computational mesh with the rod assembly, fuel tube, and cask inside surface.

A longitudinal cross section of the cask was shown in Figure 5.3. A corresponding cross section of the computational nesh is shown in Figure 5.7. Figure 5.8 indicates the location of the rod assembly, fuel tube, and cask inside surface relative to the computational mesh.

\subsubsection{Material Properties}

Material properties were obtained from Touloukian and Ho (1970). Table 5.2 lists the material properties used for all simulations. Effective thermal conductivities were estimated for those computational cells containing more than one material. For those simulations where the backfill is denoted as vacuum, it is to be understood that the actual backfill is air at approximately 0.1 atm pressure. The pressure is, however, high enough so that the mean free path of the gas is less than any significant length. The properties used for the vacuum simulations are, therefore, those of air.

The range of uncertainty for most of the property values used is not considered significant. The exceptions are the thermal conductivity of magnesium oxide and the emittances. The thermal conductivity of the magnesium oxide insulation used in the heater rods depends on its initial compacted state and its subsequent thermal history. It is believed that the rods (and the cask) had been at relatively high temperatures repeatedly prior to the start of this series of tests. For this reason, the thermal conductivity of 

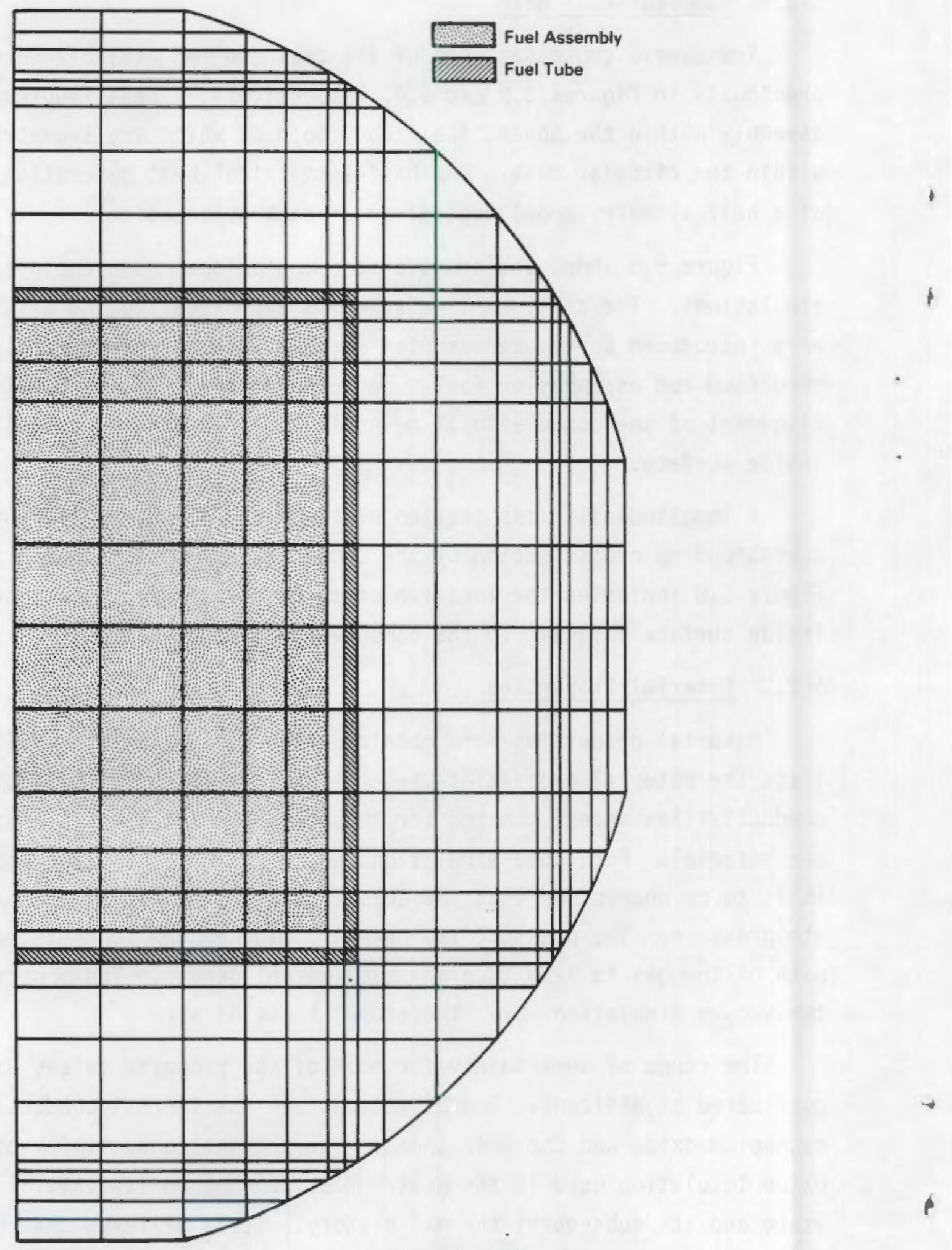

FIGURE 5.5. Transverse Computational Mesh 


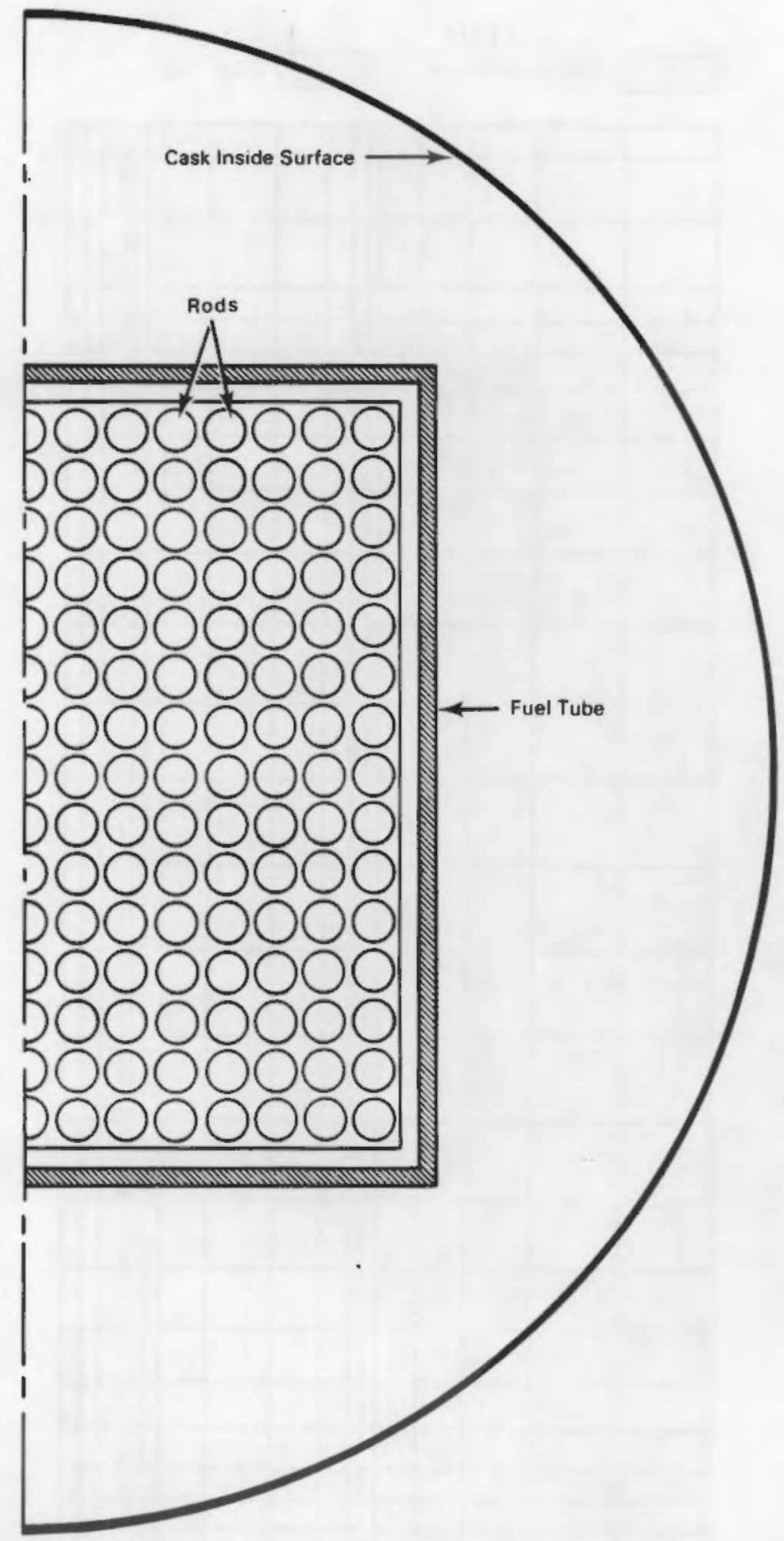

FIGURE 5.6. Alignment of Transverse Cross Section Computational Mesh with Physical Features 


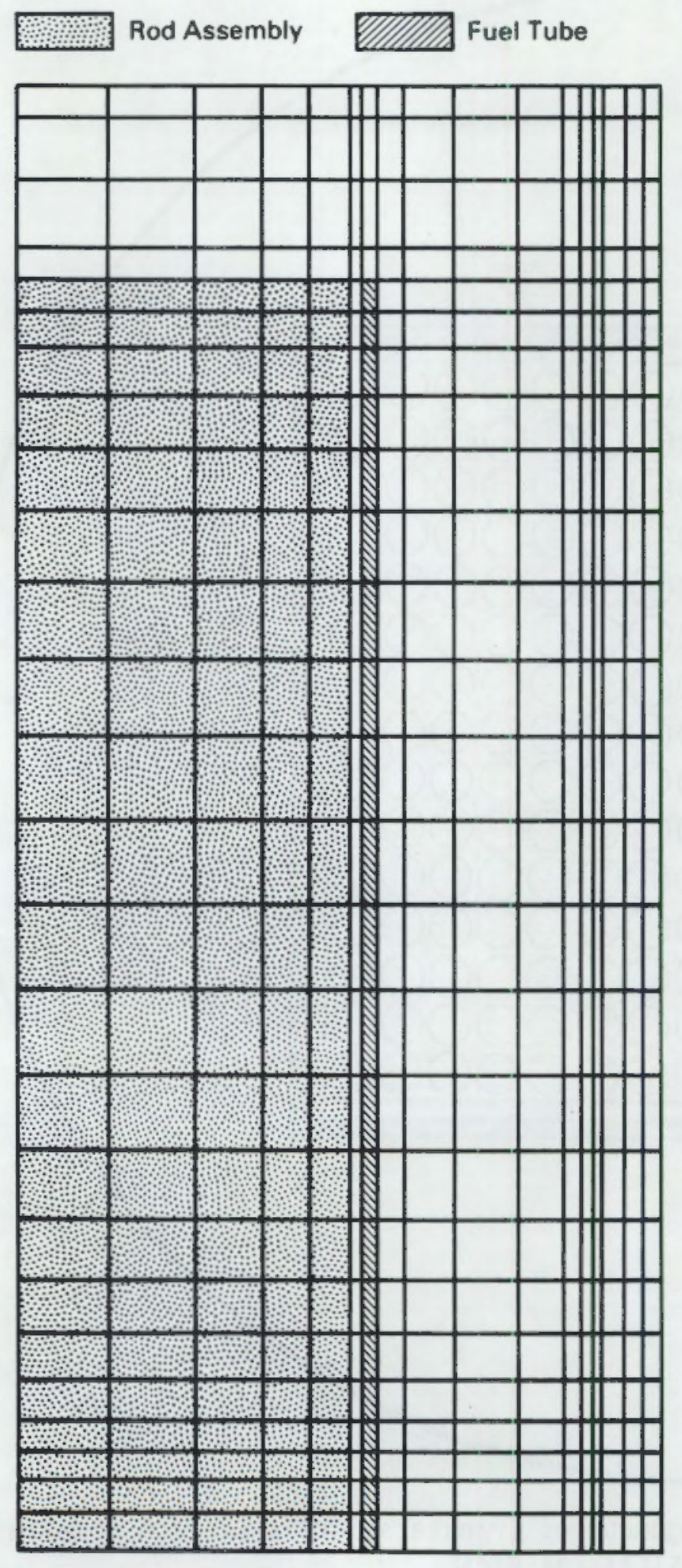

FIGURE 5.7. Longitudinal Computational Mesh 

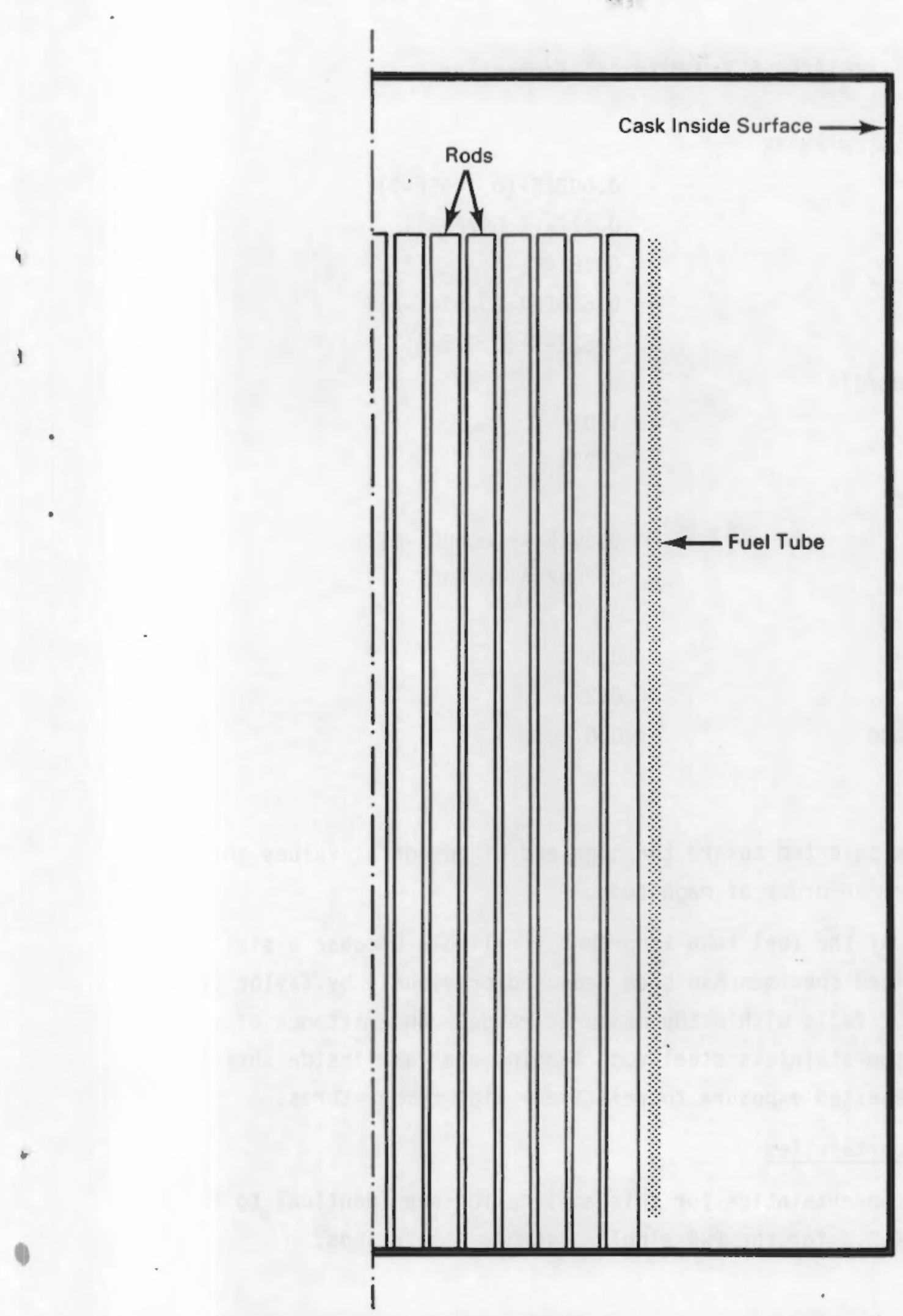

FIGURE 5.8. Physical Features Modeled in the Longitudinal Cross Section 


\section{TABLE 5.2. Material Properties}

Thermal Conductivity, $\mathrm{w} / \mathrm{cm}^{2}{ }^{\circ} \mathrm{K}$

Stainless steel

$0.09215+(0.1465 E-3) \mathrm{T}$

Boral

$0.677-(0.667 \mathrm{E}-3) \mathrm{T}$

Magnesium oxide

0.16

Air

$0.688 \mathrm{E}-4+(0.634 \mathrm{E}-6) \mathrm{T}$

Helium

$0.52 E-3+(0.32 E-5) T$

Specific Heat, w sec $/ g^{\circ} \mathrm{K}$

Air

1.0

Helium

5.234

Viscosity, $\mathrm{g} / \mathrm{cm} \mathrm{sec}$

Air

$0.608 E-4+(0.400 E-6) T$

Helium

$0.700 E-4+(0.400 E-6) T$

Emittance

Rods

0.6

Fuel tube

0.2

Cask inside surface

0.6

magnesium oxide was selected toward the high end of potential values that span a range of over an order of magnitude.

The emittance of the fuel tube is probably reliable because a similar but slightly less oxidized specimen had been measured previously by Taylor (1983). The emittance of 0.2 falls within the measured range. An emittance of 0.6 was selected for both the stainless steel rod cladding and cask inside surface because of their repeated exposure to relatively high temperatures.

\subsubsection{Modeling Uncertainties}

The potential uncertainties for this application are identical to those listed in Section 4.2.3 for the PWR single-assembly simulations. 


\subsection{PREDICTIONS COMPARED TO DATA}

Pre-look and post-test predictions of temperatures are compared to experimentally measured test data in this section. All pre-look predictions were conducted without access to the experimental results (except cask internal gas pressure, heat generation rate, and temperature boundary conditions), to ensure an unbiased evaluation of the HYDRA code. The single post-test prediction demonstrates the important benefits that turbulence modeling may provide.

Pre-look and post-test simulations were conducted with the same version of HYDRA, and all input files were identical except for the unique parameters of each test. The input files were prepared according to the best available information from cask drawings and private communications. After all tests were concluded, the cask was disassembled and inspected. It was found that the as-tested cask did not conform in all respects to the pretest information. The cask description given in Section 5.5.1 reflects the as-tested cask. The code input files, however, were based on pretest information. A discussion of the possible consequences of this mismatch and modeling uncertainties is included in Section 5.3.2.

\subsubsection{Pre-Look Predictions}

This subsection begins with a graphical summary of predictions compared to data for all simulations. Following this summary, temperature profiles are presented for those simulations with the most significance. For completeness, temperature profiles not included in this subsection are contained in the Appendix.

Figure 5.9 shows the comparison between predictions and data by means of 1) the temperature difference between the center rod and fuel tube and 2) the temperature difference between the fuel tube and cask. For example, the first simulation shown in Figure 5.9 is for vertical orientation, $1 \mathrm{~kW}$ power generation rate, and air backfill. The temperature difference of approximately $+8^{\circ} \mathrm{C}$ for center rod to fuel tube means that the predicted temperature difference is $8^{\circ} \mathrm{C}$ higher than what was measured. Similarly, the temperature difference 


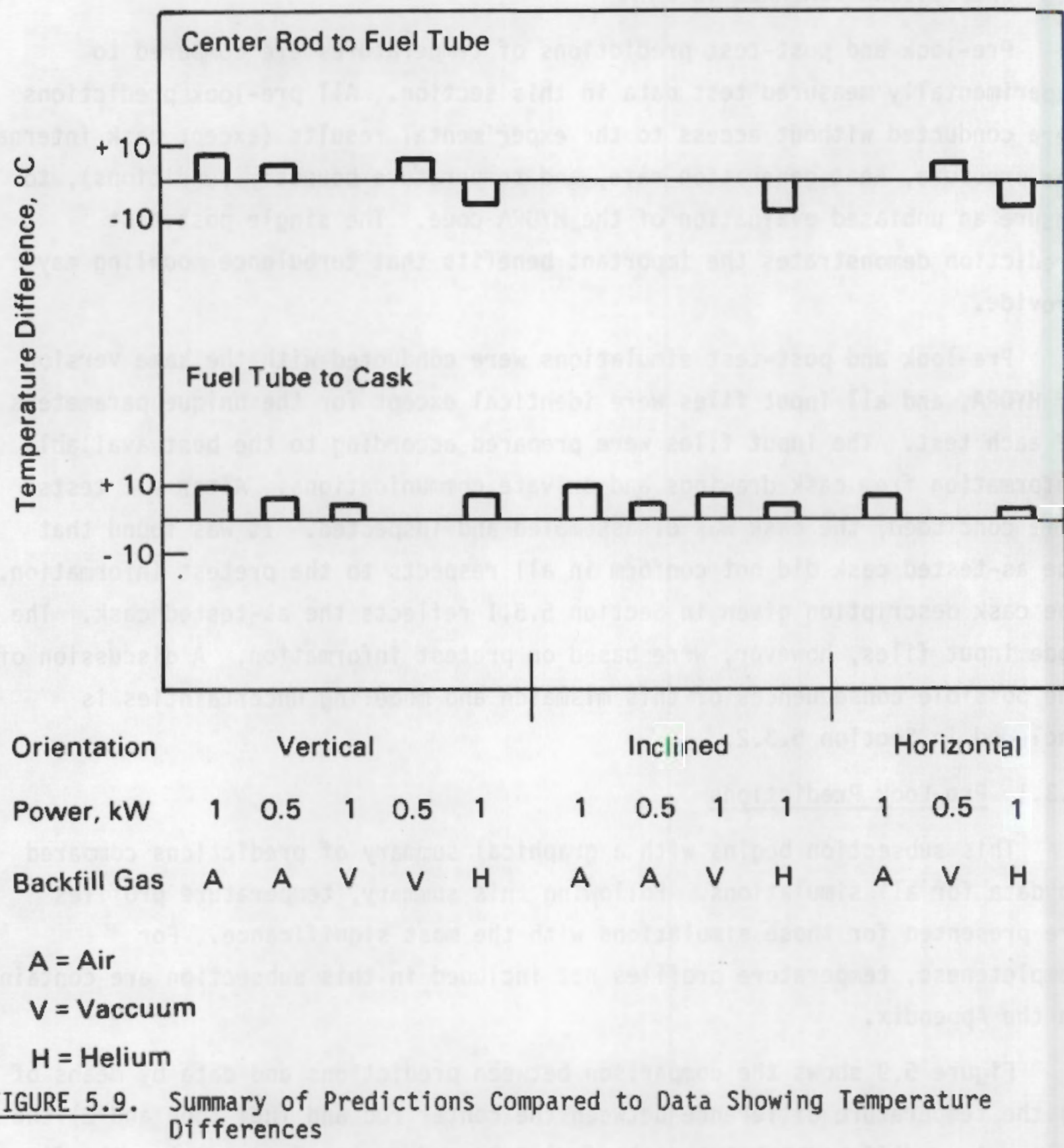

of $+10^{\circ} \mathrm{C}$ for fuel tube-to-cask means that the code prediction is $10^{\circ} \mathrm{C}$ greater than the measured temperature difference.

The fuel tube represents a barrier to both convective and radiative energy transport. Furthermore, the energy transport within the fuel tube (i.e., 
within the rod assembly) is characterized and modeled differently than is the transport external to the fuel tube (i.e., a free field). The temperature differences for these two regions might therefore be used as an indicator of the correctness of the separate models and heat transfer modes.

Each temperature difference shown in Figure 5.9 is derived from average temperatures at the elevation nearest to the peak rod temperature where experimental data exists. The temperature differences shown for center rodto-fuel tube average to approximately $0^{\circ} \mathrm{C}$ when all simulations are considered, and are at most $=8^{\circ} \mathrm{C}$ when considered individually. Probably the most significant trend indicated is that all air and vacuum simulations show temperature differences in the range of $0^{\circ} \mathrm{C}$ to $+8^{\circ} \mathrm{C}$ and all helium simulations show a temperature difference of approximately $-8^{\circ} \mathrm{C}$.

The temperature differences shown for fuel tube-to-cask are all in the range of $0^{\circ} \mathrm{C}$ to $+10^{\circ} \mathrm{C}$. A positive average of all temperature differences is believed to be significant. A possible explanation for the overprediction of this temperature difference is that the assumed emittance of the cask is too low. A complete discussion of these observations is deferred until after the results for the individual simulations have been presented.

The results of the simulations are grouped and presented according to orientation. The results for the vertical orientation are presented first, followed by the inclined and then the horizontal orientation. Where simulations were made for both $1-\mathrm{kW}$ and $0.5-\mathrm{kW}$ heat generation rates (backfill and orientation remaining the same), only the results for the 1- $\mathrm{kW}$ simulation are shown in this section. The results for the $0.5-\mathrm{kW}$ simulations are similar to those of the higher power simulations but with generally lower temperatures and therefore offer little that is of additional interest. Those simulation results not shown in this section are contained in the Appendix.

Four axial temperature profiles are shown for each simulation: center rod, corner rod, fuel tube, and cask inside surface. These transverse locations were selected because of their significance to cask designers, because they provide a good measure of the code's predictive capability, and because they 
have the largest amount of experimental data. The legend on each figure shows the precise locations.

\subsubsection{Vertical Orientation Results}

Figures 5.10,5.11, and 5.12 show the results for backfills of air, vacuum, and helium, respectively. The results for the air backfill, shown in Figure 5.10, display the largest discrepancy between predictions and data of all the simulations. One of the most striking aspects of the profiles is the shift in peak temperatures to nearly the top of the heated length. This shift does not reflect the heat generation rate, which is believed to be nearly uniform over the length of the rod assembly. The general shape of the profiles indicates that strong convection currents were present. Moreover, the predicted velocities are high enough so that appreciable turbulence is expected. The agreement between predictions and data is greatly improved by the use of an appropriate turbulence model. This assertion will, in fact, be shown to be the case when post-test results are presented.

Figures 5.11 and 5.12 show predictions compared to data for the cask in the vertical orientation with a $1-\mathrm{kW}$ heat generation rate and vacuum and helium backfills, respectively. The results are discussed together because it is instructive to note the similarities and differences in the two backfill media.

Recall that, for the vacuum tests, the backfill was actually air at approximately $0.1 \mathrm{~atm}$ pressure. This makes the density of the air comparable to that of helium at $1 \mathrm{~atm}$ pressure. The viscosities of the two gases are also comparable. The thermal conductivity of air is, however, much less than that of helium. The result is that the flow fields are similar but the temperature fields reflect the difference in thermal conductivity. The temperatures for the vacuum test are generally higher than for the helium test. Radiation transport becomes relatively more important in the vacuum test and mitigates the effects of a relatively lower thermal conductivity. 


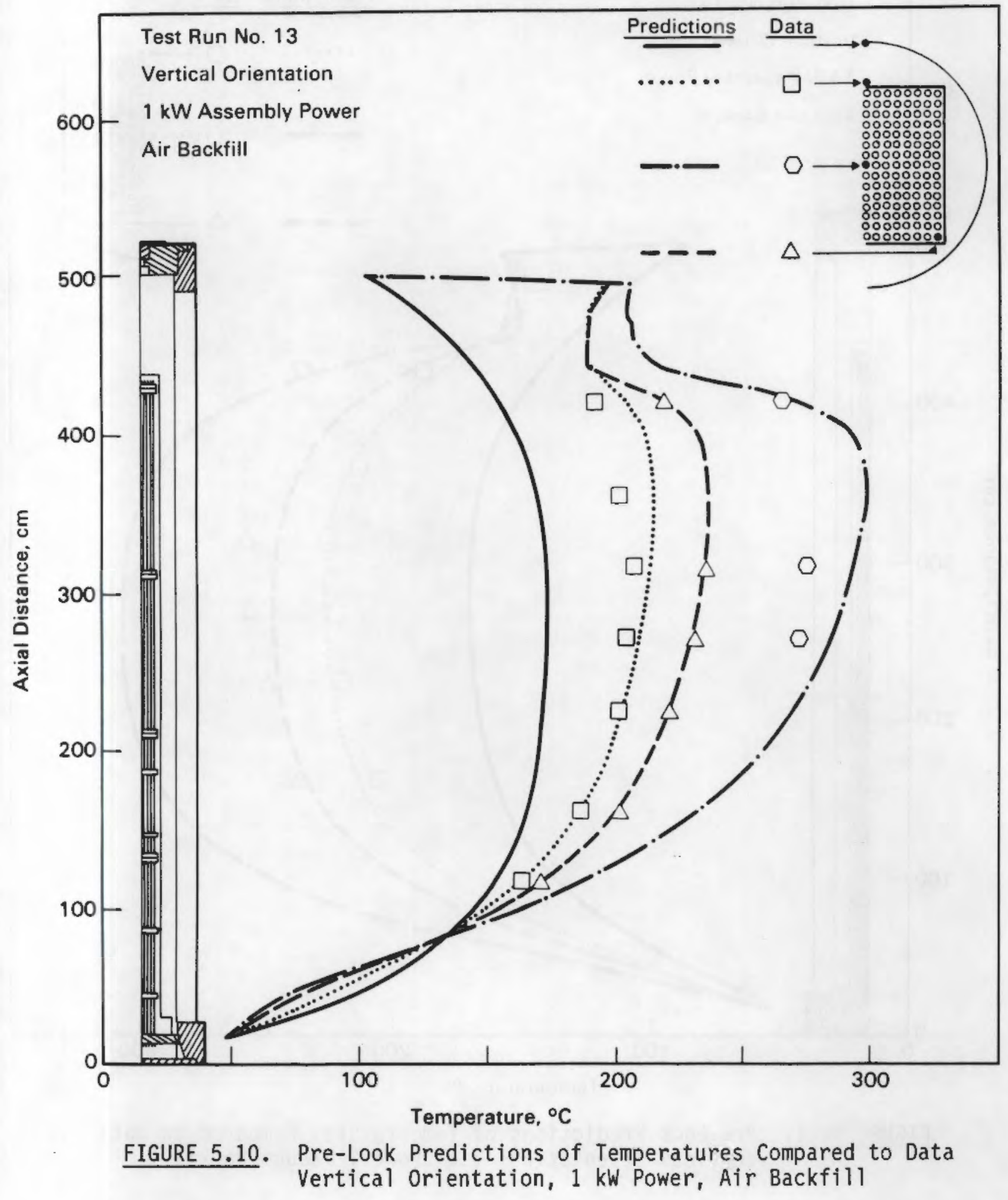




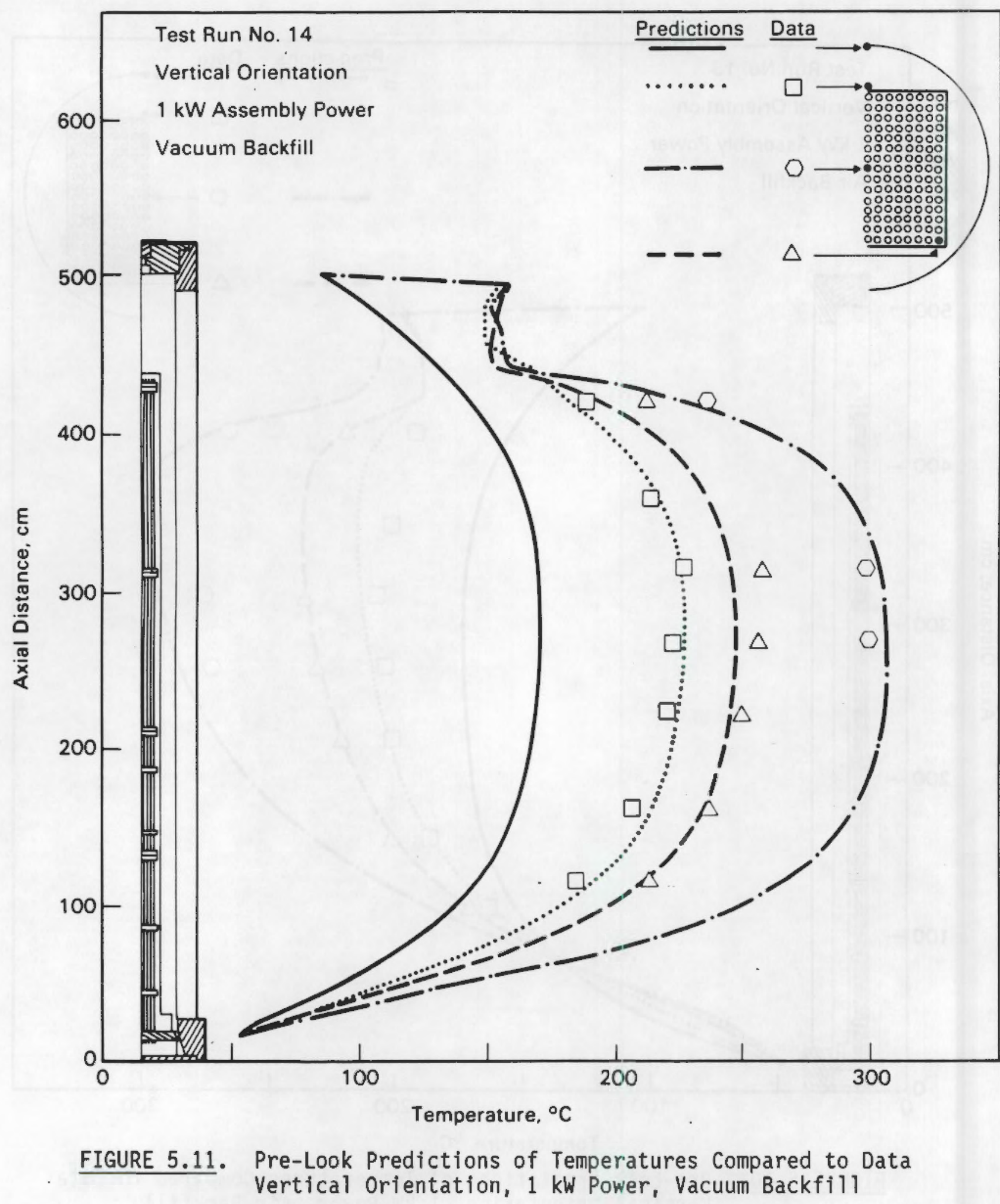




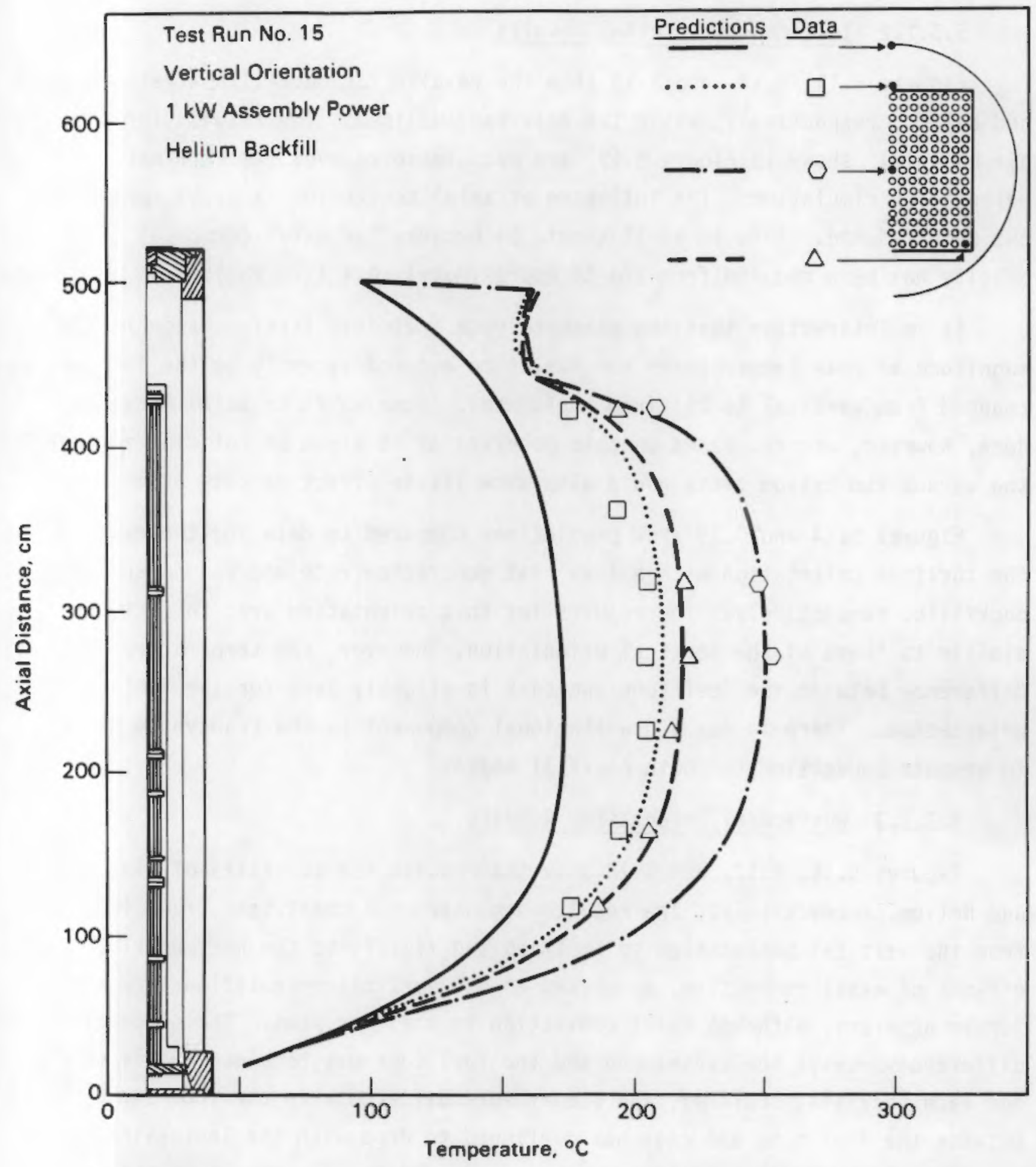

FIGURE 5.12. Pre-Look Predictions of Temperatures Compared to Data Vertical Orientation, $1 \mathrm{~kW}$ Power, Helium Backfill 


\subsubsection{Inclined Orientation Results}

Figures $5.13,5.14$, and 5.15 show the results for backfills of air, vacuum, and helium, respectively, while the cask was inclined. The results for the air backfill, shown in Figure 5.13, are much improved over the vertical orientation simulation. The influence of axial convection is still apparent but much reduced. This is as it should be because the axial component of gravity has been reduced from 1.0 to approximately $0.4\left(\sin 25^{\circ}\right)$.

It is interesting that the measured data indicates little change in the magnitude of peak temperatures for fuel tube and rod assembly as the inclination changed from vertical to $25^{\circ}$ from horizontal. Some shift in axial location does, however, occur. Based on this observation it might be anticipated that the vacuum and helium tests would also show little effect of cask orientation.

Figures 5.14 and 5.15 show predictions compared to data for the cask in the inclined orientation with a $1-\mathrm{kW}$ heat generation rate and vacuum and helium backfills, respectively. The results for this orientation are, in fact, quite similar to those of the vertical orientation. However, the temperature difference between the fuel tube and cask is slightly less for the inclined orientation. There is now a gravitational component in the transverse plane to promote convection for both backfill media.

\subsubsection{Horizontal Orientation Results}

Figures 5.16, 5.17, and 5.18 show the results for backfills of air, vacuum, and helium, respectively. The results demonstrate a consistent trend in passing from the vertical orientation to inclined and finally to the horizontal. The effects of axial convection, so marked in the vertical orientation, are no longer apparent, although axial convection is still present. The temperature difference between the center rod and the fuel tube has remained nearly constant for each backfill. Further, the temperature difference in the free field between the fuel tube and cask has continued to drop with the increasing gravitational component in the transverse direction.

The comparison between predictions and measured data was favorable for most of the simulations. An exception is the simulation for vertical orientation, 1-kW power generation rate, and air backfill. It has been 


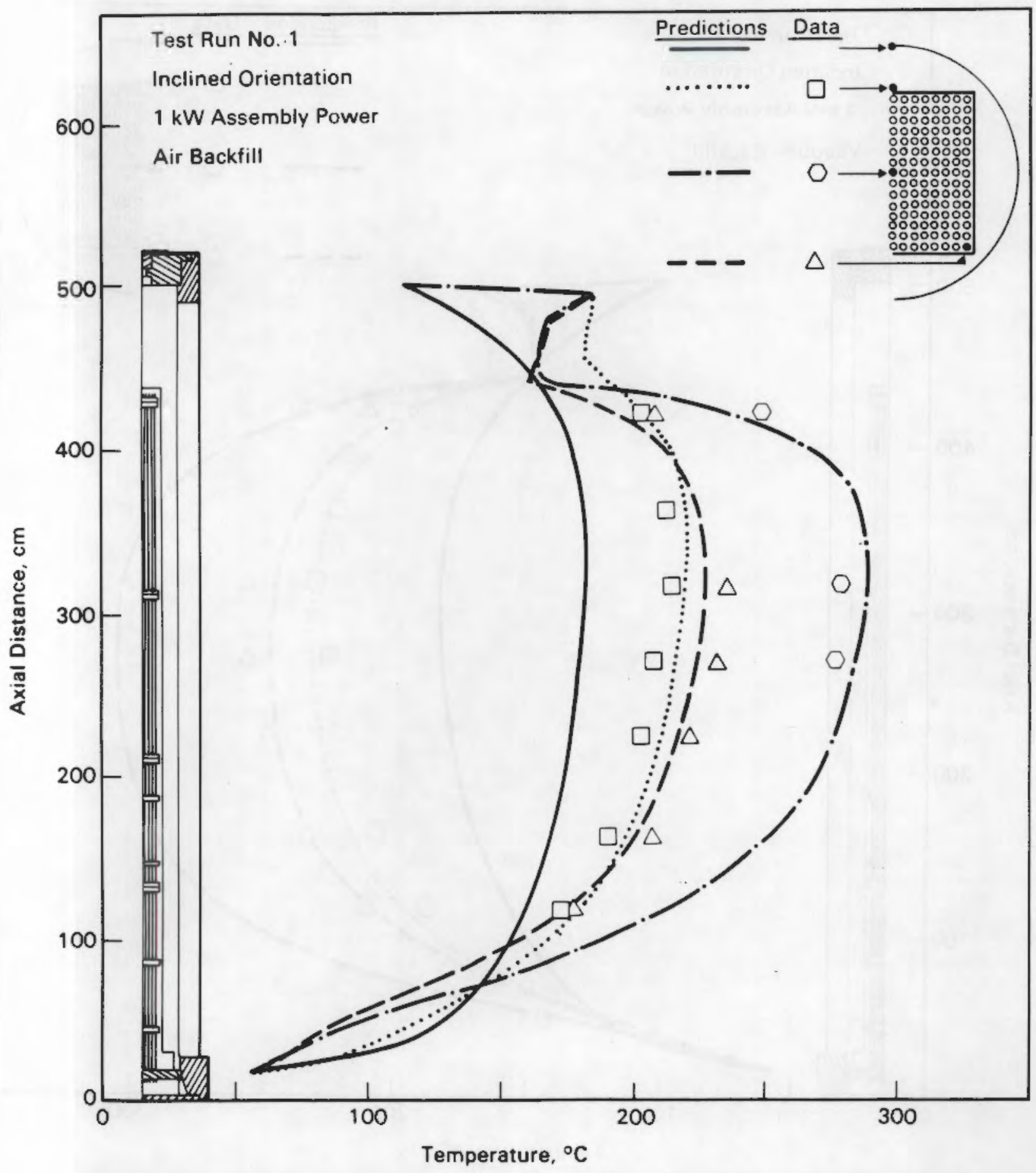

FIGURE 5.13. Pre-Look Predictions of Temperatures Compared to Data Inclined Orientation, $1 \mathrm{~kW}$ Power, Air Backfill 


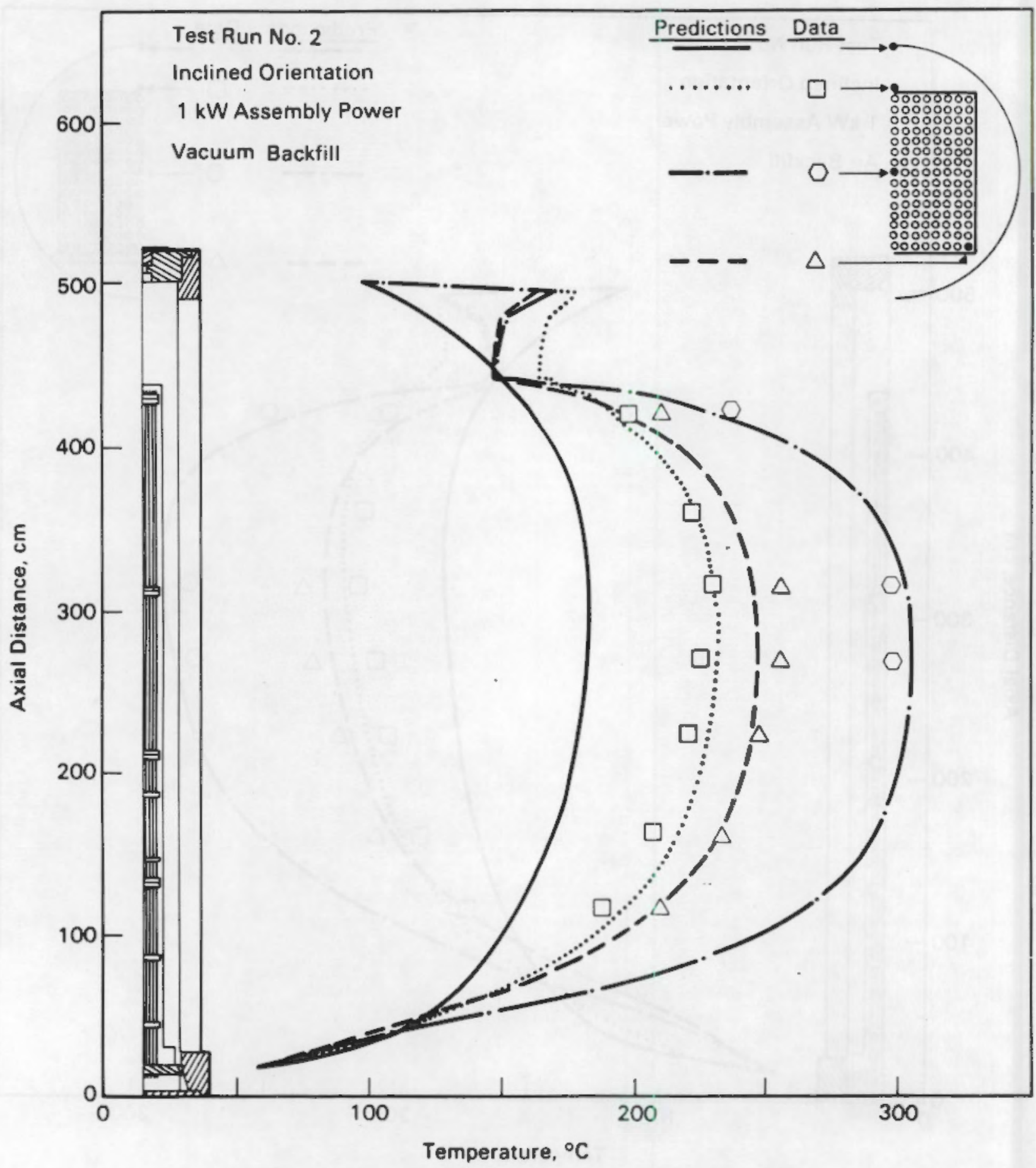

FIGURE 5.14. Pre-Look Predictions of Temperatures Compared to Data Inclined Orientation, $1 \mathrm{~kW}$ Power, Vacuum Backfill 


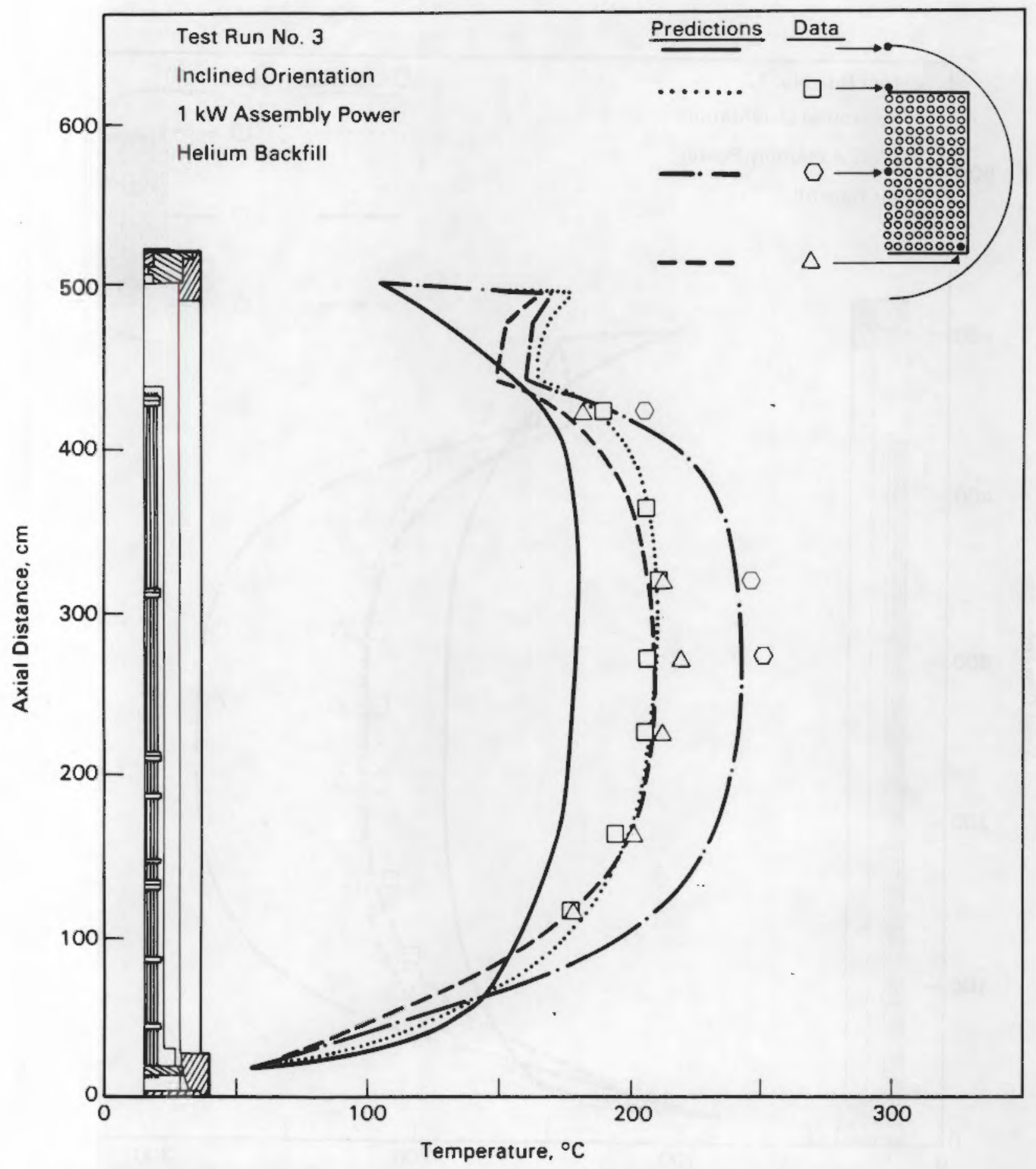

FIGURE 5.15. Pre-Look Predictions of Temperatures Compared to Data Inclined Orientation, $1 \mathrm{~kW}$ Power, Helium Backfill 


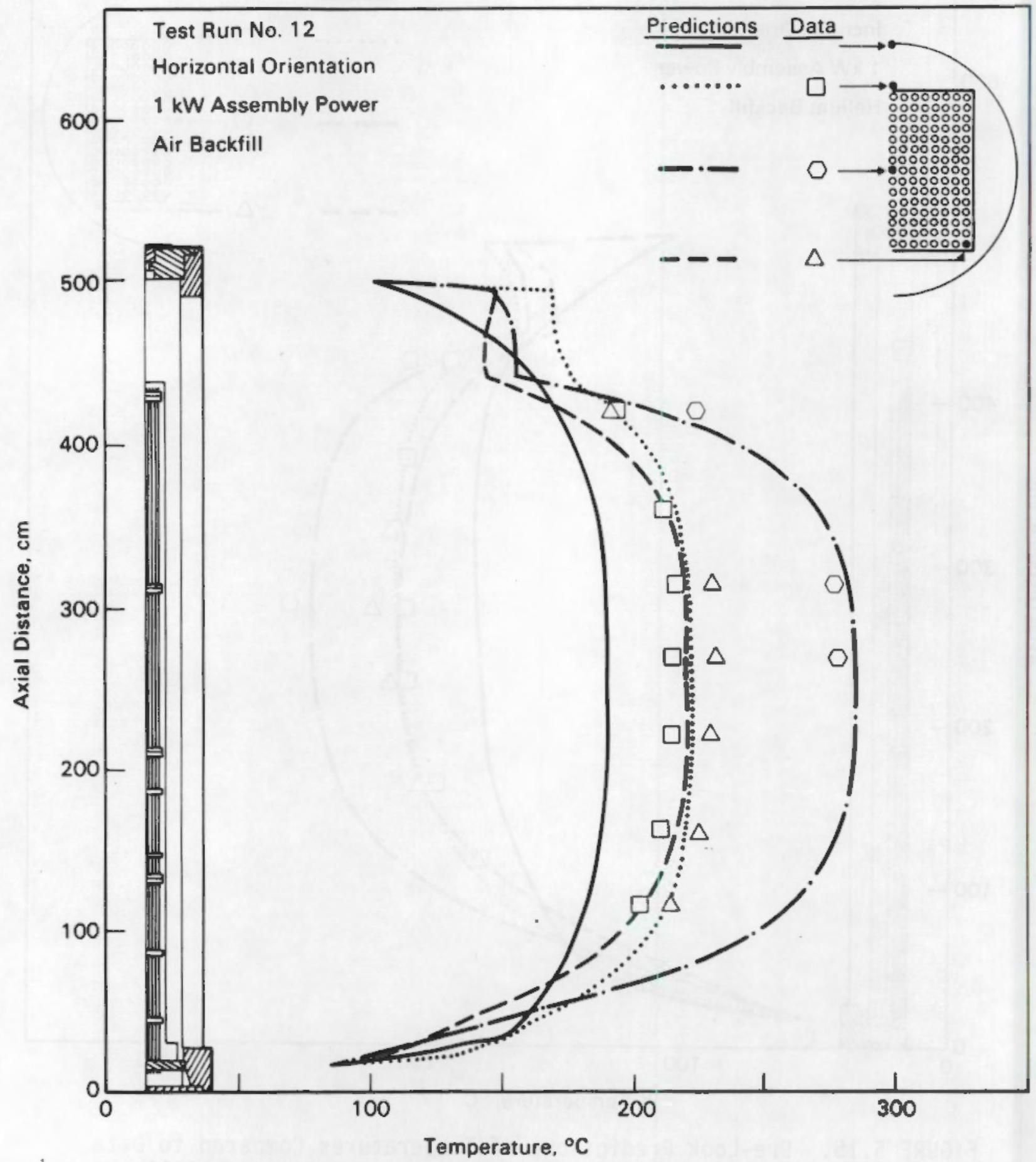

FIGURE 5.16. Pre-Look Predictions of Temperatures Compared to Data Horizontal Orientation, $1 \mathrm{~kW}$ Power, Air Backfill 


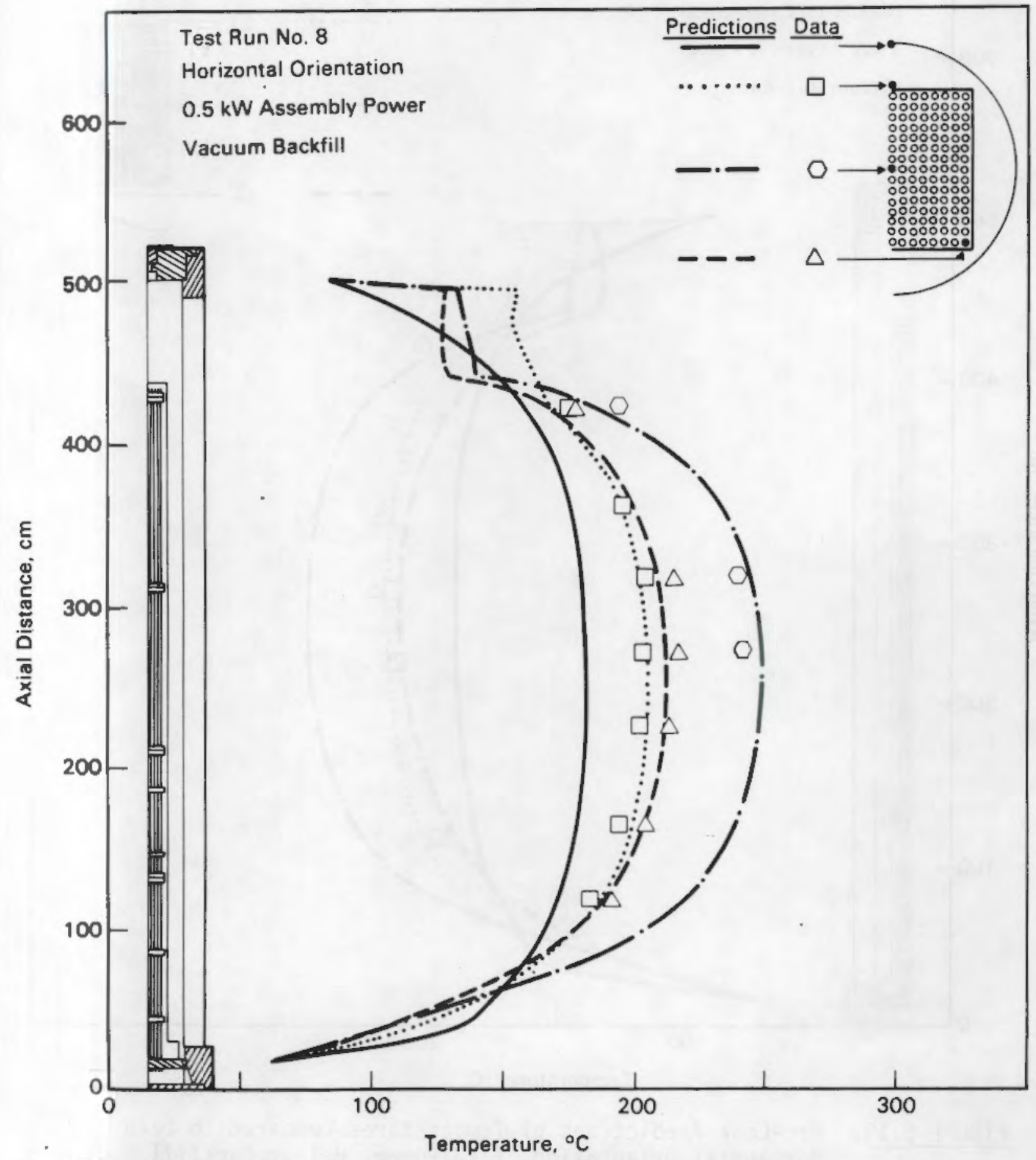

FIGURE 5.17. Pre-Look Predictions of Temperatures Compared to Data Horizontal Orientation, $0.5 \mathrm{~kW}$ Power, Vacuum Backfill 


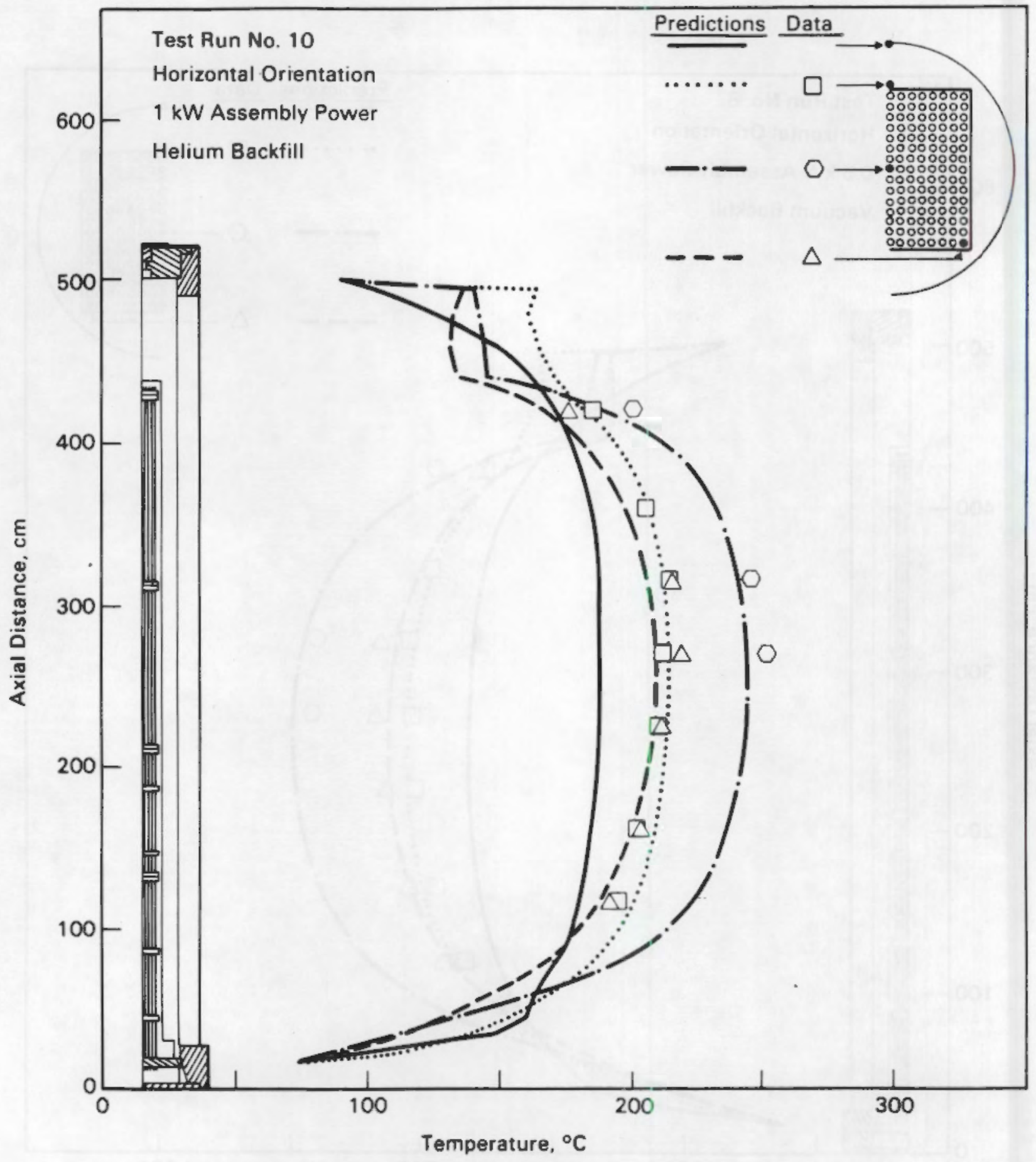

FIGURE 5.18. Pre-Look Predictions of Temperatures Compared to Data Horizontal Orientation, 1 kW Power, Helium Backfill 
suggested that significant turbulence is present in this test. This matter and other factors influence using the results for all tests will be taken up in Section 5.3.2.

\subsubsection{Post-Test Predictions}

This subsection begins with an examination of several important physical features of the as-tested cask. Comparisons are made between the actual test section and the description of the test section contained in the input files. Conclusions will be drawn as to what, if any, changes are warranted in the code and/or input files. This subsection concludes with a presentation of the results for one post-test simulation to demonstrate the effectiveness of a turbulence model.

The input files to the code were constructed based on the best available information prior to the conclusion of the tests. After the tests were concluded, the cask was disassembled and inspected. Thermocouple locations and their method of attachment were verified. Important dimensions were measured. Some of the materials used in the rod assembly were confirmed, and the general condition of the cask interior was noted. The as-tested cask was found to entirely conform to pretest information in some respects. The more significant findings are summarized below.

The fuel tube and rod assembly were intended to be centered within the cask and held in that position at both ends. It was found that the upper end had not been securely supported, resulting in an offset from the centerline estimated to be from 1 to $2 \mathrm{~cm}$ when in the horizontal position. The offset when the cask was in the vertical position is unknown. The input file specified that both the fuel tube and rod assembly were centered.

The fuel tube walls are constructed as a sandwich with a Boral interior and two stainless steel sheets as cladding. It was observed that the fuel tube had delaminated and that the inside cladding appeared to press against the rod assembly in places. The time at which this structural change occurred within the test series is unknown. The input file specified a bonded sandwich construction and a uniform gap between fuel tube and rod assembly. 
Two types of spacer grids are used in the rod assembly. One type is similar to the conventional design used in PWR fuel assemblies; the other was fabricated from flat bars. The use of flat bars results in a rod pitch that varies in both the transverse and axial directions. The rod pitch influences conduction, convection, and thermal radiation transfer within the rod assembly in a complex fashion. The net effect on predicted temperatures is different for each cask simulation. The input files specified a single nominal pitch.

The uncertainty in some thermophysical properties was mentioned previously in Section 5.2.2. The thermal conductivity of the magnesium oxide used in the heater rods has a potential range of over an order of magnitude. The emittances of the rods in the model fuel assembly and the cask inside surface were also not measured and thus are also uncertain.

The physical locations of temperature data furnished as a boundary condition for the cask inside surface were rather sparse. The data planes were spaced approximately $1 \mathrm{~m}$ apart, and temperature differences exceeding $80^{\circ} \mathrm{C}$ were common near the ends of the cask. Temperature boundary conditions are required for the solution of the internal temperature field and have a direct impact on the internal temperatures. Temperature boundary conditions were estimated where measured data was not available.

Finally, measured temperatures at some nominally symmetric locations differed by $8^{\circ} \mathrm{C}$ or more. A comparison between predictions and data was summarized for all simulations in Figure 5.9. This asymmetry in data can be seen to be comparable to the temperature differences between predictions and data for all simulations shown in Figure 5.9.

Considering all of the above factors, the agreement between pre-look predictions and measured data is, for the most part, surprisingly good. There appears to be no justification for any modification to the algorithms or models currently in HYDRA. The agreement between predictions and data could, however, be improved by adjusting some property values contained in the input files.

For example, the discrepancy in temperature differences between the fuel tube and cask ranged between $0^{\circ} \mathrm{C}$ and $10^{\circ} \mathrm{C}$ for all simulations. The average discrepancy could be reduced to zero by increasing the emittance of the cask 
surface. Unfortunately, reducing the average temperature discrepancy to zero by this means does not provide sufficient evidence that the adjusted emittance value is correct or that the code is free of errors. It is concluded that modifying the input files is of little benefit for this application.

The above remarks should not be interpreted to mean there is no need for further code improvement. One instance that suggests an area for additional code enhancement is provided by the first simulation presented in Section 5.3.1.1. That simulation was for the vertical orientation, 1-kW power generation rate, and air backfill. The results of the simulation suggest that strong convection currents are present and that appreciable turbulence is expected.

Figure 5.19 shows the comparison between post-test predictions and data for this one simulation. The superior agreement was achieved by incorporating a turbulent transport mechanism in the upper half of the cask where velocities are greatest. The benefits of an appropriate turbulence model can be appreciated by comparing the results shown in Figure 5.19 with its counterpart shown in Figure 5.10. 


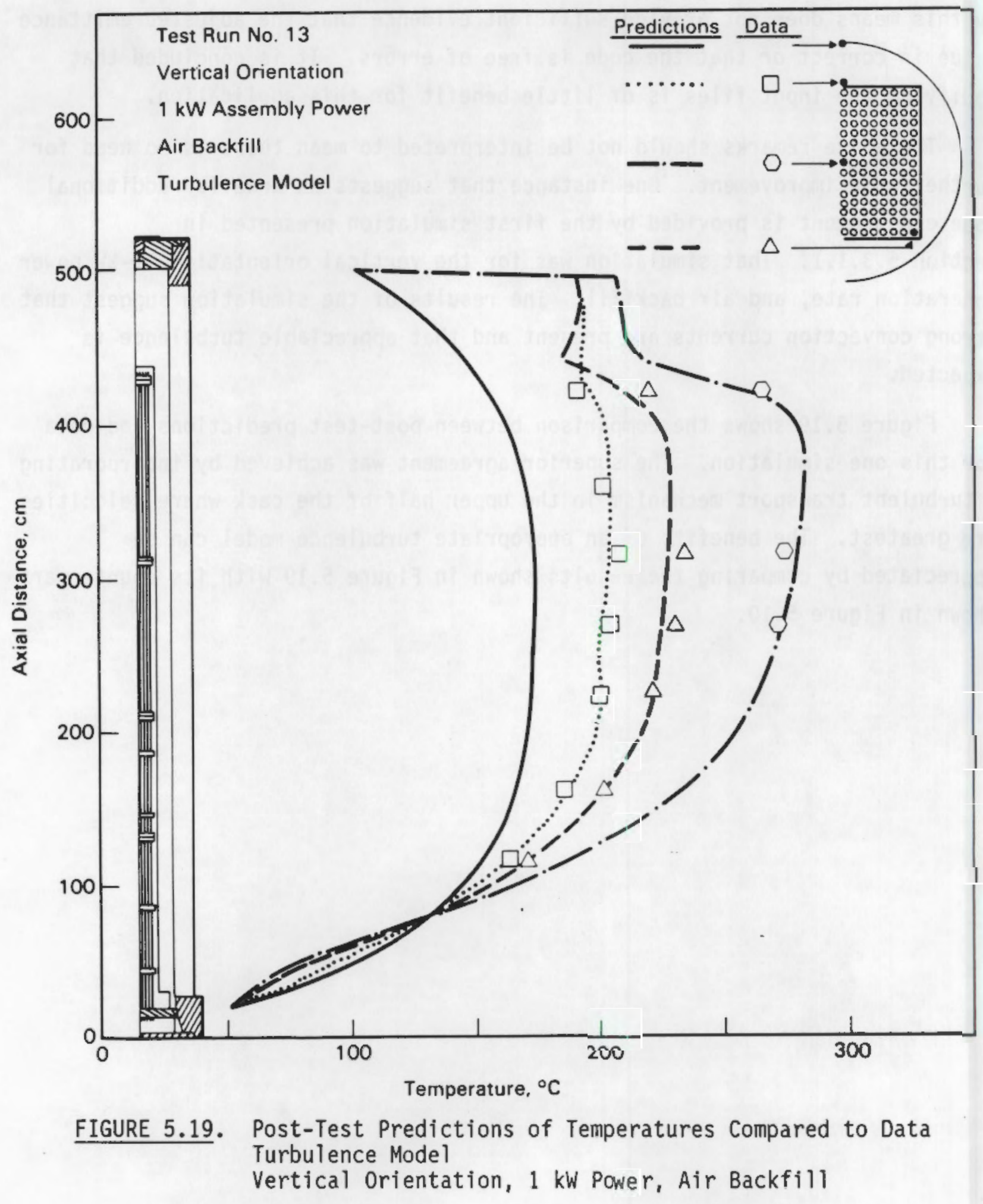




\section{REFERENCES}

Bates, J. M. 1986. Single PWR Spent Fuel Assembly Heat Transfer Data for Computer Code Evaluations. PNL-5571, Pacific Northwest Laboratory, Richland, Washington.

Davis, R. 1980. Data Report for the Nondestructive Examination of Turkey Point Spent Fuel Assemblies B02, B03, B27, B41, and B43. HEDL-TME 79-68, Hanford Engineering Development Laboratory, Richland, Washington.

DOE. 1985. Spent Fuel Storage Requirements. DOE/RL-85-2; U.S. Department of Energy, Richland Operations Office, Richland, Washington.

Douglas, J., and J. Gunn. 1964. "A General Formulation of Alternating Direction Methods." I. Numer. Math. 6:428.

EG\&G. 1980. MATPRO-Version II (Revision 1) A Handbook of Material Properties for Use in the Analysis of Light Water Reactor Fuel Rod Behavior. TREE1280, Rev. 1, EG\&G, Inc., Idaho Falls, Idaho.

Patankar, S. V. 1980. Numerical Heat Transfer and Fluid Flow. Hemisphere, Washington, D.C.

Petersen, C. 1975. Literature Search on Some Properties of Zircaloy-4 at High Temperatures. AECL-5101. Power Projects, Sheridan Park Research Community, Mississauga, Ontario. Translated from Gesellschaft fur Kernforschung m.b.H., Karlsruhe, report KFK-Ext 6/73-6, March 1973.

Raithby, G. D., and G. E. Schneider. 1979. "Numerical Solution of Problems in Incompressible Fluid Flow; Treatment of Velocity-Pressure Coupling." Numer. Heat Transfer. 2:417-440.

Raithby, G. D., and G. E. Schneider. 1980. "Erratum." Numer. Heat Transfer. $3: 513$.

Taylor, R. E. 1983. Hemispherical Total Emissivity of Stainless Steel. TPRL 324, School of Mechanical Engineering, Purdue University, West Lafayette, Indiana.

Touloukian, Y. S., and C. Y. Ho. 1970. Thermophysical Properties of Matter. Thermophysical Properties Research Center, Purdue University, West Lafayette, Indiana.

Unterzuber, R., R. D. Milnes, B. A. Marinkovich, and G. M. Kubancsek. 1982. Spent Fuel Dry Storage Testing at E-MAD (March 1978 through March 1982). AESD-TME-3162, Westinghouse Electric Corporation, Advanced Energy Systems Division, Pittsburgh, Pennyslvania. 



\section{APPENDIX}

ELECTRICALLY-HEATED SINGLE-ASSEMBLY SIMULATIONS

ADDITIONAL PREDICTIONS OF TEMPERATURES COMPARED TO DATA 


\section{APPENDIX}

\section{ELECTRICALLY-HEATED SINGLE-ASSEMBLY TESTS}

\section{ADDITIONAL PREDICTIONS OF TEMPERATURES COMPARED TO DATA}

All of the simulations where $1 \mathrm{~kW}$ of heat was generated in the electrically-heated rod assembly have been presented in the body of this report. Some simulations were also made for the $0.5-\mathrm{kW}$ heat generation rate. These additional simulations generally predict lower temperatures and offer little in the way of new features. The results are presented here for completeness. 


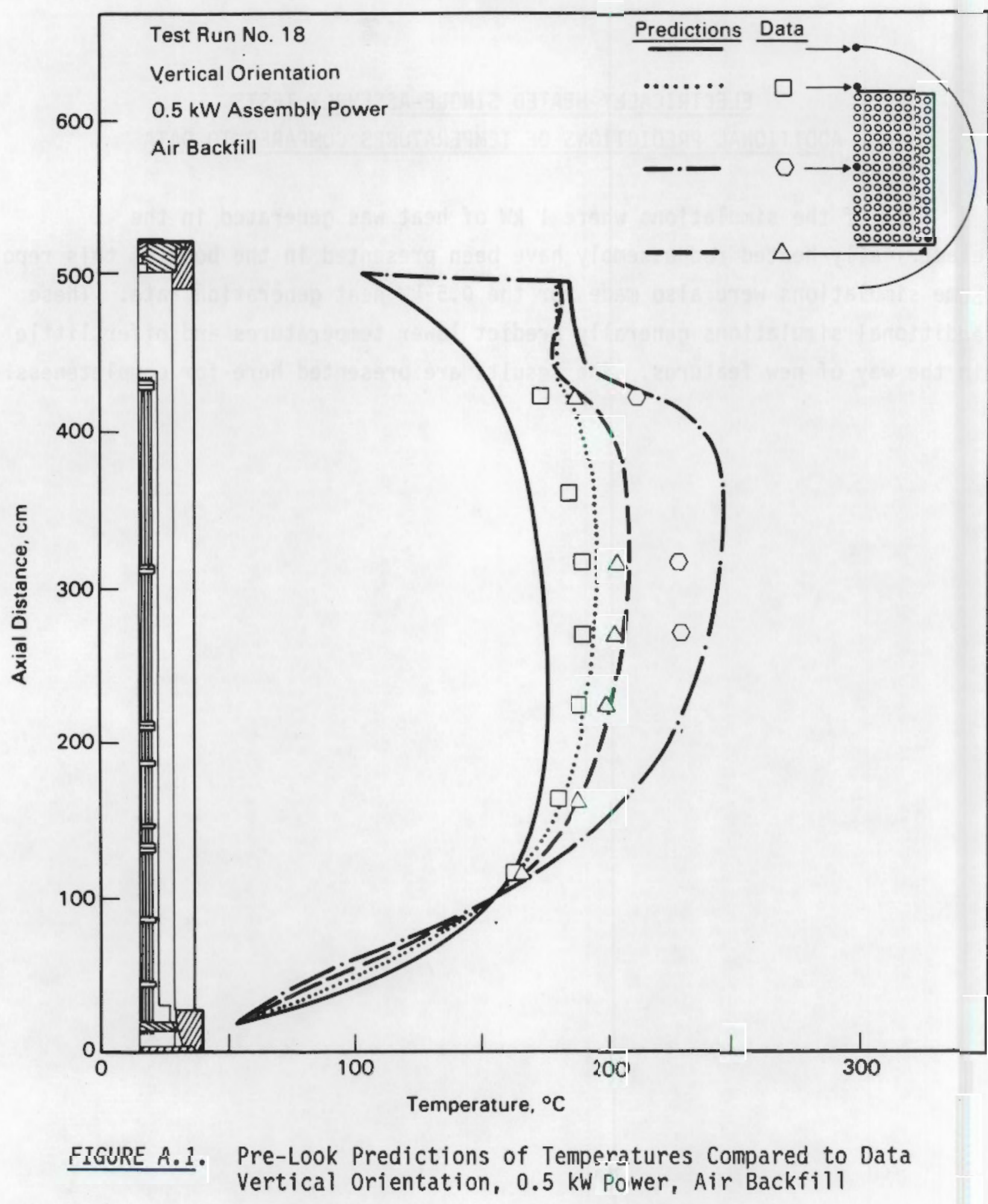




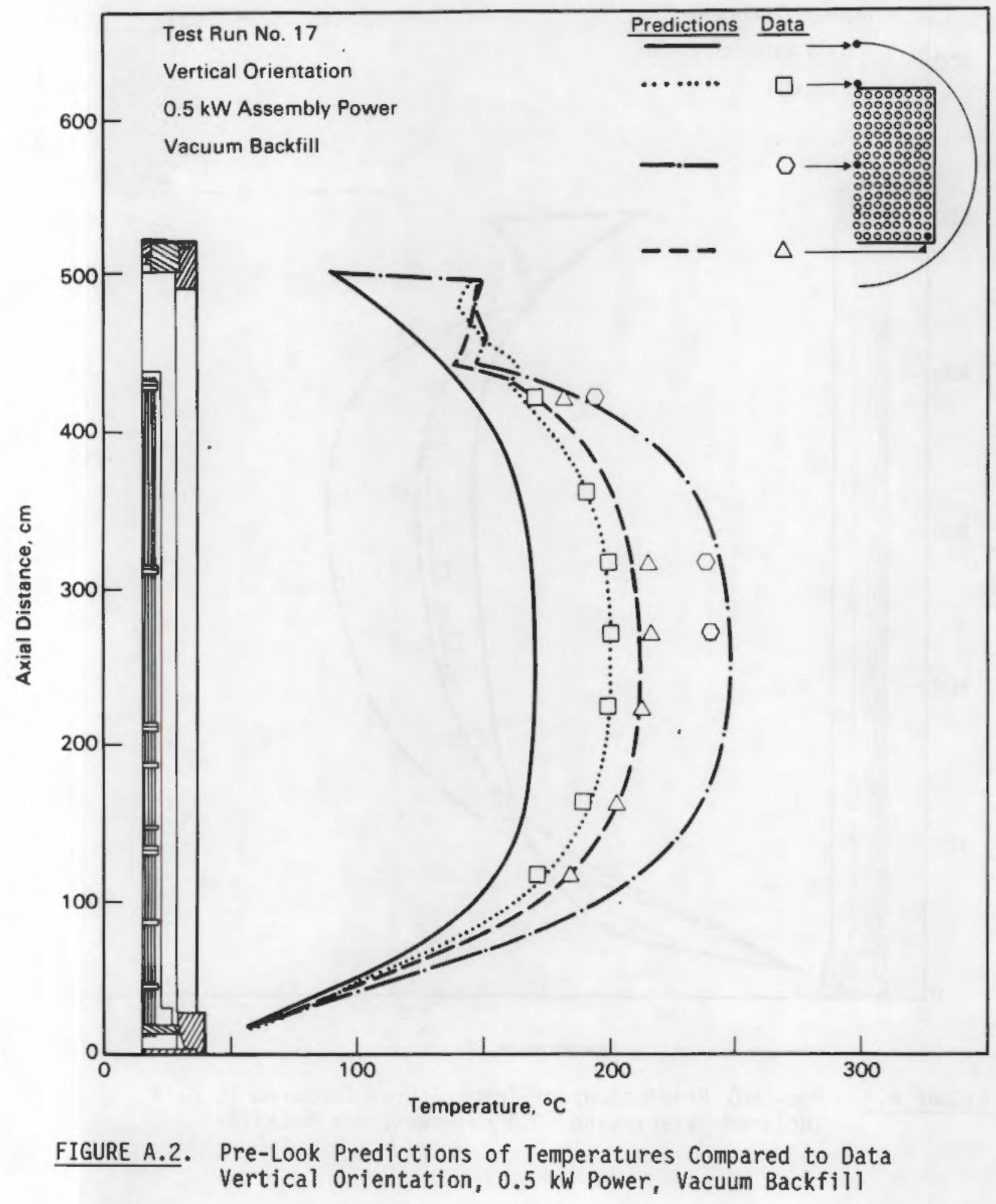




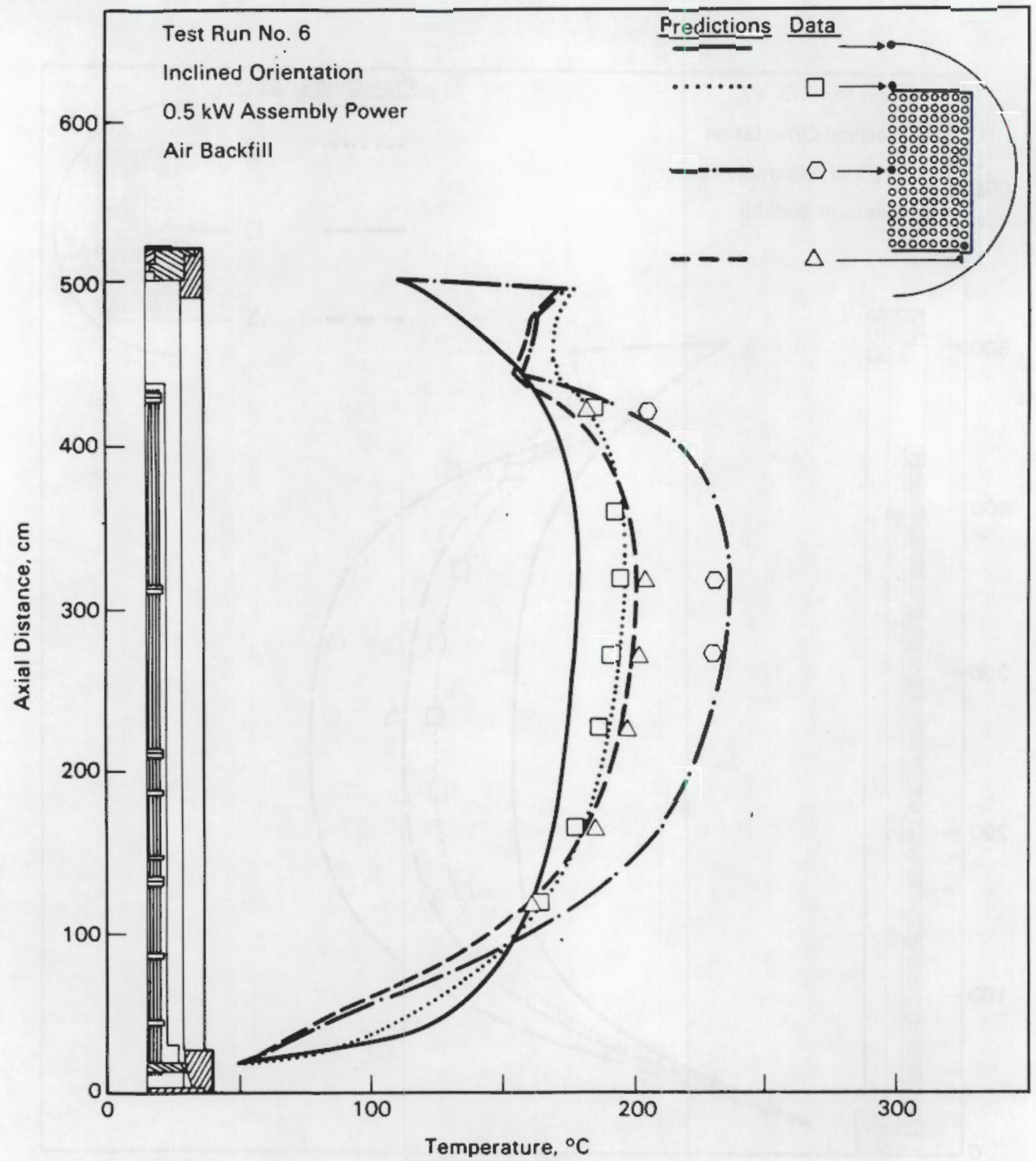

FIGURE A.3. Pre-Look Predictions of Temperatures Compared to Data Inclined Orientation, $0.5 \mathrm{~kW}$ Power, Air Backfill 


\section{DISTRIBUTION}

No. of

Copies

OFFSITE

110 DOE Technical Information Center

R. Bown

U.S. Department of Energy

Office of Civilian Radioactive Waste Management

RW-30

Washington, DC 20545

J. Epstein

U.S. Department of Energy

Office of Civilian Radioactive Waste Management

$\mathrm{RW}-30$

Washington, DC 20545

J. R. Hilley

U.S. Department of Energy

Office of Storage and

Transportation Systems

Washington, DC 20545

D. E. Shelor

U.S. Department of Energy

Office of Civilian Radioactive Waste Management

RW-32

Washington, DC 20545

H. Steinburg

U.S. Department of Energy

Office of Storage and

Transportation Systems

$R W-33$

1000 Independence Ave.

Washington, D.C 20545
No. of

Copies

W. Stringfield

U.S. Department of Energy

office of Civilian Radioactive Waste Management

Washington, D.C. 20545

C. P. Gertz

U.S. Department of Energy

Idaho Operations office

550 2nd Street

Idaho Falls, ID 83401

K. G. Golliher

U.S. Department of Energy

Albuquerque Operations office

P.0. Box 5400

Albuquerque, NM 87115

L. Lanni

U.S. Department of Energy

Magnetic Fusion and Energy

Division

San Francisco Operations Office

1333 Broadway

Oakland, CA 94612

C. Matthews

U.S. Department of Energy

Oak Ridge National Laboratory

P.0. Box E

Oak Ridge, TN 37830

D. Veith

U.S. Department of Energy

Nevada Operations Office

P.0. Box 14100

Las Vegas, NV 89114 
N. H. Davison

U.S. Nuclear Regulatory Commission

Office of Nuclear Materials

Safety and Safeguards

Washington, DC 20555

C. Feldman

U.S. Nuclear Regulatory Commission

Office of Nuclear Regulatory Research

MS $5650 \mathrm{NL}$

Washington, DC 20555

W. Lake

U.S. Nuclear Commission

Office of Nuclear Materials Safety and Safeguards

Washington, DC 20555

C. H. Peterson

U.S. Nuclear Regulatory Commission

Office of Nuclear Material

Safety and Safeguards

MS 62355

Washington, DC 20555

J. A. Carr

Battelle Memorial Institute

Office of Nuclear Waste

Isolation

505 King Avenue

Columbus, $\mathrm{OH} 43201$

B. A. Rowles

Battelle Memorial Institute

Office of Nuclear Waste

Isolation

505 King Avenue

Columbus, OH 43201
W. F. Juergens

Brocks \& Perkins

12633 Inkster Road

Livenia, MI 48150

R. Kunita

Carclina Power \& Light Co.

P.0. Box 1551

Raleigh, NC 27602

C. K. Anderson

Combustion Engineering, Inc.

1000 Prospect Hill Road

windsor, CT 06095

Ebasco Services Incorporated

Two World Trade Center

New York, NY 10048

D. H. Schoonen

$E G \& G$

P.0. Box 1625

Idaho Falls, ID 83415

P. E. Eggers

Eggers Ridihalgh Partners, Inc. 1445 Summit Street

Columbus, $\mathrm{OH} \quad 43201$

FLUOR Engineers, Inc. Advanced Technology Division P.0. Box C-11944

Santa Anna, CA 92711-1944

J. W. Doman

Morris Operation

General Electric Company

7555 E. Collins Road

Morris, IL 60450

E. E. Volland

General Electric Company

Nuclear Fuel \& Services

Division

7555 E. Collins Road

Morris, IL 60450 
No. of

Copies

$R$. Anderson

General Nuclear 5ervices, Inc. 135 Darling Drive

Ayon, CT D6001

V. J. Barnhart

General Nuclear Services, Inc. 135 Darling Orive

Avon, CT 06001

L. B. Ballou

Lawrence Livermore National Laboratory

P.0. Box 808

Livemore, CA 94550

M. W. Schwartz

Lawrence Livemore National Laboratory

P.0. Box 808

Livermore, CA 94550

C. F. Smith

Lawrence Lfvemore National Laboratory

P.0. 80x 808

Livermore, CA 94550

6. Bosler

Los Alamos National Laboratory

Los Alamos, NM 87545

P. Rinard

Los Alamos National Laboratory

Los Alamos, NH 87545

H. Lowenberg

Lowenberg Assoclates

10901 Rosemont Drive

Rockville, MD 20852

j. Houston

Nuclear Assurance Corporation

5720 Peach Tree Parkway

Norcross, $6 \mathrm{~A} 30092$
No. of

Coples

R. T. Haelslg

Nuclear Packaging Inc.

$1010 \mathrm{~S} .336 \mathrm{th}$ Street

Federal Way, WA 90003

L. E. Wilus

Numerical Applications, Inc.

825 Goethals Drive

Richland, wa 9932

J. V. Massey

NUTECH Engineers

145 Martinvale Lane

San Jose, CA 95116

C. V. Parks

Oak Ridge National Laboratory

P.O. Box $X$

Oak Ridge, TN 37831

D. Woods

Ralph M. Parson co.

100 West Wainut Street

Pasadena, Ca 91124

T* L. Sanders

Sandia National Laboratory

Albuquerque, NM

M. E. Mason

Transnuclear, Inc.

1 N. Broadway

White plains, NY 10601

B. R. Teer

Transnuclear, Inc.

1 N. Broadway

White Plains, NY 10601

TRW, Inc.

Energy Development Group

Sutte 201

200 Union Blvd.

Denver, $C 0$ 80228 
No. of

Copies

C. E. King

Uranium Mgt. Corp.

175 Curtner Ave. MC 620

San Jose, CA 95125

M. L. Smith

Virginia Power Co.

P.0. Box 26666

Richmond, VA 23261

\author{
A. R. Hakl \\ Westinghouse Electric Corp. \\ Waste Technology Services \\ Division
}

P.0. Box 10864

Pittsburg, PA 15236

J. H. Saling

Westinghouse Electric Corp.

Waste Technology Services

Division

P.0. Box 10864

Pittsburg, PA 15236

B. A. Chin

Mechanical Engineering Dept.

247 Wilmore Labs

Auburn University, AL 36849

\section{ONSITE}

2 DOE Richland Operations office

R. D. Izatt

J. P. Collins

2 Rockwell Hanford Operations

C. L. Brown

G. T. Harper

\section{Pacific Northwest Laboratory}

G. H. Beeman

L. W. Brackenbush

B. M. Cole

J. M. Cuta
No. of

Copies

J. M. Creer (10)

M. D. Freshley

E. R. Gilbert

R. J. Guenther

R. L. Goodman

R. J. Hall

C. M. Heeb

U. P. Jenquin

A. B. Johnson, Jr.

D. K. Kreid

D. L. Lessor

N. J. Lombardo

P. S. Lowery

R. A. McCann (10)

J. L. McElroy

M. A. Mckinnon

T. E. Michener

D. F. Newman

D. R. Oden, Jr.

D. R. Rector

R. A. Stokes

J. E. Tanner

D. S. Trent

C. L. Wheeler

Techinical Library (5)

Publishing Coordination (2) 